\title{
Implementation Approach for Electric Vehicles at Marine Corps Base Camp Lejeune: Task 4
}

Stephen Schey Jim Francfort

November 2015

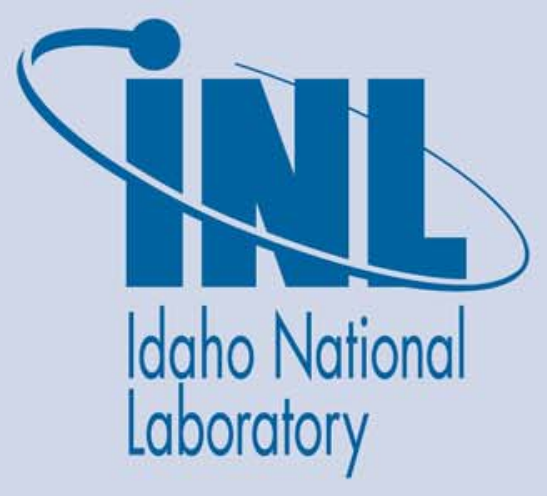

The INL is a U.S. Department of Energy National Laboratory operated by Battelle Energy Alliance 


\section{DISCLAIMER}

This information was prepared as an account of work sponsored by an agency of the U.S. Government. Neither the U.S. Government nor any agency thereof, nor any of their employees, makes any warranty, expressed or implied, or assumes any legal liability or responsibility for the accuracy, completeness, or usefulness, of any information, apparatus, product, or process disclosed, or represents that its use would not infringe privately owned rights. References herein to any specific commercial product, process, or service by trade name, trade mark, manufacturer, or otherwise, does not necessarily constitute or imply its endorsement, recommendation, or favoring by the U.S. Government or any agency thereof. The views and opinions of authors expressed herein do not necessarily state or reflect those of the U.S. Government or any agency thereof. 


\title{
Implementation Approach for Adoption of Electric Vehicles at Marine Corps Base Camp Lejeune: Task 4
}

\author{
Stephen Schey \\ Jim Francfort ${ }^{2}$ \\ ${ }^{1}$ Stephen Schey, Project Manager, Infrastructure Planning and Analysis, Intertek Testing Services, \\ North America, Phoenix, Arizona \\ ${ }^{2}$ Jim Francfort, Vehicle Systems Principal Investigator, Idaho National Laboratory, operated by \\ Battelle Energy Alliance, Idaho Falls, Idaho
}

November 2015

Idaho National Laboratory

Idaho Falls, Idaho 83415

http://avt.inl.gov

Prepared for the

U.S. Department of Energy

Office of Nuclear Energy

Under DOE Idaho Operations Office

Contract DE-AC07-05ID14517 


\section{ABSTRACT}

Battelle Energy Alliance, LLC, managing and operating contractor for the U.S. Department of Energy's Idaho National Laboratory, is the lead laboratory for the U.S. Department of Energy's advanced vehicle testing. Battelle Energy Alliance, LLC contracted with Intertek Testing Services, North America (Intertek) to conduct several U.S. Department of Defense-based studies to identify potential U.S. Department of Defense transportation systems that are strong candidates for introduction or expansion of plug-in electric vehicles (PEVs). This study focused on the Marine Corps Base Camp Lejeune (MCBCL), which is located in North Carolina.

Task 1 consisted of a survey of non-tactical fleet vehicles at MCBCL to begin review of vehicle mission assignments and types of vehicles in service. In Task 2, daily operational characteristics of vehicles were identified to select vehicles for further monitoring and attachment of data loggers. Task 3 recorded vehicle movements in order to characterize the vehicles' missions. The results of the data analysis and observations were provided. Individual observations of the selected vehicles provided the basis for recommendations related to PEV adoption (i.e., whether a battery electric vehicle or plug-in hybrid electric vehicle [collectively referred to as PEVs] can fulfill the mission requirements). It also provided the basis for recommendations related to placement of PEV charging infrastructure.

This Task 4 report focuses on an implementation plan for the near-term adoption of PEVs into the MCBCL fleet.

Intertek acknowledges the support of Idaho National Laboratory, Marine Corps headquarters, and MCBCL fleet management and personnel for participation in this study. 


\section{EXECUTIVE SUMMARY}

Federal agencies are mandated ${ }^{a}$ to purchase alternative fuel vehicles, increase consumption of alternative fuels, and reduce petroleum consumption. Available plug-in electric vehicles (PEVs) provide an attractive option in the selection of alternative fuel vehicles. PEVs, which consist of both battery electric vehicles (BEVs) and plug-in hybrid electric vehicles (PHEVs), have significant advantages over internal combustion engine (ICE) vehicles in terms of energy efficiency, reduced petroleum consumption, and reduced production of greenhouse gas emissions, and they provide performance benefits with quieter, smoother operation. This study intended to evaluate the extent to which Marine Corps Base Camp Lejeune (MCBCL) could convert part or all of their fleet of vehicles from petroleum-fueled vehicles to PEVs.

More fuel-efficient ICE vehicles, including hybrid electric vehicles, exist that may provide improvements for the current fleet; however, this study's focus is on replacing ICE vehicles with suitable PEVs.

$\mathrm{BEVs}$ provide the greatest benefit when it comes to fuel and emissions savings because all motive power is provided by the energy stored in the onboard battery pack. These vehicles use no petroleum and emit no pollutants at their point of use. PHEVs provide similar savings when their battery provides all or a majority of motive power (depending on the PHEV design), but they also have the ability to extend their operating range with an onboard ICE. Because a PHEV can meet all transportation range needs, the adoption of a PHEV will be dependent on its ability to meet other transportation needs such as cargo or passenger capability. Operation of PHEVs in charge depleting-mode, where all or a majority of motive power is provided by the battery, can be increased with opportunity charging at available charging stations. However, not all PHEVs have a mode where the battery provides all motive power at all speeds. Previous work on this study focused on the non-tactical fleet of vehicles at MCBCL to identify a subset of 60 vehicles for data logging in an effort to identify vehicles that may be replaced with PEVs, with emphasis on BEVs that provide the maximum benefit. This report provides an approach for near-term adoption of PEVs at MCBCL.

MCBCL borders on the Atlantic Ocean near Jacksonville, North Carolina. The base and surrounding community is home to an active duty, dependent, retiree, and civilian employee population of approximately 170,000 people. MCBCL contains 156,000 acres and 11 miles of beaches. ${ }^{b}$ Adoption of PEVs at MCBCL can have a positive effect on PEV adoption by the retiree and civilian population of the area.

The Task 3 report observed that a mix of BEVs and PHEVs are capable of performing most of the required missions using BEVs for the short trips and PHEVs for the longer trips. It also observed that replacement of vehicles in the current fleet could result in significant reductions in the emission of greenhouse gases and reductions in petroleum use, as well as reductions in fleet operating

\footnotetext{
${ }^{a}$ Energy Policy act of 1992, Energy Policy Act of 2005, Executive Order 13423, and Energy Independence and Security Act of 2007.

${ }^{\mathrm{b}}$ www.lejeune.marines.mil/About.aspx [accessed January 22, 2015].
} 
costs. The other Task 3 report identified potential PEV charging locations should PEV replacements occur.

This report presents a replacement approach for adoption of PEVs at MCBCL. This approach provides a gradual introduction of PEVs into the MCBCL operation and into the balance of the non-tactical fleet. The gradual approach provides a transitional period to allow greater experience in operation, maintenance, and support for PEVs in daily missions. The vehicles introduced by this approach result in $50 \%$ of the fleet as PEVs by 2026, assuming the size of the fleet remains as it was in 2015. The projected PEV adoption rate for sedans, non-sedans, and total fleet is presented in Figure ES-1.

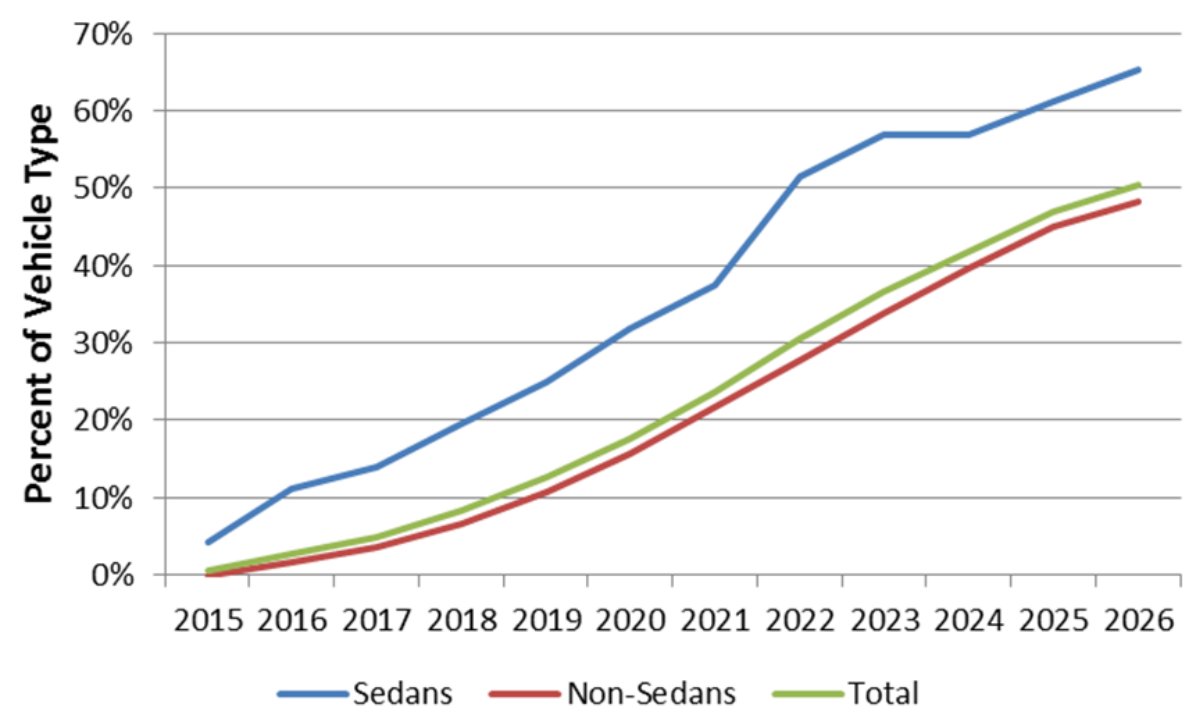

Figure ES-1. Projected PEV adoption rate at MCBCL.

MCBCL will decide whether to adopt PEVs as provided by the General Services Administration only, which now consists only of sedan-type vehicles, or to justify the adoption of non-General Services Administration-listed vehicles. While the greater emphasis and initial adoption is for General Services Administration-listed vehicles, both approaches are presented in this report. 


\section{CONTENTS}

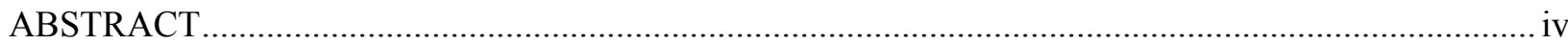

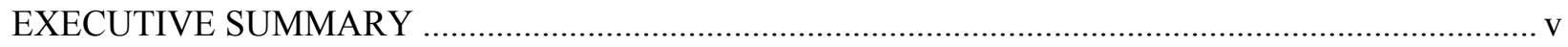

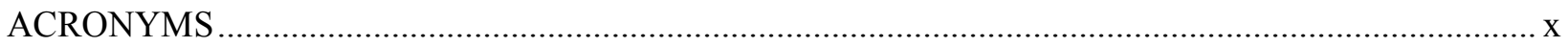

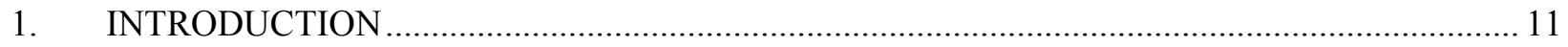

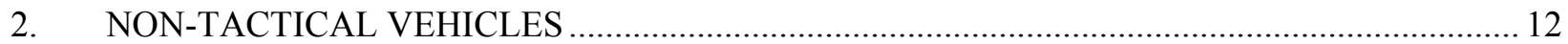

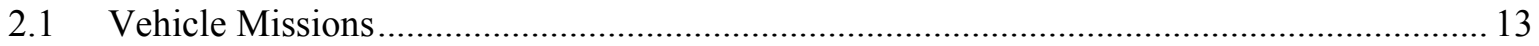

2.2 General Services Administration Vehicle Replacement Requirements ............................. 14

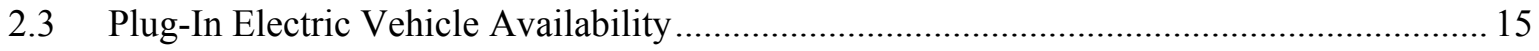

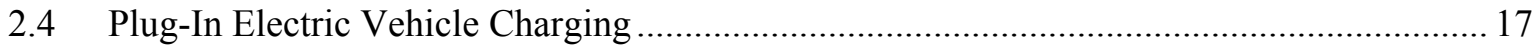

3. VEHICLE MISSION REPLACEMENT GUIDANCE …...................................................... 17

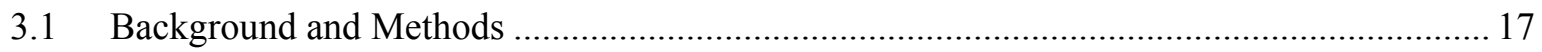

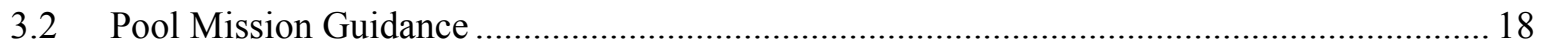

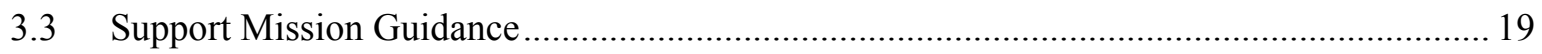

Enforcement Mission Guidance ................................................................................ 20

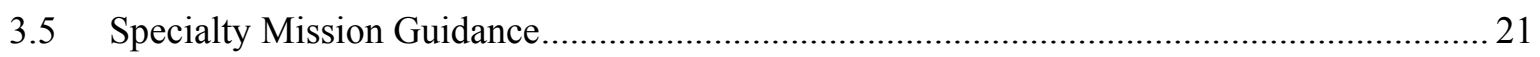

4. MARINE CORPS BASE CAMP LEJEUNE REPLACEMENT APPROACH ............................ 22

4.1 Marine Corps Base Camp Lejeune Summary Replacement Approach .............................. 23

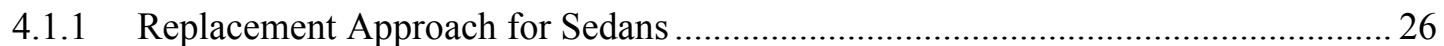

4.1.2 Replacement Approach for Non-Sedan Vehicles................................................. 27

4.2 Analysis Results - Commands Group ....................................................................... 28

4.2.1 Replacement Approach for Commands Group Sedans............................................ 28

4.2.2 Replacement Approach for Commands Group Non-Sedan Vehicles ........................ 29

4.3 Analysis Results - Marine Corps Installations East Fleet..................................................29

4.3.1 Replacement Approach for Marine Corps Installations East Group Sedans.............. 30

4.3.2 Replacement Approach for Marine Corps Installations East Group Non-Sedan Vehicles...................................................................................... 30

4.4 Balance of Marine Corps Base Camp Lejeune Fleet …...................................................... 31 
5. PLUG-IN ELECTRIC VEHICLE CHARGING INFRASTRUCTURE ...................................... 31

5.1 Plug-in Electric Vehicle Charging Infrastructure for Sedans.......................................... 32

5.2 Plug-in Electric Vehicle Charging Infrastructure for Non-Sedans ................................... 32

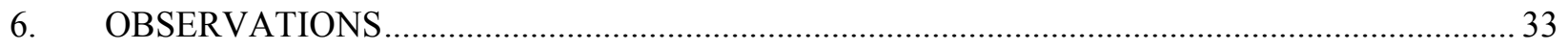

Appendix A, Commands Group Vehicle Data Sheets ...................................................................... 34

Appendix B, Marine Corps Installations East Vehicle Data Sheets ..................................................... 44

Appendix C, Commands Fleet Vehicle Replacement Approach .................................................... 67

Appendix D, Marine Corps Installations East Fleet Vehicle Analysis ................................................. 71

\section{FIGURES}

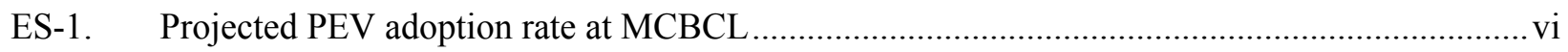

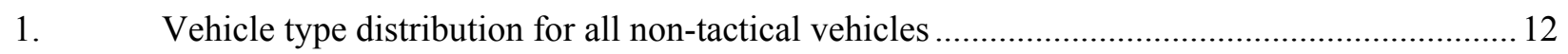

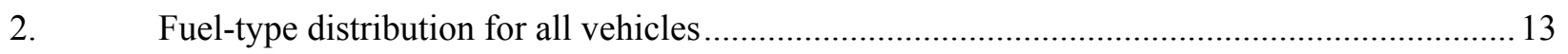

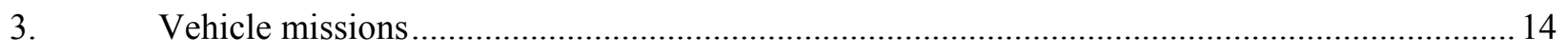

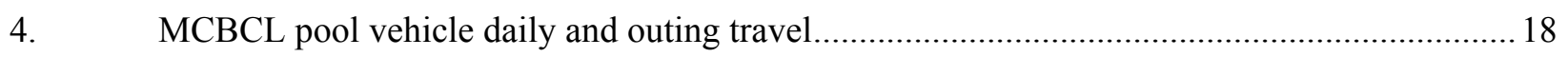

5. MCBCL support vehicle daily travel and outage distance ................................................ 19

6. MCBCL enforcement vehicle daily travel and outing travel............................................... 20

7. MCBCL specialty vehicle daily travel and outage distance ..............................................21

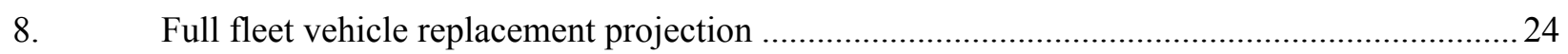

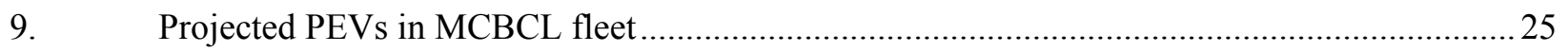

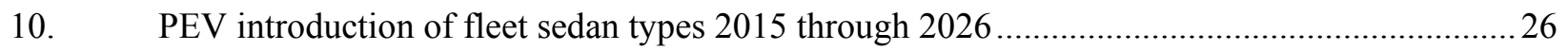

11. PEV introduction of fleet non-sedan types 2015 through 2026..........................................22

\section{TABLES}

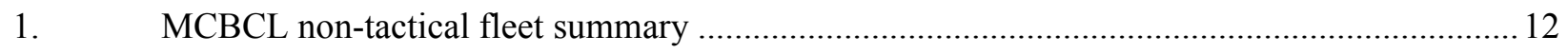

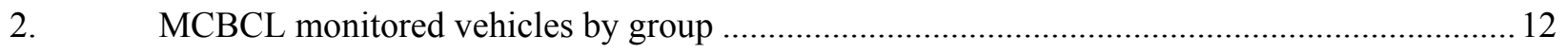




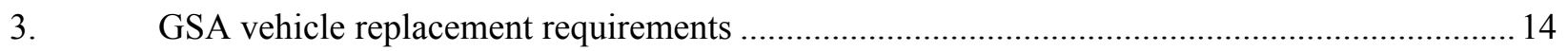

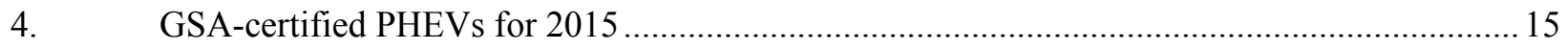

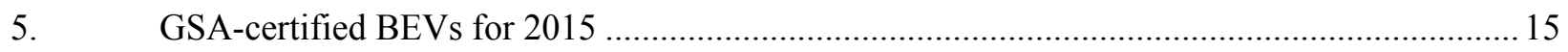

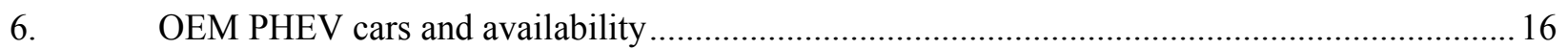

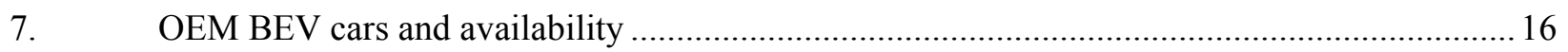

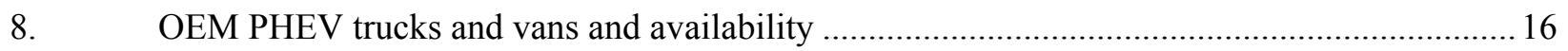

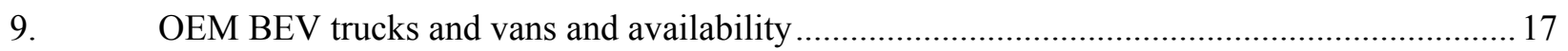

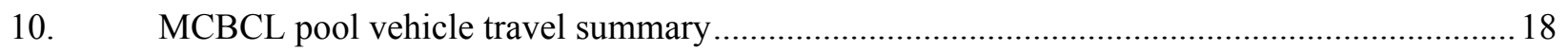

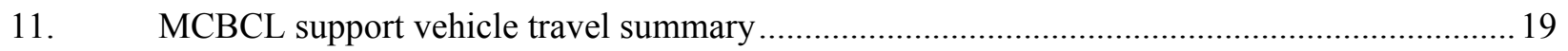

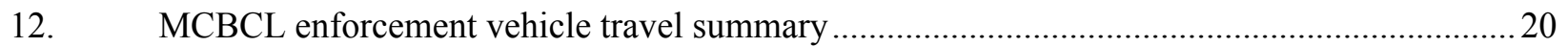

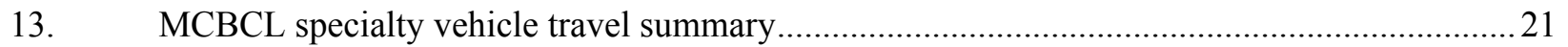

14. Projected fleet vehicle replacements at MCBCL .................................................................23

15. Projected approach for the introduction of PEVs into the MCBCL fleet ................................25

16. Planned approach for the introduction of PEV sedans at MCBCL …..................................26

17. Planned approach for the introduction of non-sedan PEVs at MCBCL …..............................2

18. The anticipated replacement schedule for the Commands Group vehicles at MCBCL ............28

19. Planned approach for the introduction of PEV sedans into the Commands Group...................28

20. Planned approach for introduction of non-sedan PEVs into the Commands Group .................29

21. Projected MCIE Group anticipated vehicle replacement schedule at MCBCL .......................29

22. Planned approach for the introduction of PEV sedans in the MCIE Group .............................30

23. Planned approach for the introduction of non-sedan PEVs in the MCIE Group...................... 31

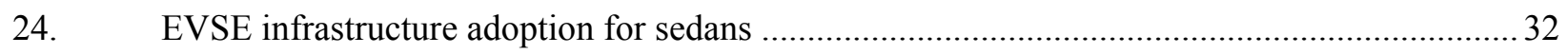

25. EVSE infrastructure adoption for non-sedan fleet............................................................ 32

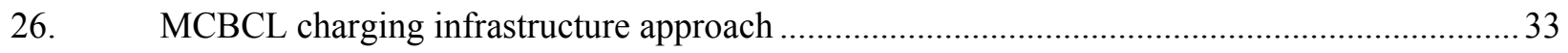




\section{ACRONYMS}

$\mathrm{AC} \quad$ alternating current

BEV battery electric vehicle

DC direct current

EPA U.S. Environmental Protection Agency

EVSE electric vehicle supply equipment

GHG greenhouse gas emissions

GSA General Services Administration

ICE internal combustion engine

Intertek Intertek Testing Services, North America

MCBCL Marine Corps Base Camp Lejeune

OEM original equipment manufacturer

PEV plug-in electric vehicles

PHEV plug-in hybrid electric vehicle

SUV sports utility vehicle 


\section{Electric Vehicle Preparedness: Implementation Approach for Plug-in Electric Vehicles at Marine Corps Base Camp Lejeune: Task 4}

\section{INTRODUCTION}

The U.S. Department of Energy and the U.S. Department of Defense signed a memorandum of understanding on July 22, 2010, for strengthening coordination of efforts to enhance national energy security and to demonstrate federal government leadership in transitioning the United States to a low carbon economy. The memorandum of understanding included efforts in the areas of energy efficiency, fossil fuels, alternative fuels, efficient transportation technologies and fueling infrastructure, grid security, smart grid, and energy storage.

In support of the memorandum of understanding, the Idaho National Laboratory, with funding provided by the U.S. Department of Energy's Vehicle Technologies Office and Federal Energy Management Program, directed Intertek Testing Services, North America (Intertek) to conduct several U.S. Department of Defense-based studies to identify potential transportation systems that are strong candidates for introduction or expansion of plug-in electric vehicles (PEVs). Intertek previously conducted similar fleet, city, state, and countrywide studies using their micro-climate assessment process, which consists of the following four main tasks:

- Task 1: Conduct a non-tactical fleet and infrastructure assessment

- Task 2: Select vehicles for mission and fleet characterizations

- Task 3: Perform detailed assessment of selected vehicles and charging infrastructure needs

- Task 4: Prepare adoption approach for PEV and charging infrastructure.

Assessment of the potential for replacing Marine Corps Base Camp Lejeune (MCBCL) fleet vehicles with PEVs starts with an assessment of the fleet vehicles' missions and vehicle characteristics. This assessment was conducted through correspondence with fleet managers and records analysis. The Task 1 report titled, Assessment of Data and Survey Results for Marine Corps Base Camp Lejeune, dated January 2015, provided a summary and fleet assessment.

PEVs generally are classified into two vehicle types: battery electric vehicles (BEVs) and plug-in hybrid electric vehicles (PHEVs). A BEV contains an onboard battery that provides all motive power. PHEVs also have an onboard battery that provides some motive power but there is also another motive power source (such as a gasoline engine). PHEVs have, in general, two modes: (1) charge-depleting (CD) mode, where the battery provides all or most (depending on the PHEV design) motive power and the battery is being depleted, and (2) charge-sustaining (CS) mode, where the non-battery power source provides the majority of the motive power while being supplemented by the battery power with the battery state of charge being maintained within a designed range. A BEV can be considered to operate solely in CD mode. Collectively, BEVs and PHEVs are PEVs.

The Task 1 effort led to identification of fleet vehicles that appeared to be good candidates for replacement by PEVs. The Task 2 report titled, Identification of Marine Corps Base Camp Lejeune Vehicles for Installation of Data Loggers, dated February 2015, identified 60 vehicles within the candidate groups for further monitoring and analysis through addition of vehicle data loggers. The data loggers were installed and data were collected on the selected vehicles. The Task 3 report titled, Utilization Assessment of Target Electrification Vehicles at Marine Corps Base Camp Lejeune, dated August 2015, provided a summary and details of data collection for the monitored vehicles and extrapolated that to the entire non-tactical fleet of vehicles at MCBCL. The other Task 3 report, titled, Assessment of Charging Infrastructure for Plug-in Electric Vehicles at Marine Corps Base Camp 
Lejeune, dated August 2015, provided the related charging infrastructure assessment. This report provides an implementation approach for adoption of PEVs at MCBCL in the next few years.

\section{NON-TACTICAL VEHICLES}

MCBCL reported 784 vehicles in its non-tactical fleet, not counting non-powered equipment, low-speed vehicles, and heavy-duty trucks. The Task 1 report identified the 25 tenant commands (i.e., Commands) and Marine Corps Installations East (i.e., MCIE) departments and divisions to which the vehicles were assigned. Table 1 provides a summary of the vehicle types by class and group.

Table 1. MCBCL non-tactical fleet summary.

\begin{tabular}{|c|c|c|c|c|c|c|c|c|c|c|}
\hline & $\begin{array}{l}\text { Sedan - } \\
\text { Compact }\end{array}$ & $\begin{array}{l}\text { Sedan - } \\
\text { Midsize }\end{array}$ & $\begin{array}{l}\text { Sedan - } \\
\text { Large }\end{array}$ & Minivan & SUV & $\begin{array}{c}\text { Van } \\
\text { Cargo }\end{array}$ & $\begin{array}{l}\text { Van } \\
\text { Pass }\end{array}$ & Pickup & Specialty & Total \\
\hline Commands & 1 & 7 & 5 & 30 & 20 & 12 & 66 & 108 & - & 249 \\
\hline MCIE & 5 & 16 & 38 & 37 & 56 & 50 & 43 & 228 & 62 & 535 \\
\hline Total & 6 & 23 & 43 & 67 & 76 & 62 & 109 & 336 & 62 & 784 \\
\hline
\end{tabular}

Figure 1 shows the vehicle type distribution for all vehicles for comparison.

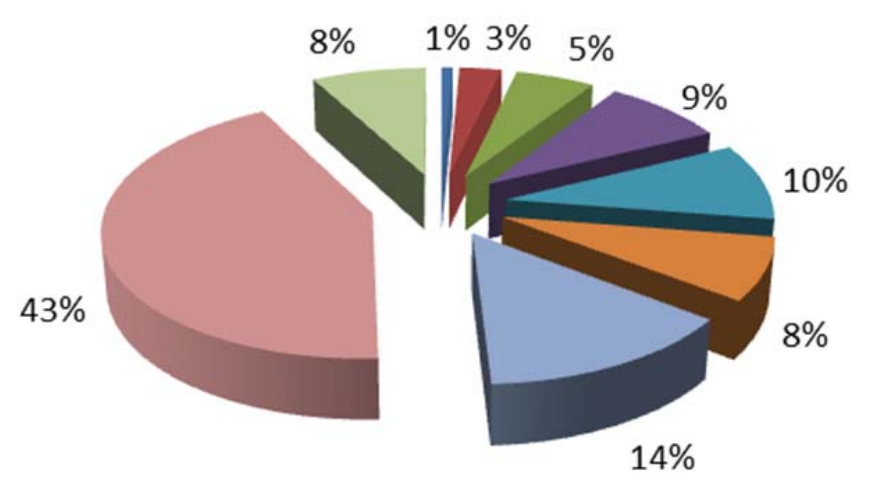

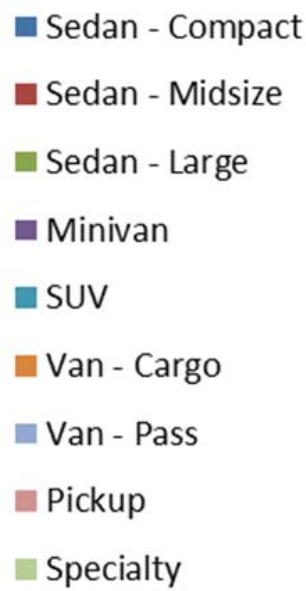

Figure 1. Vehicle type distribution for all non-tactical vehicles.

MCBCL identified 60 vehicles for further study as described in the Task 2 report. Table 2 categorizes the monitored vehicles. This distribution is approximately representative of the entire non-tactical fleet.

Table 2. MCBCL monitored vehicles by group.

\begin{tabular}{lcccccccccc}
\hline & $\begin{array}{c}\text { Sedan - } \\
\text { Compact }\end{array}$ & $\begin{array}{c}\text { Sedan - } \\
\text { Midsize }\end{array}$ & $\begin{array}{c}\text { Sedan- } \\
\text { Large }\end{array}$ & Minivan & SUV & $\begin{array}{c}\text { Van } \\
\text { Cargo }\end{array}$ & $\begin{array}{c}\text { Van } \\
\text { Pass }\end{array}$ & Pickup & Specialty & Total \\
\hline Commands & - & - & - & 2 & 3 & - & 6 & 7 & - & 18 \\
MCIE & 2 & 2 & - & 3 & 6 & 4 & 2 & 21 & 2 & 42 \\
Total & 2 & 2 & - & 5 & 9 & 4 & 8 & 28 & 2 & 60 \\
\hline
\end{tabular}

The fleet vehicles are used for a variety of purposes by several different divisions on base. Section 2.2 provides details about these purposes or missions. The category of the mission can be helpful in identifying PEVs as potential replacements.

The initial survey also identified the fuel used by the fleet vehicles. In particular, MCBCL has implemented a significant emphasis on E85 fuel used by a majority of the vehicles types. Diesel fuel is 
used primarily for specialty vehicles, larger pickup trucks, and cargo vans. Figure 2 illustrates fuel types in use at MCBCL.

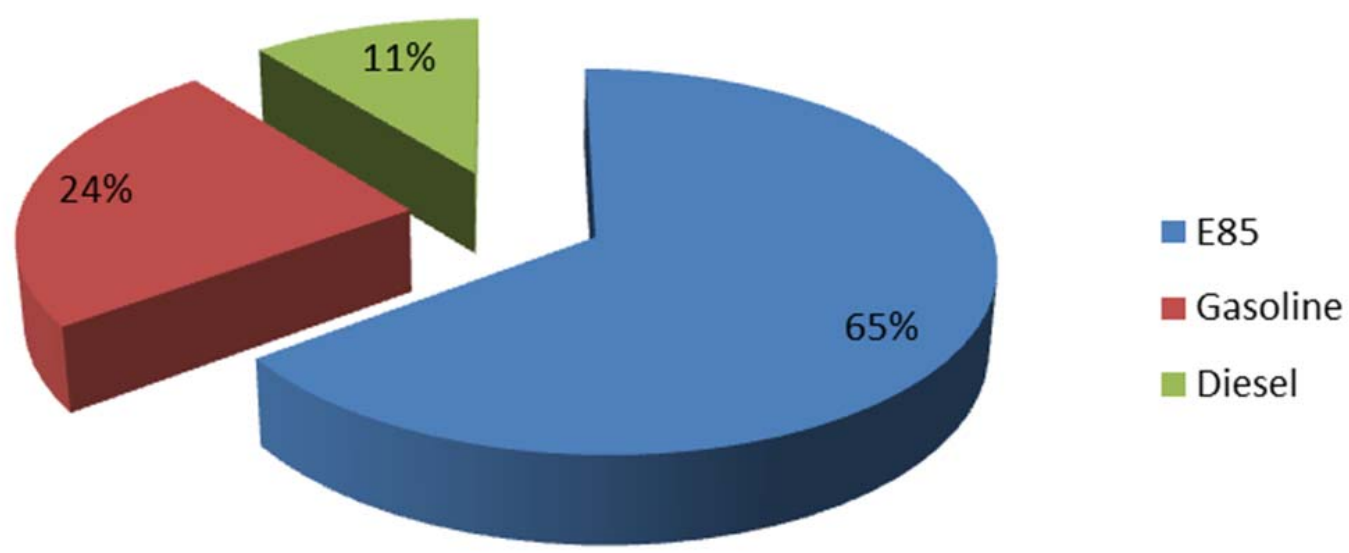

Figure 2. Fuel-type distribution for all vehicles.

\subsection{Vehicle Missions}

Vehicle mission is an important characteristic in the fleet study. Intertek has established the following seven mission/vehicle categories for analysis. The categories are listed as follows and depicted in Figure 3:

1. Pool vehicles: A pool vehicle is any automobile (other than the low-speed vehicle identified below) manufactured primarily for use in passenger transportation, with not more than 10 passengers.

2. Enforcement vehicles: Vehicles specifically approved in an agency's appropriation act for use in apprehension, surveillance, police, or other law enforcement work. This category also includes site security vehicles, parking enforcement, and general use, but the vehicles are capable of requirements to support enforcement activities.

3. Support vehicles: Vehicles assigned to a specific work function or group to support the mission of that group. Vehicles are generally passenger vehicles or light-duty pickup trucks and may contain after-market modifications to support the mission.

2. Transport vehicles: Light, medium, or heavy-duty trucks used to transport an operator and tools or equipment of a non-specific design or nature. The vehicle's possible uses include repair, maintenance, and delivery.

3. Specialty vehicles: Vehicles designed to accommodate a specific purpose or mission (such as ambulances, mobile cranes, and handicap controls).

4. Shuttles/buses: Vehicles designed to carry more than 12 passengers and further outlined in 49 CFR 532.2.

5. Low-speed vehicle: Vehicles that are legally limited to roads with posted speed limits up to 35 or 45 mph (depending on state law) and that have a limited load-carrying capability.

Vehicle mission assignments can be useful for identifying the type of potential replacement PEV (see Section 3). 


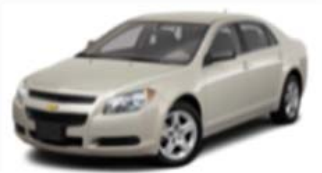

Pool Vehicle

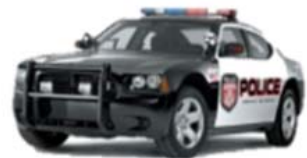

Enforcement Vehicle

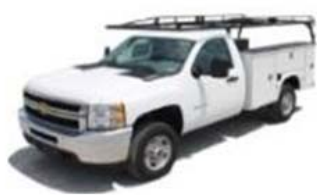

Support Vehicle

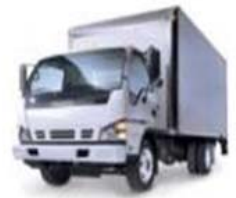

Transport Vehicle

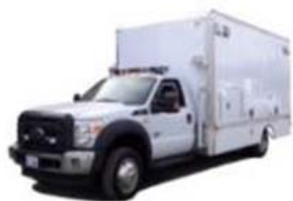

Specialty Vehicle

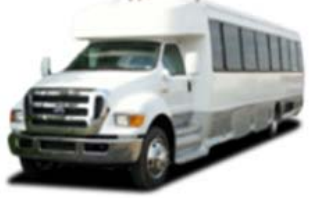

Shuttle / Bus

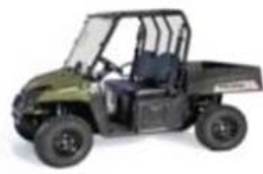

Low Speed

Vehicles

Figure 3. Vehicle missions.

\subsection{General Services Administration Vehicle Replacement Requirements}

Table 3 presents the General Services Administration (GSA) replacement requirements for fleet vehicles. Both the age and mileage requirements need to be met in order for the vehicle to qualify for replacement, except where noted as "or."

Table 3. GSA vehicle replacement requirements.

\begin{tabular}{|l|c|c|c|}
\hline \multirow{4}{*}{ Passenger vehicles } & Fuel Type & Years & Miles \\
& Gasoline or & 3 & 36,000 \\
& alternative fuel & 4 & 24,000 \\
& vehicle & 5 & Any mileage \\
& & Any age & 75,000 \\
& Hybrid & 5 & Any mileage \\
& Low-speed BEV & 6 & Any mileage \\
\hline Light trucks 4 2 & Non-diesel & 7 or & 65,000 \\
& Diesel & 8 or & 150,000 \\
& Hybrid & 7 & Any mileage \\
\hline Light trucks 4 x 4 & Non-diesel & 7 or & 60,000 \\
& Diesel & 8 or & 150,000 \\
& Hybrid & 7 & Any mileage \\
\hline Medium trucks & Non-diesel & 10 or & 100,000 \\
\hline & Diesel & 10 or & 150,000 \\
\hline Heavy Trucks & Non-diesel & 12 or & 100,000 \\
\hline & Diesel & 12 or & 250,000 \\
\hline
\end{tabular}

\footnotetext{
${ }^{3}$ http://www.gsa.gov/graphics/fas/VehicleReplacementStandardsJune2011Redux.pdf [accessed March 12, 2015].
} 


\subsection{Plug-In Electric Vehicle Availability}

The adoption of PHEVs and BEVs is the primary goal of GSA and it supports many directives in this area. As GSA increases its certification of PHEVs and BEVs, agencies can plan for vehicle replacement through GSA for passenger vehicles and trucks. GSA provides a summary of light and medium-duty passenger vehicles available for lease or purchase through the GSA portal; ${ }^{4}$ however, not all BEVs and PHEVs currently on the market are 'certified' to be GSA replacements. Vehicles not on the GSA list of 'certified' vehicles require an agency to self-certify a functional need or alternative measures for exemptions. Tables 4 and 5 summarize the vehicles that may be suitable replacements and are certified replacements through GSA. Note that the "CD/CS" column provides the U.S. Environmental Protection Agency (EPA) fuel economy values for CD and CS modes of the PHEVs, while the city and highway fuel economy values are provided for BEVs. The fuel economy of the PHEV CD mode and BEVs is provided in units of miles-per-gallon-of-gasoline-equivalent (MPGe). This metric allows electricity consumption to be compared with fuel consumption during CS mode (or against conventional vehicles). The Nissan Leaf and Mitsubishi i-MiEV are not included in the alternative fuel guide for 2015, but they have appeared in previous guides. For MCBCL, replacement is dependent on vehicle configuration characteristics and the PEV's ability to meet the vehicle's mission.

Original equipment manufacturers (OEM) provide information related to a vehicle's range in CD mode and EPA provides test results. However, actual results may vary depending on several factors other than travel that may also deplete a vehicle's battery. These factors include changes in the battery's capacity over time, area topography, weather conditions (e.g., cabin cooling/heating), payload, and so forth. This report will identify a BEV's "safe range" as 70 miles because this typically is less than the advertised range of most BEVs. The PHEV's safe range in CD mode is 30 miles.

Tables 6 through 9 provide summaries of PHEVs and BEVs that are either currently available or near commercialization in both passenger cars and pickup trucks, but do not appear on the GSA 'certified' vehicle list. These vehicles may qualify for use by the agency through demonstrating a functional need.

Table 4. GSA-certified PHEVs for 2015.

\begin{tabular}{lcccc}
\multicolumn{1}{c}{ Make/Model } & GSA Class & Type & CD/CS & GSA Incremental Price \\
\hline Chevrolet Volt* & Sedan, Subcompact & PHEV & $98 \mathrm{MPGe} / 37 \mathrm{mpg}$ & $\$ 17,692.17$ \\
Ford C-MAX Energi & Sedan, Subcompact & PHEV & $88 / 38 \mathrm{mpg}$ & $\$ 14,062.23$ \\
Ford Fusion Energi & Sedan, Compact & PHEV & $88 / 38 \mathrm{mpg}$ & $\$ 13,640.05$ \\
\hline
\end{tabular}

*The Chevrolet Volt has an all-electric CD mode rated for 38 miles. The Ford vehicles have blended CD modes rated for 20 miles.

Table 5. GSA-certified BEVs for 2015.

\begin{tabular}{ccccc}
\hline Make/Model & GSA Class & Type & City/Highway & GSA Incremental Price \\
\hline Ford Focus Electric & Sedan, Subcompact & BEV & $110 / 99 \mathrm{MPGe}$ & $\$ 11,351.15$ \\
Smart Fortwo ED & Sedan, Microcompact & BEV & $123 / 93 \mathrm{MPGe}$ & $\$ 7,277.05$ \\
\hline
\end{tabular}

Note that EPA differs from GSA in vehicle class designation. EPA identifies the Volt as a compact, the C-MAX Energi as a midsize, the Fusion Energi as a midsize, and the Focus as a compact. ${ }^{5}$

\footnotetext{
${ }^{4}$ http://www.gsa.gov/portal/content/104211 [accessed August 1, 2014]

${ }^{5}$ http://www.fueleconomy.gov/feg/Find.do?action=sbs\&id=34130 [accessed August 1, 2014]
} 
Table 6. OEM PHEV cars and availability.

\begin{tabular}{cccc}
\hline Make & EPA Class & Model & $\begin{array}{c}\text { Initial Model Year/Estimated } \\
\text { Year for Commercialization }\end{array}$ \\
\hline Chevrolet & Compact & Volt & 2011 \\
Ford & Midsize & C-MAX Energi & 2013 \\
Ford & Midsize & Fusion Energi & 2013 \\
Toyota & Midsize & Prius PHEV & 2012 \\
Honda & Midsize & Accord PHEV* & 2014 \\
Cadillac & Subcompact & ELR & 2014 \\
Porsche & Large & Panamera S E-Hybrid & 2014 \\
BMW & Subcompact & i3 REx & 2014 \\
BMW & Subcompact & i8 & 2014 \\
Hyundai & Midsize & Sonata PHEV & 2015 (estimate) \\
Audi & Compact & A3 e-Tron & 2016 (estimate) \\
Mercedes & Subcompact & C350 PHEV & 2016 (estimate) \\
Mercedes & Large & S550 PHEV & 2016 (estimate) \\
\hline * Honda did not release a MY2015 Accord PHEV; the return of this vehicle model is uncertain.
\end{tabular}

Table 7. OEM BEV cars and availability.

\begin{tabular}{cccc}
\hline Make & EPA Class & Model & $\begin{array}{c}\text { Initial Model Year/Estimated } \\
\text { Year for Commercialization }\end{array}$ \\
\hline Nissan & Midsize & Leaf & 2011 \\
Ford & Compact & Focus Electric & 2012 \\
Tesla & Large & Model S & 2012 \\
Mitsubishi & Subcompact & i-MiEV* & 2012 \\
Fiat & Mini & $500 \mathrm{e}$ & 2013 \\
Honda & Small Station Wagon & Fit EV & 2013 \\
smart & Two Seater & Fortwo ED & 2013 \\
BMW & Subcompact & i3 & 2014 \\
Chevrolet & Subcompact & Spark EV & 2014 \\
Kia & Small Station Wagon & Soul EV & 2014 \\
Volkswagen & Compact & e-Golf & 2015 \\
Mercedes-Benz & Midsize & B-Class Electric Drive & 2015 \\
Chevrolet & Compact & Bolt & 2017 (estimate) \\
\hline
\end{tabular}

* Mitsubishi did not manufacture a MY15 i-MiEV; the vehicle returned in the 2016 MY.

Table 8. OEM PHEV trucks and vans and availability.

\begin{tabular}{cccc}
\hline Make & EPA Class & Model & $\begin{array}{c}\text { Initial Model Year/Estimated } \\
\text { Year for Commercialization }\end{array}$ \\
\hline Via & Standard Pickup Truck & VTRUX VR300 & 2013 \\
Via & Special Purpose Vehicle & VTRUX Cargo Van & 2013 \\
Via & Vans, Cargo Type & VTRUX Pass Van & 2013 \\
Mercedes & SUV & GLE 550e & 2016 (estimate) \\
Mitsubishi & Small SUV & Outlander PHEV & 2016 (estimate) \\
Volvo & SUV & XC90 T8 & 2016 (estimate) \\
BMW & SUV & X5 xDrive 40e & 2016 (estimate) \\
Chrysler & Minivan & Town \& Country & 2017 (estimate) \\
Audi & SUV & Q7 e-Tron Quattro & 2017 (estimate) \\
\hline
\end{tabular}


Table 9. OEM BEV trucks and vans and availability.

\begin{tabular}{cccc} 
& & & Initial Model Year/Estimated \\
Make & EPA Class & Model & Year for Commercialization \\
\hline Tesla & Standard SUV & Model X & 2015 (estimate) \\
Nissan & Van & e-NV200 & 2016 (estimate) \\
\hline
\end{tabular}

As further indication of the expanding market for PEVs, companies are offering after-market vehicle upgrades involving addition of plug-in capabilities to OEM vehicles. For example, Echo Automotive headquartered in Scottsdale, Arizona offers a “...low-cost, bolt-on, plug-in hybrid system that can quickly be installed on new or existing fleet vehicles to increase fuel efficiency and decrease operating costs - all without affecting the OEM power train or requiring costly infrastructure." ${ }^{, 6}$ EVAOS conducts upgrades of Ford F-series pickup trucks to PHEV models and has delivered vehicles to the U.S. Air Force. ${ }^{7}$ Options such as these conversions might be of benefit for vehicles in the MCBCL fleet for which no replacement PEV is currently available.

\subsection{Plug-In Electric Vehicle Charging}

Refueling electric vehicles presents some challenges and some opportunities not encountered when refueling petroleum-fueled vehicles. Recharging the battery of a PHEV follows the same methodology as that for BEVs. The Task 3 infrastructure report provides detailed information on recharging PEVs.

Most PEV manufacturers supply an alternating current (AC) Level 1 cordset with the vehicle, which provides sufficient capabilities for some drivers, but more typically provides an emergency backup capability because of the long recharge times. AC recharging capabilities found in the public arena more typically are AC Level 2.

Because the battery of a BEV is typically much larger than that of a PHEV, recharge times are longer. $\mathrm{BEVs}$ that see daily mileage near the limits of the advertised range do better when recharged using AC Level 2 electric vehicle supply equipment (EVSE) or direct current (DC) fast charging, because AC Level 1 recharge times are usually extensive. PHEVs, on the other hand, generally can use AC Level 1 EVSE for overnight charging to ensure a fully charged battery at the start of daily use. AC Level 2 EVSE units provide greater range in the shortest amount of time when intermediate or opportunity charging. DC fast charging provides the fastest recharge capability for those vehicles equipped with DC fast charge inlets; however, currently, no PHEVs have DC fast charging capability available and there are no announced plans for one to be introduced. The Task 3 reports show that the PEVs studied do not need to rely on DC fast charging to complete their missions.

\section{VEHICLE MISSION REPLACEMENT GUIDANCE}

\subsection{Background and Methods}

Section 2.2 identified the mission categories for analysis. The Task 3 report provided specific information for the monitored fleet based on vehicle mission. When suitable PEV types are available to replace the internal combustion engine (ICE) vehicles in the current fleet, the specific mission of the vehicle to be replaced can be a guide in determining whether a BEV or PHEV should be selected. As previously noted, the greater fuel cost savings and greenhouse gas (GHG) reductions occur with BEVs than with PHEVs, which suggests a greater emphasis on BEVs. For MCBCL, the missions monitored included pool, support, enforcement, and two specialty vehicles.

\footnotetext{
${ }^{6}$ http://www.echoautomotive.com/index.php?option=com content\&view=article\&id=8 [accessed July 14, 2014].

${ }^{7}$ http://www.evaos.com [accessed November 20, 2014].
} 
Aside from specific mission functions, the distance a PEV can travel in CD mode between charge opportunities is the most important factor in considering vehicle replacement. The two most significant considerations in vehicle analysis include the vehicle's total daily travel and vehicle outings.

\subsection{Pool Mission Guidance}

Ten of the vehicles monitored at MCBCL were assigned a pool mission. These vehicles included one sedan, two minivans, two sports utility vehicles (SUVs), two passenger vans, one cargo van, and two pickups. The overall summary for these vehicles is shown in Table 10. These vehicles traveled 6,672 miles, logged 446 hours, and idled for 155 hours during the 31-day study period.

Table 10. MCBCL pool vehicle travel summary.

\begin{tabular}{|c|c|c|c|c|}
\hline \multicolumn{5}{|c|}{ Pool Vehicles Travel Summary } \\
\hline & $\begin{array}{c}\text { Per Day } \\
\text { Average/Peak }\end{array}$ & $\begin{array}{c}\text { Per Outing } \\
\text { Average/Peak }\end{array}$ & $\begin{array}{c}\text { Per Trip } \\
\text { Average/Peak }\end{array}$ & Total \\
\hline Travel Distance (Miles) & $35.9 / 289.4$ & $8.9 / 537.2$ & $4.6 / 258.5$ & 6,672 \\
\hline Travel Time (Minutes) & $144.0 / 1,140.0$ & $35.9 / 875.0$ & $18.4 / 504.0$ & 26,781 \\
\hline Idle Time (Minutes) & $50.2 / \mathrm{NA}$ & $12.5 / \mathrm{NA}$ & $6.4 / \mathrm{NA}$ & 9,328 \\
\hline
\end{tabular}

Figure 4 shows daily travel and outing travel for the group of pool vehicles.
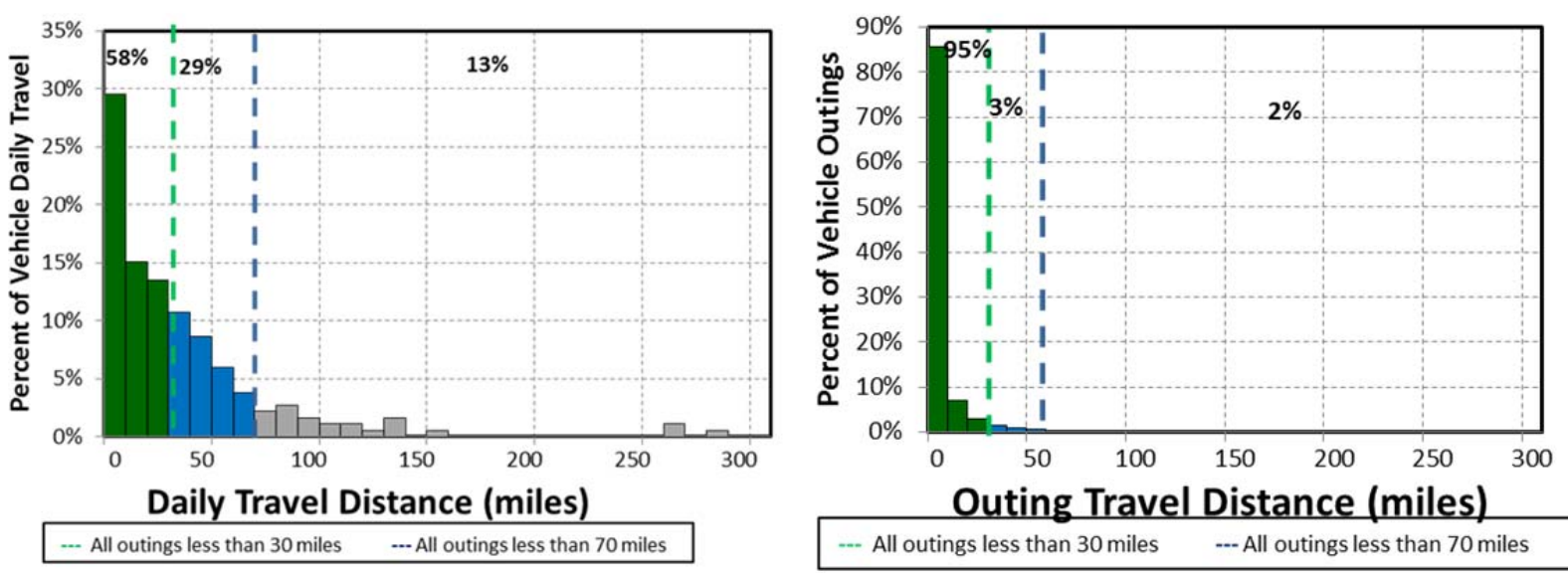

Figure 4. MCBCL pool vehicle daily and outing travel.

The highest outing distance of 537 miles is not displayed in Figure 4 for clarity of scale. A BEV's safe range is considered to be 70 miles (blue and green bars in Figure 4). While a BEV's range can vary based on several factors, most BEVs provide at least 70 miles of vehicle range on a single battery charge.

The average travel distance per day when driven for pool vehicles was 35.9 miles. On $87 \%$ of the vehicle travel days, the daily travel was less than the 70 miles considered to be within the BEV safe range. Meanwhile, $58 \%$ of vehicle travel days were less than 30 miles considered to be within the CD range of a PHEV (green bars of Figure 4).

The average outing distance driven by pool vehicles was 8.9 miles. Further, $98 \%$ of the outing travel was less than the 70 miles considered to be within the BEV safe range (blue and green bars in Figure 4). Meanwhile, $95 \%$ of the vehicle outings were less than the 30 miles considered to be within the CD range of a PHEV (green bars of Figure 4).

In general then, if a suitable PEV body style meets vehicle requirements, then $87 \%$ of a pool fleet could be BEVs and 13\% PHEVs to allow for daily travel greater than the range of the BEV. The fleet 
manager would likely desire a more conservative approach to allow for flexibility, but this shows the high capability of BEVs to meet the pool mission at MCBCL.

\subsection{Support Mission Guidance}

Forty-three of the vehicles monitored at MCBCL provided a support mission. These vehicles included three compact and mid-size sedans, three minivans, five SUVs, 23 pickup trucks, six passenger vans, and three cargo vans. The overall summary for these vehicles is shown in Table 11 . These vehicles traveled 36,601 miles, logged 1,745 hours, and idled for 439 hours during the study period.

Table 11. MCBCL support vehicle travel summary.

\begin{tabular}{lcccc}
\hline & Support Vehicles Travel Summary & & \\
& $\begin{array}{c}\text { Per Day } \\
\text { Average/Peak }\end{array}$ & $\begin{array}{c}\text { Per Outing } \\
\text { Average/Peak }\end{array}$ & $\begin{array}{c}\text { Per Trip } \\
\text { Average/Peak }\end{array}$ & Total \\
\hline Travel Distance (Miles) & $46.0 / 405.0$ & $18.1 / 1,012.4$ & $6.8 / 208.1$ & 36,601 \\
Travel Time (Minutes) & $131.5 / 836.0$ & $51.7 / 1,443.0$ & $19.4 / 362.0$ & 104,690 \\
Idle Time (Minutes) & $33.1 / \mathrm{NA}$ & $13.0 / \mathrm{NA}$ & $4.9 / \mathrm{NA}$ & 26,336 \\
\hline
\end{tabular}

Figure 5 shows the daily travel and outing travel for the group of support vehicles.
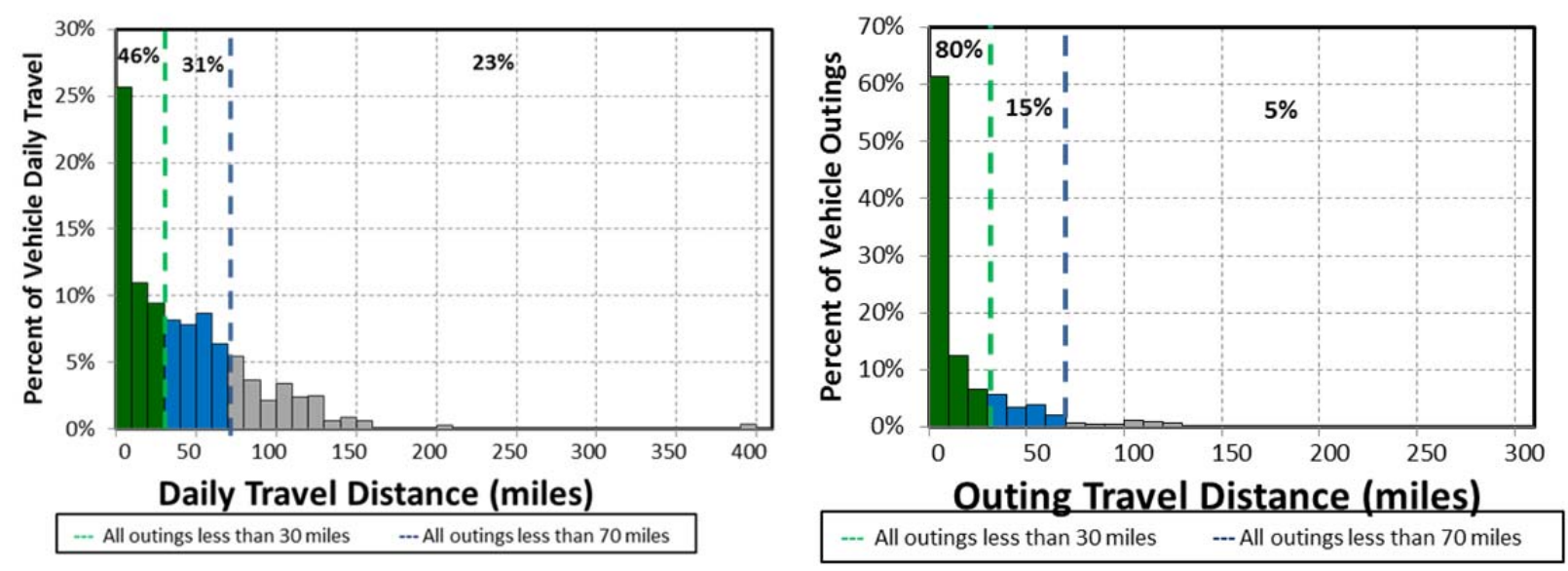

Figure 5. MCBCL support vehicle daily travel and outage distance.

Figure 5 does not show the highest outings of 1,012; 788; and 785 miles for clarity of scale.

The average travel distance per day when driven for support vehicles was 46 miles. On $77 \%$ of the vehicle travel days, the daily travel was less than the 70 miles considered to be within the BEV safe range (blue and green bars in Figure 5). In addition, $46 \%$ of vehicle travel days were less than 30 miles considered to be within the CD range of a PHEV (green bars of Figure 5).

The average travel outing when driven for support vehicles was 18.1 miles. On $95 \%$ of these vehicle outings, the distance traveled was less than the 70 miles considered to be within the BEV safe range. Meanwhile, $5 \%$ of support outing travel was greater than 70 miles. Furthermore, $80 \%$ of vehicle travel outings were less than the 30 miles considered to be within the CD range of a PHEV.

In general then, if a suitable PEV body style meets vehicle requirements, $77 \%$ of the support fleet could be BEVs and 23\% PHEVs to allow for daily travel greater than the range of the BEV. The fleet manager would likely desire a more conservative approach to allow for flexibility, but this shows the high capability of BEVs to meet the support mission at MCBCL. 


\subsection{Enforcement Mission Guidance}

Enforcement vehicles are typically light-duty motor vehicles specifically approved in an agency's appropriation act for use in apprehension, surveillance, police, or other law enforcement work. Enforcement missions can vary by agency, location, and jurisdiction; however, they typically utilize sedans, minivans, vans, or small pickup trucks and typically do not carry specific cargo or equipment with the exception of K-9 units. Five of the vehicles monitored at MCBCL provided the enforcement mission. These vehicles included two SUVs and three pickup trucks. The overall summary for these vehicles is shown in Table 12. These vehicles traveled 6,106 miles, logged 520 hours, and idled for 295 hours during the study period.

Table 12. MCBCL enforcement vehicle travel summary.

\begin{tabular}{lcccc}
\hline \multicolumn{5}{c}{ Enforcement Vehicles Travel Summary } \\
& $\begin{array}{c}\text { Per Day } \\
\text { Average/Peak }\end{array}$ & $\begin{array}{c}\text { Per Outing } \\
\text { Average/Peak }\end{array}$ & $\begin{array}{c}\text { Per Trip } \\
\text { Average/Peak }\end{array}$ & Total \\
\hline Travel Distance (Miles) & $51.3 / 208.1$ & $20.6 / 167.6$ & $6.8 / 99.7$ & 6,106 \\
Travel Time (Minutes) & $262.4 / 1,464.0$ & $105.5 / 1,209.0$ & $35.0 / 752.0$ & 31,228 \\
Idle Time (Minutes) & $149.7 / \mathrm{NA}$ & $60.2 / \mathrm{NA}$ & $20.0 / \mathrm{NA}$ & 17,726 \\
\hline
\end{tabular}

Figure 6 shows the daily travel and outing travel for the group of enforcement vehicles. The average travel distance per day when driven for enforcement vehicles was 51.3 miles. On $73 \%$ of the vehicle travel days, the daily travel was less than the 70 miles considered to be within the BEV safe range (blue and green bars in Figure 6). Meanwhile, 27\% of vehicle travel days were less than the 30 miles considered to be within the CD range of a PHEV (green bars of Figure 6).

The average outing distance driven by support vehicles was 20.6 miles. Further, $95 \%$ of the outing travel was less than the 70 miles considered to be within the BEV's safe range (blue and green bars in Figure 6). Meanwhile, $80 \%$ of vehicle outings were less than the 30 miles considered to be within the CD range of a PHEV (green bars of Figure 6).
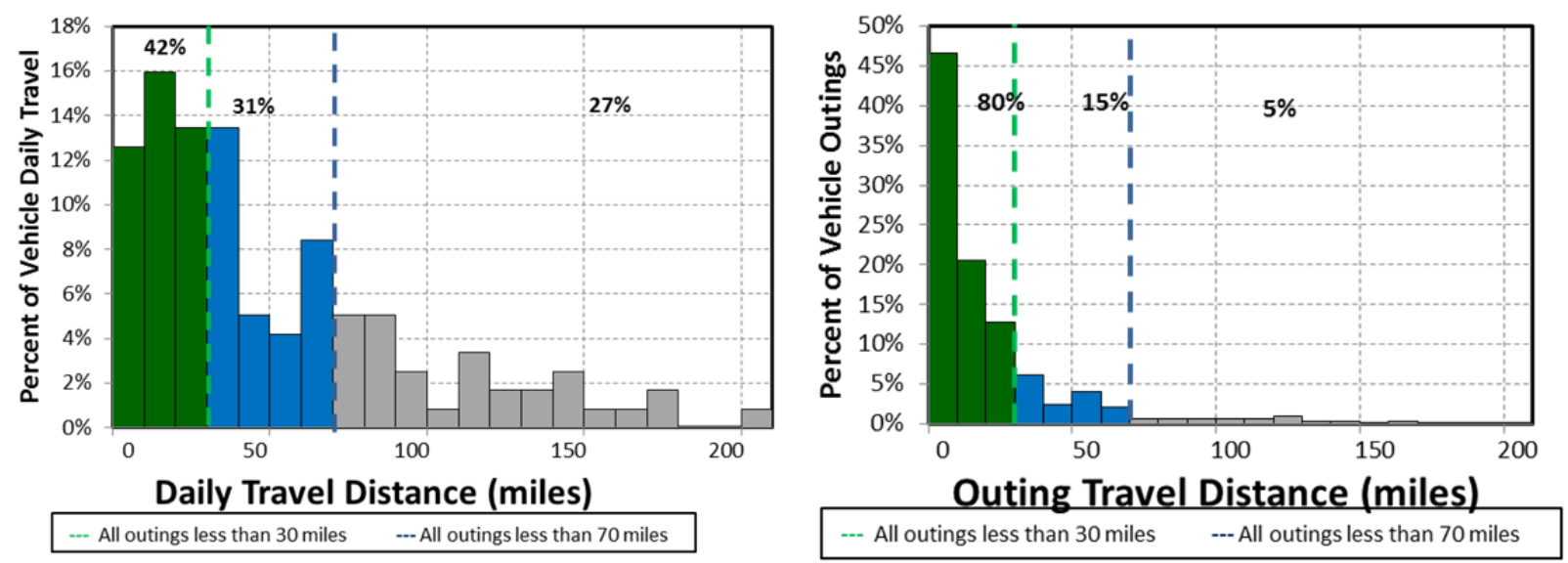

Figure 6. MCBCL enforcement vehicle daily travel and outing travel.

In general, if a suitable PEV body style meets vehicle requirements, $73 \%$ of an enforcement fleet could be BEVs and $27 \%$ PHEVs to allow for daily travel greater than the range of the BEV. However, enforcement fleet managers typically will desire vehicles without range limitations and would favor a higher percentage of PHEVs. The specific duties of some enforcement vehicles, such as parking 
enforcement, could be accomplished by BEVs. Although more PHEVs might be desired, this analysis shows the high capability of BEVs to meet this enforcement mission at MCBCL.

\subsection{Specialty Mission Guidance}

Two of the vehicles monitored at MCBCL provided a specialty mission. One is a refrigeration truck and the other a bucket truck. The refrigeration truck, operated as a pool vehicle, was not used during the study period. The overall summary for the bucket truck is shown in Table 13. This vehicle traveled 237 miles, logged 21 hours, and idled for 12 hours.

Table 13. MCBCL specialty vehicle travel summary.

\begin{tabular}{lcccc}
\hline \multicolumn{4}{c}{ Specialty Vehicles Travel Summary } & \\
& $\begin{array}{c}\text { Per Day } \\
\text { Average/Peak }\end{array}$ & $\begin{array}{c}\text { Per Outing } \\
\text { Average/Peak }\end{array}$ & $\begin{array}{c}\text { Per Trip } \\
\text { Average/Peak }\end{array}$ & Total \\
\hline Travel Distance (Miles) & $23.7 / 69.4$ & $8.5 / 39.0$ & $4.8 / 39.0$ & 237 \\
Travel Time (Minutes) & $126.6 / 271.0$ & $45.2 / 171.0$ & $25.8 / 152.0$ & 1,266 \\
Idle Time (Minutes) & $2.1 / \mathrm{NA}$ & $26.6 / \mathrm{NA}$ & $5.2 / \mathrm{NA}$ & 746 \\
\hline
\end{tabular}

Figure 7 shows the daily travel and outing travel for this specialty vehicle.

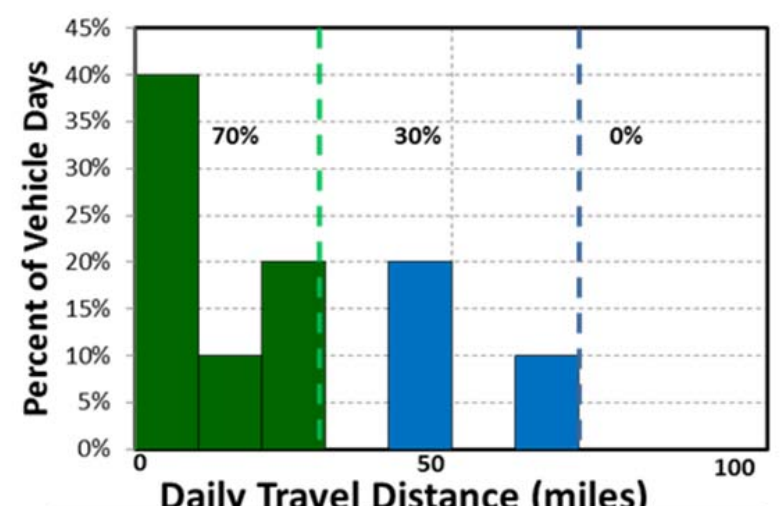

Daily Travel Distance (miles)

... All travel less than 30 miles $\quad$... All travel less than 70 miles

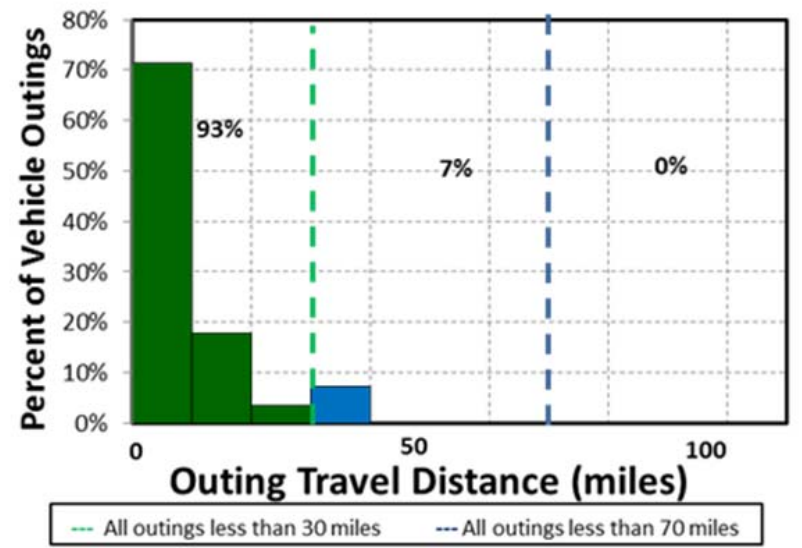

Figure 7. MCBCL specialty vehicle daily travel and outage distance.

The average travel distance per day when driven for this specialty vehicle was 23.7 miles. On all vehicle travel days, the daily travel was less than the 70 miles considered to be within the BEV safe range (blue and green bars in Figure 7). In addition, 70\% of vehicle travel days were less than the 30 miles considered to be within the CD range of a PHEV (green bars of Figure 7).

The average outing distance driven by this specialty vehicle was 8.5 miles. All outing travel was less than the 70 miles considered to be within the BEV safe range (blue and green bars in Figure 7).

Meanwhile, $93 \%$ of vehicle outings were less than the 30 miles considered to be within the CD range of a PHEV (green bars of Figure 7).

In general, if a suitable PEV body style meets vehicle requirements, all of the specialty fleet could be BEVs. However, at this writing, bucket trucks are available only in a PHEV model. This model could fulfill the bucket truck requirements for MCBCL. 


\section{MARINE CORPS BASE CAMP LEJEUNE REPLACEMENT APPROACH}

Executive Order 13693 issued on March 25, 2015, directs “...that by December 31, 2020, zero emission vehicles or plug-in hybrid vehicles account for 20 percent of all new agency passenger vehicle acquisitions and by December 31, 2025, zero emission vehicles or plug-in hybrid vehicles account for 50 percent of all new agency passenger vehicles...". ${ }^{8}$ The goal of the approach outlined here is to be consistent with this executive order.

Sixty vehicles belonging to Commands and MCIE were included in the study at MCBCL. The specific requirements of each necessitated that data be analyzed for each individual fleet. The results were extrapolated to the entire non-tactical fleet at MCBCL.

Tables 4 and 5 identified that at the time of this report, GSA has certified five sedan vehicles for replacement as PEVs: three PHEVs and two BEVs. Consequently, the group of potential replacements involves only sedans - a rather small subset of fleet vehicles and only $9 \%$ of the vehicles at MCBCL.

Tables 6 through 9 identified other vehicles that are currently or soon to be available but are not listed by GSA. These vehicles provide potential replacements for all non-tactical fleet vehicles except heavy-duty trucks, buses, and specialty vehicles. While the PEV market has introduced and delivered several specialty vehicles on heavy-duty truck frames (e.g., delivery trucks) and electric buses to several customers, their charging needs are typically specialized and generally are not included in this report. Bucket trucks were the primary exception because electric utilities are promoting the conversion of ICE vehicles to PHEV models.

If all PEVs in the tables are included for replacement consideration, the potential includes most (i.e., 775) of the vehicles at MCBCL, except heavy-duty trucks, non-powered vehicles, material handling equipment, and 53 specialty vehicles.

After-market vehicle modifications are also available for converting ICE vehicles to PHEVs and may be considered by MCBCL for vehicles types not currently available.

Appendices A and B provide the details of each monitored vehicle as reported in the Task 3 report. These also identify the suggested PEV replacement vehicle. Note that these replacements are examples of potential PEV replacement. When the ICE vehicle at MCBCL is scheduled for replacement, the available PEV replacements at that time may provide a greater selection opportunity.

The replacement approach for each of the groups and the balance of the MCBCL vehicles is presented in Appendices C and D.

There are four approaches identified for each group:

- Monitored vehicles

- $\quad$ GSA-listed PEVs only

- All potential PEV types

- Balance of the full fleet

- GSA-listed PEVs only

- $\quad$ All potential PEV types.

MCBCL will need to develop their approach based on specific conditions and requirements. For example, if GSA continues to list sedans only, either MCBCL will need to justify vehicles not listed by

${ }^{8}$ http://www.gpo.gov/fdsys/pkg/FR-2015-03-25/pdf/2015-07016.pdf [accessed August 4, 2015] 
GSA or review vehicle needs to replace other vehicle types with sedans. For example, pickup trucks are the most popular vehicle type, but it may be possible that the mission for many of the pickups can be accomplished by a sedan. It is more likely that GSA will list other PEV body types in the coming years to provide more options as more PEVs become available.

The extensive analysis conducted for monitored vehicles (Task 3) results in high confidence that the suggested vehicle can meet the mission requirements. The suggested vehicles for the full fleet rely on extrapolation of those monitored vehicles and the guidance identified in Section 3.

The overall plan is presented first in this section followed by the effects to each of the fleet groups.

\subsection{Marine Corps Base Camp Lejeune Summary Replacement Approach}

Table 1 identified the types of vehicles by fleet group at MCBCL at the time of the analysis. Supporting incorporation of PEVs into this fleet is the objective of this task. The full fleet inventory was analyzed in 2015 and replacement vehicles were projected for 2015 through 2035 . Tale 14 provides the full fleet replacement projections based on GSA replacement criteria and current fleet inventory age, quantity, and mileage. Many of the MCBCL vehicles have exceeded the minimum replacement criteria; this is expected to continue into the coming years of these projections. Note that heavy-duty trucks and buses were excluded from this list. Some heavy-duty specialty trucks have completed conversion to PEVs in demonstration projects. However, few have become commercialized. Electric utilities have promoted bucket trucks with electric drive and these were considered in this replacement approach.

Table 14. Projected fleet vehicle replacements at MCBCL.

\begin{tabular}{|c|c|c|c|c|c|c|c|c|c|c|}
\hline Year & $\begin{array}{l}\text { Sedan - } \\
\text { Compact }\end{array}$ & $\begin{array}{l}\text { Sedan - } \\
\text { Midsize }\end{array}$ & $\begin{array}{l}\text { Sedan- } \\
\text { Large }\end{array}$ & Minivan & SUV & $\begin{array}{c}\text { Cargo } \\
\text { Van }\end{array}$ & $\begin{array}{c}\text { Pass. } \\
\text { Van }\end{array}$ & Pickup & Specialty & Total \\
\hline 2015 & - & - & 3 & 1 & - & - & 1 & - & - & 5 \\
\hline 2016 & - & - & 20 & - & 5 & 3 & 13 & 13 & 5 & 59 \\
\hline 2017 & - & 2 & - & 7 & 6 & 5 & 5 & 16 & 2 & 43 \\
\hline 2018 & - & 1 & 5 & 7 & 9 & 3 & 12 & 22 & 2 & 61 \\
\hline 2019 & - & - & 4 & 3 & 13 & 1 & 7 & 21 & - & 49 \\
\hline 2020 & - & 3 & 3 & 6 & 12 & 3 & 13 & 27 & 3 & 70 \\
\hline 2021 & - & 2 & 2 & 10 & 8 & 4 & 7 & 19 & 1 & 53 \\
\hline 2022 & 3 & 12 & - & 3 & 6 & 6 & 7 & 16 & 1 & 54 \\
\hline 2023 & 2 & 2 & 1 & 4 & 1 & 2 & 9 & 27 & 1 & 49 \\
\hline 2024 & - & - & - & 6 & 5 & 5 & 8 & 23 & 2 & 49 \\
\hline 2025 & - & 1 & 3 & 9 & 1 & 4 & 6 & 21 & 4 & 49 \\
\hline 2026 & 1 & - & 2 & 3 & - & 4 & 2 & 21 & 7 & 40 \\
\hline 2027 & - & - & - & 6 & - & 3 & 4 & 12 & - & 25 \\
\hline 2028 & - & - & - & - & 2 & 3 & 6 & 18 & 3 & 32 \\
\hline 2029 & - & - & - & 2 & 1 & 8 & 1 & 23 & 8 & 43 \\
\hline 2030 & - & - & - & - & 4 & 1 & 1 & 33 & 2 & 41 \\
\hline 2031 & - & - & - & - & 2 & 1 & 3 & 12 & 3 & 21 \\
\hline 2032 & - & - & - & - & 1 & 1 & - & 5 & 7 & 14 \\
\hline 2033 & - & - & - & - & - & - & - & 1 & 6 & 7 \\
\hline 2034 & - & - & - & - & - & 3 & - & 2 & 3 & 8 \\
\hline 2035 & - & - & - & - & - & 2 & 4 & 4 & 2 & 12 \\
\hline Total & 6 & 23 & 43 & 67 & 76 & 62 & 109 & 336 & 62 & 784 \\
\hline
\end{tabular}


Replacing vehicles in accordance with this schedule is illustrated in Figure 8. Note that vehicles replaced in the next few years may be replaced prior to 2035. Vehicles projected for replacement in 2030 through 2035 (i.e., 15 to 20 years from this writing) are primarily low-mileage specialty vehicles, pickups, and vans.

As noted above, the vehicles projected for replacement in the later years of this analysis are primarily low-mileage specialty vehicles. Because many of the vehicles projected for replacement in the next few years will likely be replaced themselves, only the vehicles to be replaced during years 2015 through 2026 are projected for further analysis.

The projected approach to PEV introduction is to replace selected ICE vehicles with PEVs as they would normally be replaced. The replacement approach presents a structured and gradual introduction of PEVs into the MCBCL fleet. This approach is based on an increasing percentage of PEVs as replacements are considered over the next few years. While no PEVs are currently in the MCBCL fleet, this approach allows for growth in experience in management, support, and maintenance of the PEV fleet. The presented approach for incorporation of PEVs at MCBCCL is presented in Table 15. Non-sedan types are included to gain initial experience with the vehicle types even though they are not listed on the GSA schedule. GSA may list some of these vehicles in the next few years.

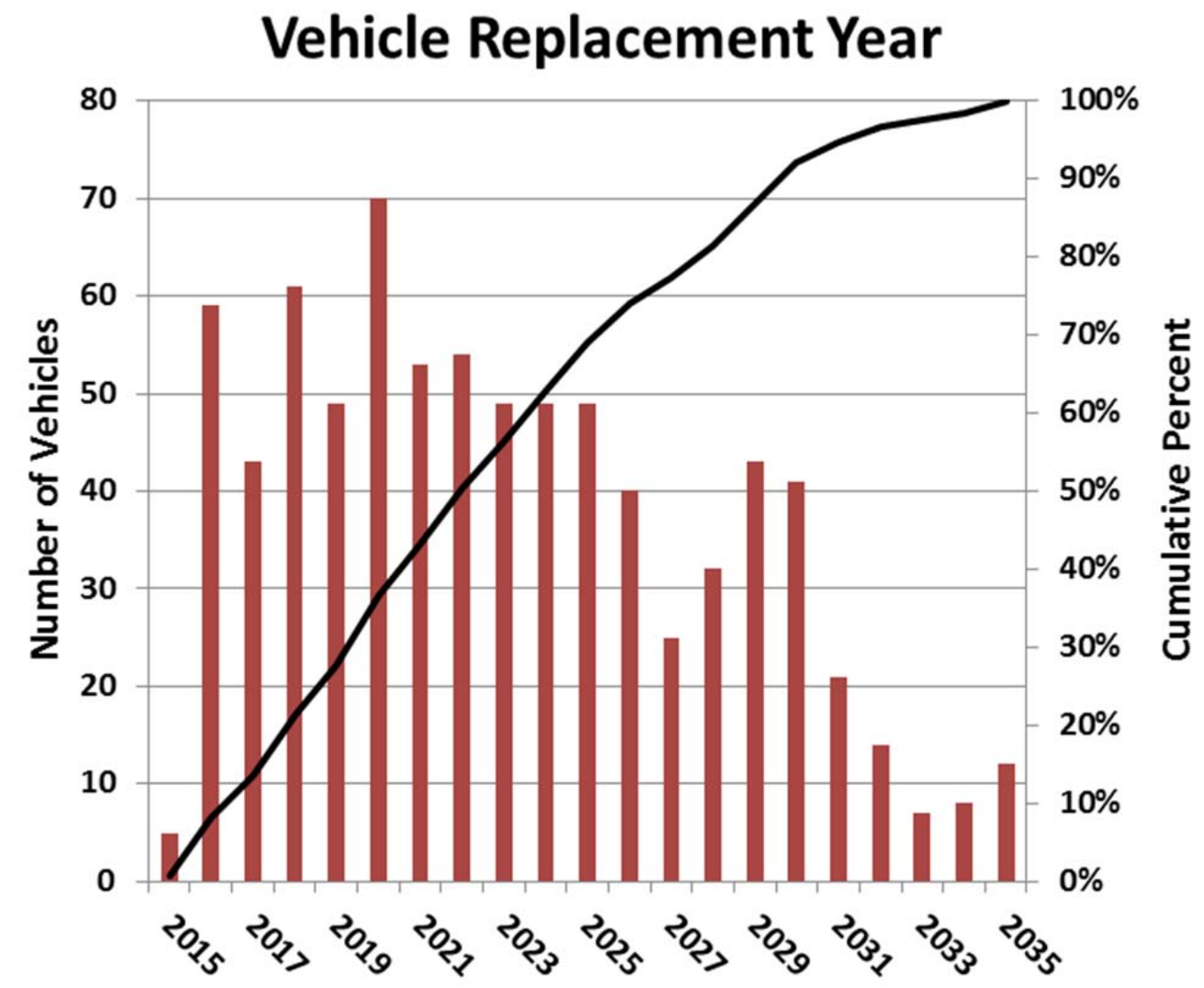

Figure 8. Full fleet vehicle replacement projection. 
Table 15. Projected approach for the introduction of PEVs into the MCBCL fleet.

\begin{tabular}{|c|c|c|c|c|c|c|c|c|c|c|c|}
\hline Year & $\begin{array}{c}\text { Sedan - } \\
\text { Compact }\end{array}$ & $\begin{array}{l}\text { Sedan - } \\
\text { Midsize }\end{array}$ & $\begin{array}{l}\text { Sedan- } \\
\text { Large }\end{array}$ & Minivan & SUV & $\begin{array}{l}\text { Cargo } \\
\text { Van }\end{array}$ & $\begin{array}{l}\text { Pass. } \\
\text { Van }\end{array}$ & Pickup & Specialty & Total & $\begin{array}{l}\text { Percent of all } \\
\text { Replacements }\end{array}$ \\
\hline 2015 & - & - & 3 & - & - & - & - & - & - & 3 & $60 \%$ \\
\hline 2016 & - & - & 5 & - & 2 & 1 & 3 & 2 & - & 13 & $22 \%$ \\
\hline 2017 & - & 2 & - & 3 & 2 & 1 & 1 & 3 & - & 12 & $28 \%$ \\
\hline 2018 & - & - & 4 & 1 & 2 & 2 & 2 & 9 & - & 20 & $33 \%$ \\
\hline 2019 & - & - & 4 & 1 & 5 & 1 & 4 & 10 & - & 25 & $50 \%$ \\
\hline 2020 & - & 3 & 2 & 2 & 4 & 3 & 6 & 10 & - & 30 & $43 \%$ \\
\hline 2021 & - & 2 & 2 & 2 & 6 & 4 & 5 & 14 & - & 35 & $66 \%$ \\
\hline 2022 & 3 & 7 & - & 2 & 4 & 4 & 7 & 12 & 1 & 40 & $74 \%$ \\
\hline 2023 & 2 & 2 & - & 2 & 1 & 2 & 5 & 20 & 1 & 35 & $71 \%$ \\
\hline 2024 & - & - & - & 3 & 2 & 4 & 5 & 15 & 1 & 30 & $61 \%$ \\
\hline 2025 & - & 1 & 2 & 5 & 1 & 4 & 4 & 13 & - & 30 & $61 \%$ \\
\hline 2026 & 1 & - & 2 & 2 & - & 2 & 1 & 9 & 3 & 20 & $50 \%$ \\
\hline Total & 6 & 17 & 24 & 23 & 29 & 28 & 43 & 117 & 6 & 293 & \\
\hline
\end{tabular}

The vehicles replaced by this approach would result in 50\% of the fleet as PEVs in 2026, assuming the size of the fleet remains as it was in 2015. This approach exceeds the purchase percentages of the Executive Order (Figure 9). Certainly, MCBCL can include PEVs at a greater rate if desired.

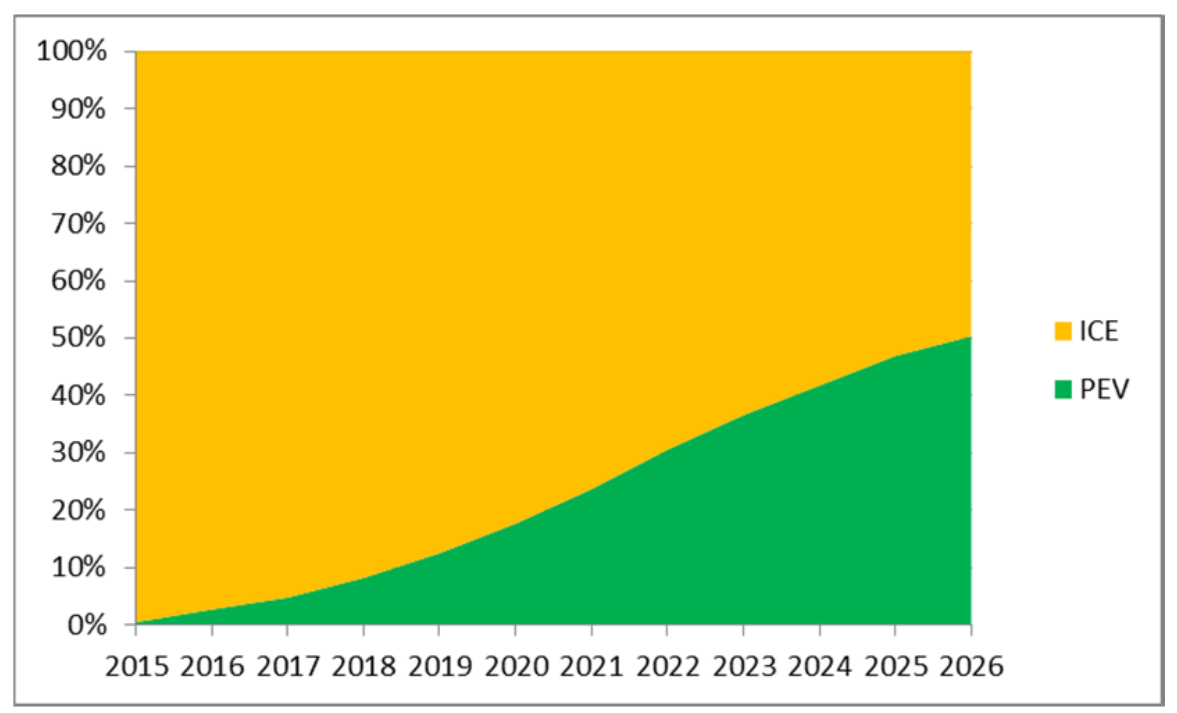

Figure 9. Projected PEVs in MCBCL fleet.

When considering replacement of vehicles with PEVs, MCBCL fleet managers may note the vehicle mission guidance of Section 3. It would be most desirable to select a BEV if the body type and capabilities meet the vehicle's mission in order to gain the most benefit in fuel cost and GHG emission reduction. In most cases, the greatest component of a particular fleet can be BEVs. The analysis in Task 3 shows that the average vehicle travels less than 8,000 miles per year. This is an average of 667 miles per month or about 150 miles per week. This also reflects the opportunity for increasing the percentage of BEVs over PHEVs in each fleet. 


\subsubsection{Replacement Approach for Sedans}

Table 16 presents a planned approach for replacement of sedans with PEVs; this is the sedan portion of Table 14. At the end of the 12-year period with this approach, $65 \%$ of fleet sedans will be PEVs with $47 \%$ BEVs and 53\% PHEVs. Note that the initial years are populated more toward the PHEV because the sedans replaced already have high usage and mileage and this allows an easier transition to PEVs. Of course, MCBCL can select BEVs as replacement vehicles with consideration of fleet capabilities. Note that no sedans are projected to be replaced in the year 2024.

Table 16. Planned approach for the introduction of PEV sedans at MCBCL.

\begin{tabular}{cccccccc}
\hline Year & ICE & BEV & PHEV & $\begin{array}{c}\text { Total } \\
\text { PEVs }\end{array}$ & $\begin{array}{c}\text { Vehicles } \\
\text { Replaced }\end{array}$ & $\begin{array}{c}\text { Percentage } \\
\text { PEV/Year }\end{array}$ & $\begin{array}{c}\text { Cumulative } \\
\text { Percent PEV }\end{array}$ \\
\hline 2015 & - & - & 3 & 3 & 3 & $100 \%$ & $4 \%$ \\
2016 & 15 & - & 5 & 5 & 20 & $25 \%$ & $11 \%$ \\
2017 & - & - & 2 & 2 & 2 & $100 \%$ & $14 \%$ \\
2018 & 2 & - & 4 & 4 & 6 & $67 \%$ & $19 \%$ \\
2019 & - & - & 4 & 4 & 4 & $100 \%$ & $25 \%$ \\
2020 & 1 & 4 & 1 & 5 & 6 & $83 \%$ & $32 \%$ \\
2021 & - & 2 & 2 & 4 & 4 & $100 \%$ & $38 \%$ \\
2022 & 5 & 7 & 3 & 10 & 15 & $67 \%$ & $51 \%$ \\
2023 & 1 & 3 & 1 & 4 & 5 & $80 \%$ & $57 \%$ \\
2024 & - & - & - & - & - & - & $57 \%$ \\
2025 & 1 & 3 & - & 3 & 4 & $75 \%$ & $61 \%$ \\
2026 & - & 3 & - & 3 & 3 & $100 \%$ & $65 \%$ \\
Total & 25 & 22 & 25 & 47 & 72 & & $4 \%$ \\
\hline
\end{tabular}

Assuming the total fleet inventory remains at 72 sedans, this replacement approach results in the fleet composition shown in Figure 10 for the years 2015 through 2026.

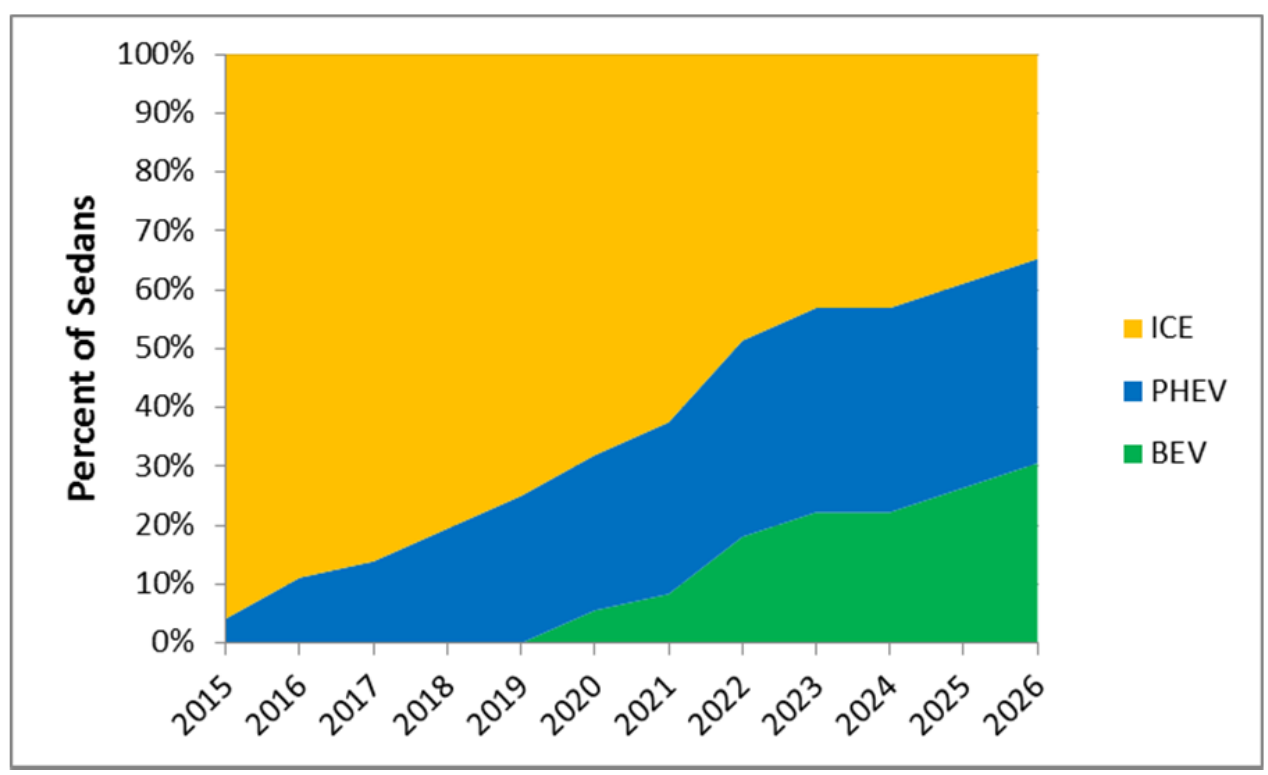

Figure 10. PEV introduction of fleet sedan types 2015 through 2026.

See Appendices A and B for a list of potential replacement PEV sedans. 


\subsubsection{Replacement Approach for Non-Sedan Vehicles}

As noted above, the non-sedan portion of the MCBCL fleet is presented separately because there are no current GSA-listed vehicles as potential replacements. These are included in the suggested replacement approach to allow MCBCL to gain initial experience with the vehicle types. GSA may in fact list some of these vehicles in the next few years. The non-sedan portion of Table 14 is shown in Table 17.

Table 17. Planned approach for the introduction of non-sedan PEVs at MCBCL.

\begin{tabular}{lcccccccc}
\hline \multicolumn{1}{c}{ Year } & Minivan & SUV & $\begin{array}{c}\text { Cargo } \\
\text { Van }\end{array}$ & $\begin{array}{c}\text { Pass. } \\
\text { Van }\end{array}$ & Pickup & Specialty & Total & $\begin{array}{c}\text { Percentage } \\
\text { PEV/Year }\end{array}$ \\
\hline 2015 & 0 & 0 & 0 & 0 & 0 & 0 & 0 & $0 \%$ \\
2016 & 0 & 2 & 1 & 3 & 2 & 0 & 8 & $21 \%$ \\
2017 & 3 & 2 & 1 & 1 & 3 & 0 & 10 & $24 \%$ \\
2018 & 1 & 2 & 2 & 2 & 9 & 0 & 16 & $29 \%$ \\
2019 & 1 & 5 & 1 & 4 & 10 & 0 & 21 & $46 \%$ \\
2020 & 2 & 4 & 3 & 6 & 10 & 0 & 25 & $39 \%$ \\
2021 & 2 & 6 & 4 & 5 & 14 & 0 & 31 & $63 \%$ \\
2022 & 2 & 4 & 4 & 7 & 12 & 1 & 30 & $77 \%$ \\
2023 & 2 & 1 & 2 & 5 & 20 & 1 & 31 & $70 \%$ \\
2024 & 3 & 2 & 4 & 5 & 15 & 1 & 30 & $61 \%$ \\
2025 & 5 & 1 & 4 & 4 & 13 & 0 & 27 & $60 \%$ \\
2026 & 2 & 0 & 2 & 1 & 9 & 3 & 17 & \\
Total & 23 & 29 & 28 & 43 & 117 & 6 & 246 & \\
Percent & $39 \%$ & $43 \%$ & $70 \%$ & $48 \%$ & $52 \%$ & $21 \%$ & $48 \%$ & \\
\hline
\end{tabular}

At the end of the 12-year period, with this approach and assuming 784 vehicles remain in the total fleet, $48 \%$ of the non-sedan fleets will be PEVs with approximately $55 \%$ BEVs and $45 \%$ PHEVs. This adoption is illustrated in Figure 11.

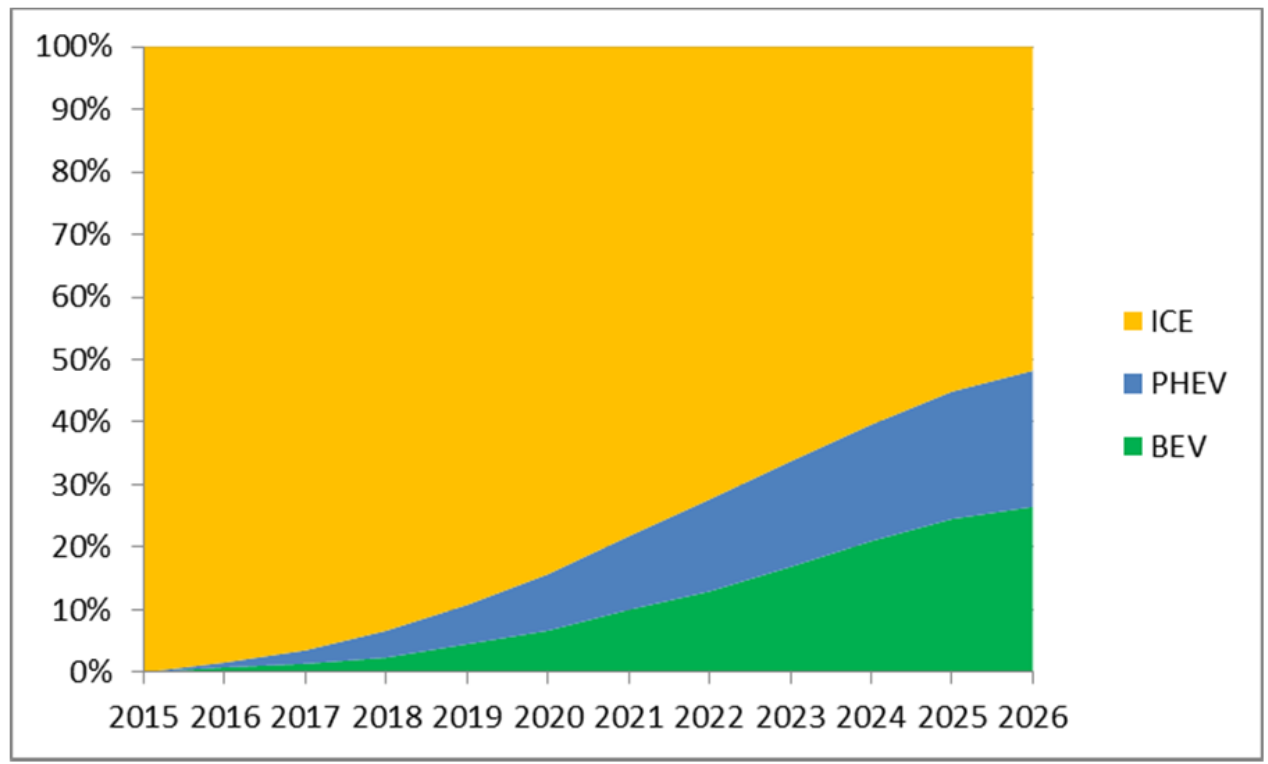

Figure 11. PEV introduction of fleet non-sedan types 2015 through 2026. 


\subsection{Analysis Results - Commands Group}

The Commands Group fleet contains 249 vehicles, with 18 of those vehicles monitored in this study. The monitored vehicles include two minivans, three SUVs, six passenger vans, and seven pickup trucks. The details of each vehicle monitored are included in Appendix A. Appendix C provides the detailed evaluation for the approach summarized in the following sections.

Table 18 identifies the projected year the current vehicle will be replaced based on GSA requirements and extrapolated vehicle mileage. This table factors into the full table provided in Table 14.

Table 18. The anticipated replacement schedule for the Commands Group vehicles at MCBCL.

\begin{tabular}{|c|c|c|c|c|c|c|c|c|c|c|}
\hline Year & $\begin{array}{c}\text { Sedan } \\
\text { Compact/ } \\
\text { Subcomnact }\end{array}$ & $\begin{array}{c}\text { Sedan } \\
\text { Midsize }\end{array}$ & $\begin{array}{l}\text { Sedan } \\
\text { Large }\end{array}$ & $\begin{array}{c}\text { Mini- } \\
\text { Van }\end{array}$ & SUV & $\begin{array}{c}\text { Cargo } \\
\text { Van } \\
\end{array}$ & $\begin{array}{c}\text { Pass. } \\
\text { Van }\end{array}$ & Pickup & Specialty & Total \\
\hline 2015 & - & - & - & 1 & - & - & 1 & - & - & 2 \\
\hline 2016 & - & - & - & - & - & - & 12 & 6 & - & 18 \\
\hline 2017 & - & - & - & 5 & 2 & - & 4 & 3 & - & 14 \\
\hline 2018 & - & 1 & - & 7 & 2 & - & 10 & 9 & - & 29 \\
\hline 2019 & - & - & - & 1 & 6 & - & 5 & 10 & - & 22 \\
\hline 2020 & - & - & 1 & 3 & 3 & - & 8 & 14 & - & 29 \\
\hline 2021 & - & - & 1 & 7 & 1 & - & 6 & 11 & - & 26 \\
\hline 2022 & 1 & 6 & - & 1 & 1 & 2 & 3 & 5 & - & 19 \\
\hline 2023 & - & - & - & - & 1 & - & 5 & 4 & - & 10 \\
\hline 2024 & - & - & - & 2 & - & - & 1 & 4 & - & 7 \\
\hline 2025 & - & - & 2 & 1 & 1 & - & 1 & 5 & - & 10 \\
\hline 2026 & - & - & 1 & - & - & - & 1 & 6 & - & 8 \\
\hline Total & 1 & 7 & 5 & 28 & 17 & 2 & 57 & 77 & - & 194 \\
\hline
\end{tabular}

\subsubsection{Replacement Approach for Commands Group Sedans}

Table 19 presents a planned approach for the replacement of sedans with PEVs that flows into the totals shown in Table 15. The percentage of vehicles replaced each year by PEVs is also shown in the table. Appendix $\mathrm{C}$ notes that none of the sedans in the Commands group are projected for replacement until 2022.

Table 19. Planned approach for the introduction of PEV sedans into the Commands Group.

\begin{tabular}{cccccc}
\hline Year & ICE & BEV & PHEV & Total PEVs & Percentage PEV/Year \\
\hline 2015 & - & - & - & - & - \\
2016 & - & - & - & - & - \\
2017 & - & - & - & - & - \\
2018 & 1 & - & - & - & - \\
2019 & - & - & - & - & $100 \%$ \\
2020 & - & - & 1 & 1 & $100 \%$ \\
2021 & - & - & 1 & 1 & - \\
2022 & 4 & 3 & - & 3 & - \\
2023 & - & - & - & - & $100 \%$ \\
2024 & - & - & - & - & $100 \%$ \\
2025 & - & 2 & - & 2 & \\
2026 & - & 1 & - & 1 & 8 \\
Total & 5 & 6 & 2 & 8 & \\
Percent & $38 \%$ & $46 \%$ & $15 \%$ & $62 \%$ & \\
\hline
\end{tabular}


The final complement of sedans includes $62 \%$ PEVs with the PEV component of $75 \%$ BEVs and $25 \%$ PHEVs. See Appendix C for the list of vehicles recommended for replacement in this approach.

\subsubsection{Replacement Approach for Commands Group Non-Sedan Vehicles}

Table 20 presents a planned approach for replacement of non-sedans with PEVs that flows into the totals shown in Table 16. The percentage of non-sedan vehicles replaced each year by PEVs is also shown in the table.

Table 20. Planned approach for introduction of non-sedan PEVs into the Commands Group.

\begin{tabular}{ccccccccc}
\hline Year & Minivan & SUV & $\begin{array}{c}\text { Cargo } \\
\text { Van }\end{array}$ & $\begin{array}{c}\text { Pass. } \\
\text { Van }\end{array}$ & Pickup & Specialty & Total & $\begin{array}{c}\text { Percentage } \\
\text { PEV/Year }\end{array}$ \\
\hline 2015 & - & - & - & - & - & - & - & $0 \%$ \\
2016 & - & - & - & 3 & - & - & 3 & $17 \%$ \\
2017 & 3 & - & - & - & - & - & 3 & $21 \%$ \\
2018 & 1 & 1 & - & 2 & 2 & - & 6 & $21 \%$ \\
2019 & 1 & 2 & - & 3 & 6 & - & 12 & $55 \%$ \\
2020 & 1 & 1 & - & 5 & 6 & - & 13 & $46 \%$ \\
2021 & 2 & 1 & - & 4 & 7 & - & 14 & $56 \%$ \\
2022 & - & 1 & 1 & 3 & 3 & - & 8 & $67 \%$ \\
2023 & - & 1 & - & 3 & 3 & - & 7 & $70 \%$ \\
2024 & 1 & - & - & 1 & 2 & - & 4 & $57 \%$ \\
2025 & - & 1 & - & 0 & 2 & - & 3 & $38 \%$ \\
2026 & - & - & - & 1 & 3 & - & 4 & $57 \%$ \\
Total & 9 & 8 & 1 & 25 & 34 & - & & \\
Percent & $32 \%$ & $47 \%$ & $50 \%$ & $44 \%$ & $44 \%$ & - & & \\
\hline
\end{tabular}

In this approach, the final complement of non-sedans includes $43 \%$ PEVs. The final composition of each vehicle type in the fleet is also shown in Table 20. See Appendix C for the list of vehicles recommended for replacement in this approach.

\subsection{Analysis Results - Marine Corps Installations East Fleet}

The MCIE group fleet contains 535 vehicles, with 42 of those vehicles monitored in this study. This section provides a replacement strategy for this group. The details of each vehicle monitored are included in Appendix B. Appendix D provides the detailed evaluation for the approach summarized in the following sections.

The projected year the current vehicle will be replaced based on GSA requirements and extrapolated vehicle mileage is shown in Table 21. Note the heavy-duty trucks and most specialty vehicles are not included. This table is the MCIE group portion of Table 14.

Table 21. Projected MCIE Group anticipated vehicle replacement schedule at MCBCL.

\begin{tabular}{ccccccccccc}
\hline Year & $\begin{array}{c}\text { Sedan - } \\
\text { Compact }\end{array}$ & $\begin{array}{c}\text { Sedan - } \\
\text { Midsize }\end{array}$ & $\begin{array}{c}\text { Sedan- } \\
\text { Large }\end{array}$ & Minivan & SUV & $\begin{array}{c}\text { Cargo } \\
\text { Van }\end{array}$ & $\begin{array}{c}\text { Pass. } \\
\text { Van }\end{array}$ & Pickup & Specialty & Total \\
\hline 2015 & - & - & 3 & - & - & - & - & - & - & 3 \\
2016 & - & - & 20 & - & 5 & 3 & 1 & 7 & 5 & 41 \\
2017 & - & 2 & - & 2 & 4 & 5 & 1 & 13 & 2 & 29 \\
2018 & - & - & 5 & - & 7 & 3 & 2 & 13 & 2 & 32 \\
2019 & - & - & 4 & 2 & 8 & 1 & 2 & 11 & - & 28 \\
\hline
\end{tabular}




\begin{tabular}{|c|c|c|c|c|c|c|c|c|c|c|}
\hline Year & $\begin{array}{c}\text { Sedan - } \\
\text { Compact }\end{array}$ & $\begin{array}{l}\text { Sedan - } \\
\text { Midsize }\end{array}$ & $\begin{array}{l}\text { Sedan- } \\
\text { Large }\end{array}$ & Minivan & SUV & $\begin{array}{c}\text { Cargo } \\
\text { Van }\end{array}$ & $\begin{array}{c}\text { Pass. } \\
\text { Van }\end{array}$ & Pickup & Specialty & Total \\
\hline 2020 & - & 3 & 2 & 3 & 9 & 3 & 5 & 13 & 3 & 41 \\
\hline 2021 & - & 2 & 1 & 3 & 7 & 4 & 1 & 8 & 1 & 27 \\
\hline 2022 & 2 & 6 & - & 2 & 5 & 4 & 4 & 11 & 1 & 35 \\
\hline 2023 & 2 & 2 & 1 & 4 & - & 2 & 4 & 23 & 1 & 39 \\
\hline 2024 & - & - & - & 4 & 5 & 5 & 7 & 19 & 2 & 42 \\
\hline 2025 & - & 1 & 1 & 8 & - & 4 & 5 & 16 & 4 & 39 \\
\hline 2026 & 1 & - & 1 & 3 & - & 4 & 1 & 15 & 7 & 32 \\
\hline Total & 5 & 16 & 38 & 31 & 50 & 38 & 33 & 149 & 28 & 388 \\
\hline
\end{tabular}

\subsubsection{Replacement Approach for Marine Corps Installations East Group Sedans}

Table 22 presents a planned approach for replacement of sedans with PEVs that flows into the totals shown in Table 15. The percentage of sedans replaced each year by PEVs is also shown in the table. Note that no sedans are projected for replacement in the year 2024.

Table 22. Planned approach for the introduction of PEV sedans in the MCIE Group.

\begin{tabular}{cccccc}
\hline Year & ICE & BEV & PHEV & Total PEVs & Percentage PEV/Year \\
\hline 2015 & - & - & 3 & 3 & $100 \%$ \\
2016 & 15 & - & 5 & 5 & $25 \%$ \\
2017 & - & - & 2 & 2 & $100 \%$ \\
2018 & 1 & - & 4 & 4 & $80 \%$ \\
2019 & - & - & 4 & 4 & $100 \%$ \\
2020 & 1 & 4 & - & 4 & $80 \%$ \\
2021 & - & 2 & 1 & 3 & $100 \%$ \\
2022 & 1 & 4 & 3 & 7 & $88 \%$ \\
2023 & 1 & 3 & 1 & 4 & $80 \%$ \\
2024 & - & - & - & - & - \\
2025 & 1 & 1 & - & 1 & $50 \%$ \\
2026 & - & 2 & - & 2 & $100 \%$ \\
Total & 20 & 16 & 23 & 39 & \\
Percent & $34 \%$ & $27 \%$ & $39 \%$ & $66 \%$ & \\
\hline
\end{tabular}

The final complement of sedans includes $66 \%$ PEVs with the PEV component of $41 \%$ BEVs and $59 \%$ PHEVs. See Appendix D for the list of vehicles recommended for replacement in this approach.

\subsubsection{Replacement Approach for Marine Corps Installations East Group Non-Sedan Vehicles}

Table 23 presents a planned approach for replacement of non-sedans with PEVs that flows into the totals shown in Table 16. The percentage of non-sedan vehicles replaced each year by PEVs is also shown in the table. 
Table 23. Planned approach for the introduction of non-sedan PEVs in the MCIE Group.

\begin{tabular}{ccccccccc}
\hline Year & Minivan & SUV & $\begin{array}{c}\text { Cargo } \\
\text { Van }\end{array}$ & $\begin{array}{c}\text { Pass. } \\
\text { Van }\end{array}$ & Pickup & Specialty & Total & $\begin{array}{c}\text { Percentage } \\
\text { PEV/Year }\end{array}$ \\
\hline 2015 & - & - & - & - & - & - & - & - \\
2016 & - & 2 & 1 & - & 2 & - & 5 & $24 \%$ \\
2017 & - & 2 & 1 & 1 & 3 & - & 7 & $26 \%$ \\
2018 & - & 1 & 2 & - & 7 & - & 10 & $37 \%$ \\
2019 & - & 3 & 1 & 1 & 4 & - & 9 & $38 \%$ \\
2020 & 1 & 3 & 3 & 1 & 4 & - & 12 & $33 \%$ \\
2021 & - & 5 & 4 & 1 & 7 & - & 17 & $71 \%$ \\
2022 & 2 & 3 & 3 & 4 & 9 & 1 & 22 & $81 \%$ \\
2023 & 2 & - & 2 & 2 & 17 & 1 & 24 & $71 \%$ \\
2024 & 2 & 2 & 4 & 4 & 13 & 1 & 26 & $62 \%$ \\
2025 & 5 & - & 4 & 4 & 11 & - & 24 & $65 \%$ \\
2026 & 2 & - & 2 & - & 6 & 3 & 13 & $43 \%$ \\
Total & 14 & 21 & 27 & 18 & 83 & 6 & & \\
Percent & $45 \%$ & $42 \%$ & $71 \%$ & $55 \%$ & $56 \%$ & $21 \%$ & & \\
\hline
\end{tabular}

In this approach, the final complement of non-sedans includes 51\% PEVs. The proportion of each vehicle type is also shown in Table 23. See Appendix D for the list of vehicles recommended for replacement in this approach.

\subsection{Balance of Marine Corps Base Camp Lejeune Fleet}

The balance of the MCBCL fleet consists of heavy-duty trucks and specialty vehicles. The balance of the powered equipment was not analyzed because there are few PEVs available as potential replacements. Nevertheless, many after-market manufacturers are converting some heavy-duty trucks to electric drive. These are expected to become commercially available in the next several years. None of these types of vehicles were monitored as part of the study.

\section{PLUG-IN ELECTRIC VEHICLE CHARGING INFRASTRUCTURE}

Preparations for adoption of PEVs also require consideration of recharging stations. With the potential replacements identified in the previous section, the deployment of fleet EVSE can be provided.

The Task 3 infrastructure report provides a detailed review of EVSE types and installation considerations. A detailed review of potential charging locations was completed and, for all of the monitored fleets, charging at the vehicle's home base is all that is typically required. MCBCL may find future value in locating additional charging stations for employee or visitor use for privately owned vehicles, but those locations are not identified as part of this study.

The Task 3 report identifies that AC Level 1 EVSE is sufficient for charging PHEVs whereas AC Level 2 EVSE is recommended for BEVs. As MCBCL begins the planned introduction of PEVs into the fleets, it is recommended that the initial vehicles be provided with AC Level 2 EVSE in order to gain experience with the charging systems and to provide the greatest charge return for all vehicles. In this manner, MCBCL need not be concerned in the early years whether the vehicle is a PHEV or a BEV, but rather focus on adding infrastructure to accommodate AC Level 1 EVSE (that come standard with a PEV purchase) in later years. In addition, the Task 3 report identified that as experience is gained in the management of PEVs, there need not be an EVSE unit for every PEV. However, for these first vehicles, it is recommended that each be assigned its own EVSE unit at its home base. It was also noted in the Task 3 report that many locations had a single monitored vehicle assigned. 
Based on the replacement approach identified in Section 4, the charging infrastructure needs of sedans and non-sedan vehicles are discussed separately.

\subsection{Plug-in Electric Vehicle Charging Infrastructure for Sedans}

Table 24 provides the projected schedule for introduction of EVSE to support the sedan replacement approach. As noted, AC Level 2 infrastructure is emphasized over AC Level 1in the early adoption years. Typically, the EVSE are installed as dual units to reduce installation costs. However, because many buildings host a single PEV, the installation should at least include the stub-in of a second unit.

Table 24. EVSE infrastructure adoption for sedans.

\begin{tabular}{cccc}
\hline & Commands Group & MCIE Group & Total \\
Year & AC Level 2/AC Level 1 & AC Level 2/AC Level 1 & AC Level 2/AC Level 1 \\
\hline 2015 & - & $3 /-$ & $3 /-$ \\
2016 & - & $4 / 1$ & $4 / 1$ \\
2017 & - & $-/ 2$ & $-/ 2$ \\
2018 & - & $-/ 4$ & $-/ 4$ \\
2019 & - & $-/ 4$ & $-/ 4$ \\
2020 & $1 /-$ & $4 /-$ & $5 /-$ \\
2021 & - & $2 / 1$ & $2 / 1$ \\
2022 & $1 /-$ & $4 / 3$ & $5 / 3$ \\
2023 & $1 / 2$ & $3 / 1$ & $4 / 3$ \\
2024 & - & - & - \\
2025 & $2 /-$ & $1 /-$ & $3 /-$ \\
2026 & $1 /-$ & $2 /-$ & $3 /-$ \\
Total & $6 / 2$ & $23 / 16$ & $29 / 18$ \\
\hline
\end{tabular}

The Task 3 report detailed the potential for maximizing each group's conversion to PEVs and the potential savings in fuel costs and GHG emissions that result. Table 24 assumes that each PEV is assigned its own EVSE. The Task 3 report identified that with management attention, fewer units may be sufficient because some PEVs can share convenient EVSE.

\subsection{Plug-in Electric Vehicle Charging Infrastructure for Non-Sedans}

As above, Table 25 provides the schedule for introduction of EVSE to support the non-sedan fleet replacement approach. Again, AC Level 2 infrastructure is emphasized in the early adoption years over AC Level 1. Typically, the EVSE are installed as dual units to reduce installation costs. As above, the facility may not need more than one EVSE because many facilities host a single PEV. In that case, the installation should at least include the stub-in of a second unit.

Table 25. EVSE infrastructure adoption for non-sedan fleets

\begin{tabular}{|cccc}
\hline Year & $\begin{array}{c}\text { Commands Groun } \\
\text { AC Level 2/AC Level 1 }\end{array}$ & $\begin{array}{c}\text { MCIE Group } \\
\text { AC Level 2/AC Level 1 }\end{array}$ & $\begin{array}{c}\text { Total } \\
\text { AC Level 2/AC Level 1 }\end{array}$ \\
\hline 2015 & - & - & - \\
2016 & $3 /-$ & $5 /-$ & $8 /-$ \\
2017 & $3 /-$ & $7 /-$ & $10 /-$ \\
2018 & $2 / 4$ & $4 / 6$ & $6 / 10$ \\
2019 & $6 / 6$ & $3 / 7$ & $9 / 13$ \\
2020 & $9 / 4$ & $6 / 6$ & $15 / 10$ \\
2021 & $7 / 7$ & $6 / 11$ & $13 / 18$ \\
\hline
\end{tabular}




\begin{tabular}{|c|c|c|c|}
\hline Year & $\begin{array}{c}\text { Commands Group } \\
\text { AC Level 2/AC Level } 1 \\
\end{array}$ & $\begin{array}{c}\text { MCIE Group } \\
\text { AC Level 2/AC Level 1 }\end{array}$ & $\begin{array}{c}\text { Total } \\
\text { AC Level 2/AC Level } 1 \\
\end{array}$ \\
\hline 2022 & $2 / 6$ & $8 / 14$ & $10 / 20$ \\
\hline 2023 & $7 /-$ & $13 / 11$ & $20 / 11$ \\
\hline 2024 & $3 / 1$ & $13 / 13$ & $16 / 14$ \\
\hline 2025 & $2 / 1$ & $16 / 8$ & $18 / 9$ \\
\hline 2026 & $4 /-$ & $6 / 6$ & $10 / 6$ \\
\hline Total & $48 / 29$ & $87 / 82$ & $135 / 111$ \\
\hline
\end{tabular}

The Task 3 report detailed the potential for maximizing each group's conversion to PEVs and the potential savings in fuel costs and GHG emissions that result. Table 25 only considers the adoption approach identified in this report. The Task 3 report identified that with management attention, fewer units may be sufficient because some PEVs can share convenient EVSE. Table 26 summarizes the fleet charging needs.

Table 26. MCBCL charging infrastructure approach.

\begin{tabular}{lccc}
\hline \multicolumn{1}{c}{ Year } & Commands Group & MCIE Group & Total \\
& AC Level 2/AC Level 1 & AC Level 2/AC Level 1 & AC Level 2/AC Level 1 \\
\hline Sedan & $6 / 2$ & $23 / 16$ & $29 / 18$ \\
Non-Sedan & $48 / 29$ & $87 / 82$ & $135 / 111$ \\
Total & $54 / 31$ & $110 / 98$ & $164 / 129$ \\
\hline
\end{tabular}

The Task 3 infrastructure report provides recommendations regarding placement of these EVSE units.

\section{OBSERVATIONS}

As a result of this intensive study, Intertek suggests that MCBCL is poised for the successful introduction of PEVs into daily operation and that BEVs can provide support for most of the vehicle missions while providing savings in fuel costs and GHG emissions. In meeting the directives and mandates, the adoption approach outlined here should provide input to MCBCL's overall strategy and present an opportunity to gain experience in the operation, support, and maintenance of PEVs. MCBCL may wish to move forward in the near future with the replacement of pool, support, and enforcement vehicles with PEVs as current budget considerations allow. Certainly, the vehicle types studied may be candidates for immediate replacement.

Intertek appreciates presenting the results of this evaluation and working with MCBCL personnel in this study. 


\section{Appendix A Commands Group Vehicle Data Sheets}

Note that the replacement years identified in the following data sheets are based on the GSA requirements noted in Table 2 and current fleet usage. The final replacement approach may suggest later years based on vehicle use. Note that none of the monitored vehicles for the Commands group was a sedan. Thus, none of the monitored vehicles PEV replacements would be listed on the GSA schedule.

Table A-1 identifies a potential replacement approach using all currently or soon-to-be available PEVs.

Table A-1. MCBCL Commands Group monitored vehicle replacement (all potential vehicles).

\begin{tabular}{cccccc}
\hline \multicolumn{5}{c}{ Fleet } & \multicolumn{3}{c}{ All Vehicle Replacement Approach } \\
Vehicle Id & Make/Model & Year & EPA Class & Potential Replacement & Replacement \\
\hline 291073 & Ford E250 & 2007 & Van - Pass & eNV200 & Year \\
301321 & Ford F350 & 2012 & Pickup & eNV200 & 2022 \\
G41-0762M & Dodge Grd Caravan & 2012 & Minivan & Outlander & 2017 \\
G41-1846K & Dodge Grd Caravan & 2011 & Minivan & Outlander & 2017 \\
G41-2399K & Dodge Dakota & 2010 & Pickup & eNV200 & 2021 \\
G42-0216F & Ford E150 & 2008 & Van - Pass & eNV200 & 2016 \\
G42-0883M & Ford E150 & 2012 & Van - Pass & VTRUX Van & 2018 \\
G42-0898M & Ford E150 & 2012 & Van - Pass & VTRUX Van & 2018 \\
G43-0326H & Chevrolet 2500HD & 2009 & Pickup & eNV200 & 2022 \\
G43-1453G & ChevroletG2300 & 2008 & Van - Pass & Soul & 2016 \\
G43-1855P & Ford F350 & 2015 & Pickup & VTRUX PU & 2029 \\
G43-2025K & Ford F250 & 2010 & Pickup & Soul & 2025 \\
G43-4073F & Chevrolet G2300 & 2008 & Van - Pass & eNV200 & 2016 \\
G61-0594L & Jeep Patriot & 2011 & SUV & Outlander & 2020 \\
G61-2644P & Jeep Patriot & 2015 & SUV & Outlander & 2019 \\
G62-0791H & Ford Expedition & 2009 & SUV & Outlander & 2018 \\
G63-0309R & Ford F350 & 2015 & Pickup & VTRUX PU & 2025 \\
G63-0934G & Chevrolet K3500 & 2008 & Pickup & VTRUX PU & 2020 \\
\hline & & & & & \\
\hline
\end{tabular}




\section{Vehicle G10-291073}

\begin{tabular}{|c|c|c|}
\hline & Make/Model/Year & Ford E250 - 2007 \\
\hline-1 & EPA Class Size & Van - Passenger \\
\hline & Mission & Support \\
\hline & Contact & Marine Headquarters \\
\hline & Parking Location & Building PP2 \\
\hline & Fleet Vehicle ID & 291073 \\
\hline & Fuel Type & Gas \\
\hline & Potential Replacement PEV Make/Model & eNV200 \\
\hline 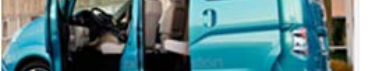 & Potential Annual Fuel Cost Savings & $\$ 421$ \\
\hline & Potential Annual GHG Reduction $\left(\mathrm{lb}-\mathrm{CO}_{2} \mathrm{e}\right)$ & 2,260 \\
\hline & EVSE Type for Recharging & AC Level 2 \\
\hline & Estimated Replacement Year & 2022 \\
\hline & Vehicle Age at Estimated Replacement (Year) & 15 \\
\hline & Odometer at Estimated Replacement Date & 66,092 \\
\hline
\end{tabular}

Vehicle 301321

\begin{tabular}{|c|c|c|}
\hline & Make/Model/Year & Ford F350 - 2012 \\
\hline & EPA Class Size & Pickup \\
\hline$a$ & Mission & Support \\
\hline ) & Contact & School of Infantry \\
\hline & Parking Location & Building TC771 \\
\hline & Fleet Vehicle ID & 301321 \\
\hline & Fuel Type & E85 \\
\hline & Potential Replacement PEV Make/Model & eNV200 \\
\hline & Potential Annual Fuel Cost Savings & $\$ 714$ \\
\hline e & Potential Annual GHG Reduction (lb- $\left.\mathrm{CO}_{2} \mathrm{e}\right)$ & 3,351 \\
\hline & EVSE Type for Recharging & AC Level 2 \\
\hline & Estimated Replacement Year & 2027 \\
\hline & Vehicle Age at Estimated Replacement (Year) & 15 \\
\hline & Odometer at Estimated Replacement Date & 55,877 \\
\hline
\end{tabular}




\section{Vehicle G41-0762M}

\begin{tabular}{|l|l|c|}
\hline & Make/Model/Year & $\begin{array}{c}\text { Dodge Grand Caravan - } \\
2012\end{array}$ \\
\hline & Minivan \\
\hline & Sission & Support \\
\hline Contact & Marine Aircraft Group 26 \\
\hline Parking Location & Building AS217 \\
\hline Fleet Vehicle ID & G41-0762M \\
\hline Fuel Type & E85 \\
\hline \multirow{2}{*}{} & Potential Replacement PEV Make/Model & Outlander \\
\cline { 2 - 3 } & Potential Annual Fuel Cost Savings & $\$ 954$ \\
\hline Potential Annual GHG Reduction $\left(\right.$ lb-CO $\left.{ }_{2} \mathrm{e}\right)$ & 3,490 \\
\hline & EVSE Type for Recharging & AC Level 1 \\
\hline & Estimated Replacement Year & 2017 \\
\hline & Vehicle Age at Estimated Replacement (Year) & 5 \\
\hline & Odometer at Estimated Replacement Date & 65,190 \\
\hline
\end{tabular}

\section{Vehicle G41-1846K}

\begin{tabular}{|c|c|c|}
\hline 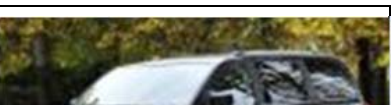 & Make/Model/Year & $\begin{array}{c}\text { Dodge Grand Caravan - } \\
2011\end{array}$ \\
\hline & EPA Class Size & Minivan \\
\hline 8 & Mission & Support \\
\hline & Contact & Special Operation Training \\
\hline & Parking Location & Building BA134 \\
\hline & Fleet Vehicle ID & G41-1846K \\
\hline & Fuel Type & E85 \\
\hline & Potential Replacement PEV Make/Model & Outlander \\
\hline & Potential Annual Fuel Cost Savings & $\$ 346$ \\
\hline$\longrightarrow$ & Potential Annual GHG Reduction $\left(\mathrm{lb}-\mathrm{CO}_{2} \mathrm{e}\right)$ & 1,266 \\
\hline & EVSE Type for Recharging & AC Level 1 \\
\hline & Estimated Replacement Year & 2017 \\
\hline & Vehicle Age at Estimated Replacement (Year) & 6 \\
\hline & Odometer at Estimated Replacement Date & 67,785 \\
\hline
\end{tabular}




\section{Vehicle G41-2399K}

\begin{tabular}{|c|c|c|}
\hline & Make/Model/Year & Dodge Dakota - 2010 \\
\hline & EPA Class Size & Pickup \\
\hline$\tau=1=\theta$ & Mission & Support \\
\hline & Contact & 2nd Marine Division \\
\hline & Parking Location & Building 1707 \\
\hline & Fleet Vehicle ID & G41-2399K \\
\hline & Fuel Type & E85 \\
\hline & Potential Replacement PEV Make/Model & eNV200 \\
\hline & Potential Annual Fuel Cost Savings & $\$ 989$ \\
\hline 5 & Potential Annual GHG Reduction $\left(\mathrm{lb}-\mathrm{CO}_{2} \mathrm{e}\right)$ & 9,821 \\
\hline & EVSE Type for Recharging & AC Level 2 \\
\hline & Estimated Replacement Year & 2021 \\
\hline & Vehicle Age at Estimated Replacement (Year) & 11 \\
\hline & Odometer at Estimated Replacement Date & 97,335 \\
\hline
\end{tabular}

Vehicle G42-0216F

\begin{tabular}{|c|c|c|}
\hline & Make/Model/Year & Ford E150-2008 \\
\hline & EPA Class Size & Van - Passenger \\
\hline & Mission & Support \\
\hline & Contact & Marine Headquarters Group \\
\hline & Parking Location & Building 102 \\
\hline & Fleet Vehicle ID & G42-0216F \\
\hline & Fuel Type & Gas \\
\hline & Potential Replacement PEV Make/Model & eNV200 \\
\hline$H$ & Potential Annual Fuel Cost Savings & $\$ 314$ \\
\hline on & Potential Annual GHG Reduction $\left(\mathrm{lb}-\mathrm{CO}_{2} \mathrm{e}\right)$ & 1,685 \\
\hline & EVSE Type for Recharging & AC Level 2 \\
\hline & Estimated Replacement Year & 2016 \\
\hline & Vehicle Age at Estimated Replacement (Year) & 8 \\
\hline & Odometer at Estimated Replacement Date & 18,545 \\
\hline
\end{tabular}




\begin{tabular}{|c|c|c|}
\hline & Make/Model/Year & Ford E150 - 2012 \\
\hline & EPA Class Size & Van - Passenger \\
\hline & Mission & Support \\
\hline & Contact & Marine Aircraft Group 29 \\
\hline & Parking Location & Building AS4108 \\
\hline & Fleet Vehicle ID & G42-0883M \\
\hline & Fuel Type & E85 \\
\hline & Potential Replacement PEV Make/Model & VTRUX Van \\
\hline & Potential Annual Fuel Cost Savings & $\$ 976$ \\
\hline 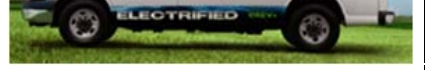 & Potential Annual GHG Reduction $\left(\mathrm{lb}-\mathrm{CO}_{2} \mathrm{e}\right)$ & 4,241 \\
\hline & EVSE Type for Recharging & AC Level 1 \\
\hline & Estimated Replacement Year & 2018 \\
\hline & Vehicle Age at Estimated Replacement (Year) & 6 \\
\hline & Odometer at Estimated Replacement Date & 93,244 \\
\hline
\end{tabular}

\section{Vehicle G42-0898M}

\begin{tabular}{|c|c|c|}
\hline & Make/Model/Year & Ford E150-2012 \\
\hline - & EPA Class Size & Van - Passenger \\
\hline & Mission & Support \\
\hline & Contact & $\begin{array}{l}\text { 2nd Marine Logistics } \\
\text { Group }\end{array}$ \\
\hline & Parking Location & Building FC400 \\
\hline & Fleet Vehicle ID & G42-0898M \\
\hline & Fuel Type & E85 \\
\hline & Potential Replacement PEV Make/Model & VTRUX Van \\
\hline & Potential Annual Fuel Cost Savings & $\$ 1,954$ \\
\hline 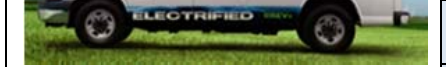 & Potential Annual GHG Reduction $\left(\mathrm{lb}-\mathrm{CO}_{2} \mathrm{e}\right)$ & 8,492 \\
\hline & EVSE Type for Recharging & AC Level 1 \\
\hline & Estimated Replacement Year & 2018 \\
\hline & Vehicle Age at Estimated Replacement (Year) & 6 \\
\hline & Odometer at Estimated Replacement Date & 85,203 \\
\hline
\end{tabular}




\section{Vehicle G43-0326H}

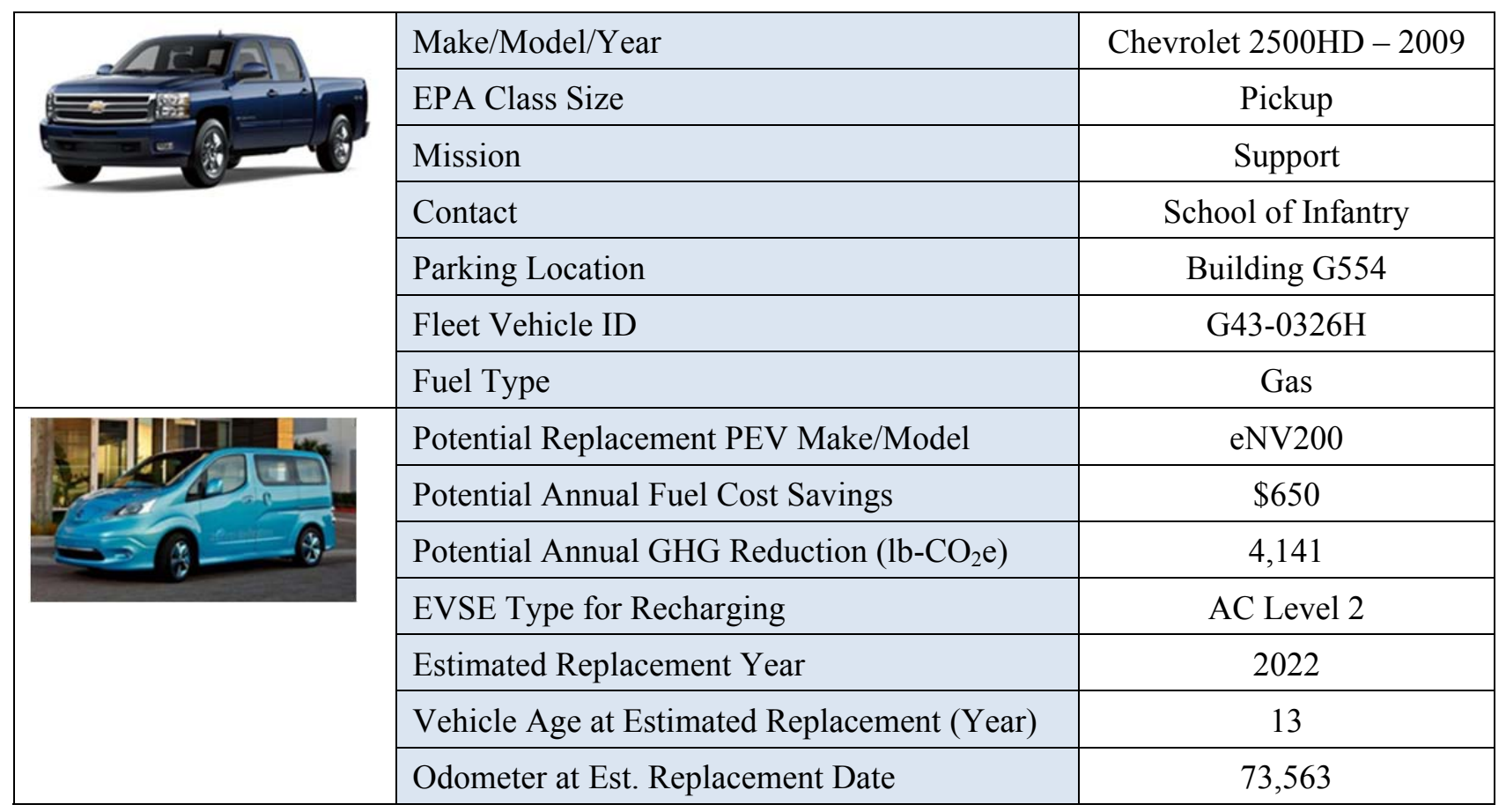

Vehicle G43-1453G

\begin{tabular}{|c|c|c|}
\hline fonstas & Make/Model/Year & Chevrolet G2300 - 2008 \\
\hline & EPA Class Size & Van - Passenger \\
\hline & Mission & Support \\
\hline & Contact & MARSOC \\
\hline & Parking Location & FC306 \\
\hline & Fleet Vehicle ID & G43-1453G \\
\hline & Fuel Type & Gas \\
\hline & Potential Replacement PEV Make/Model & Soul \\
\hline & Potential Annual Fuel Cost Savings & $\$ 2,145$ \\
\hline & Potential Annual GHG Reduction $\left(\mathrm{lb}-\mathrm{CO}_{2} \mathrm{e}\right)$ & 12,278 \\
\hline & EVSE Type for Recharging & AC Level 2 \\
\hline & Estimated Replacement Year & 2016 \\
\hline & Vehicle Age at Estimated Replacement (Year) & 8 \\
\hline & Odometer at Estimated Replacement Date & 80,068 \\
\hline
\end{tabular}


Vehicle G43-1855P

\begin{tabular}{|c|c|c|}
\hline \multirow{7}{*}{ 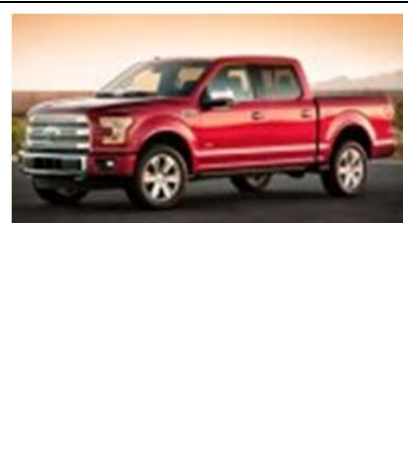 } & Make/Model/Year & Ford F350-2015 \\
\hline & EPA Class Size & Pickup \\
\hline & Mission & Support \\
\hline & Contact & School of Infantry \\
\hline & Parking Location & G702 \\
\hline & Fleet Vehicle ID & G43-1855P \\
\hline & Fuel Type & E85 \\
\hline \multirow{7}{*}{ bring } & Potential Replacement PEV Make/Model & VTRUX PU \\
\hline & Potential Annual Fuel Cost Savings & $\$ 265$ \\
\hline & Potential Annual GHG Reduction $\left(\mathrm{lb}-\mathrm{CO}_{2} \mathrm{e}\right)$ & 863 \\
\hline & EVSE Type for Recharging & ACL1 \\
\hline & Estimated Replacement Year & 2029 \\
\hline & Vehicle Age at Estimated Replacement (Year) & 14 \\
\hline & Odometer at Estimated Replacement Date & 69722 \\
\hline
\end{tabular}

\section{Vehicle G43-2025K}

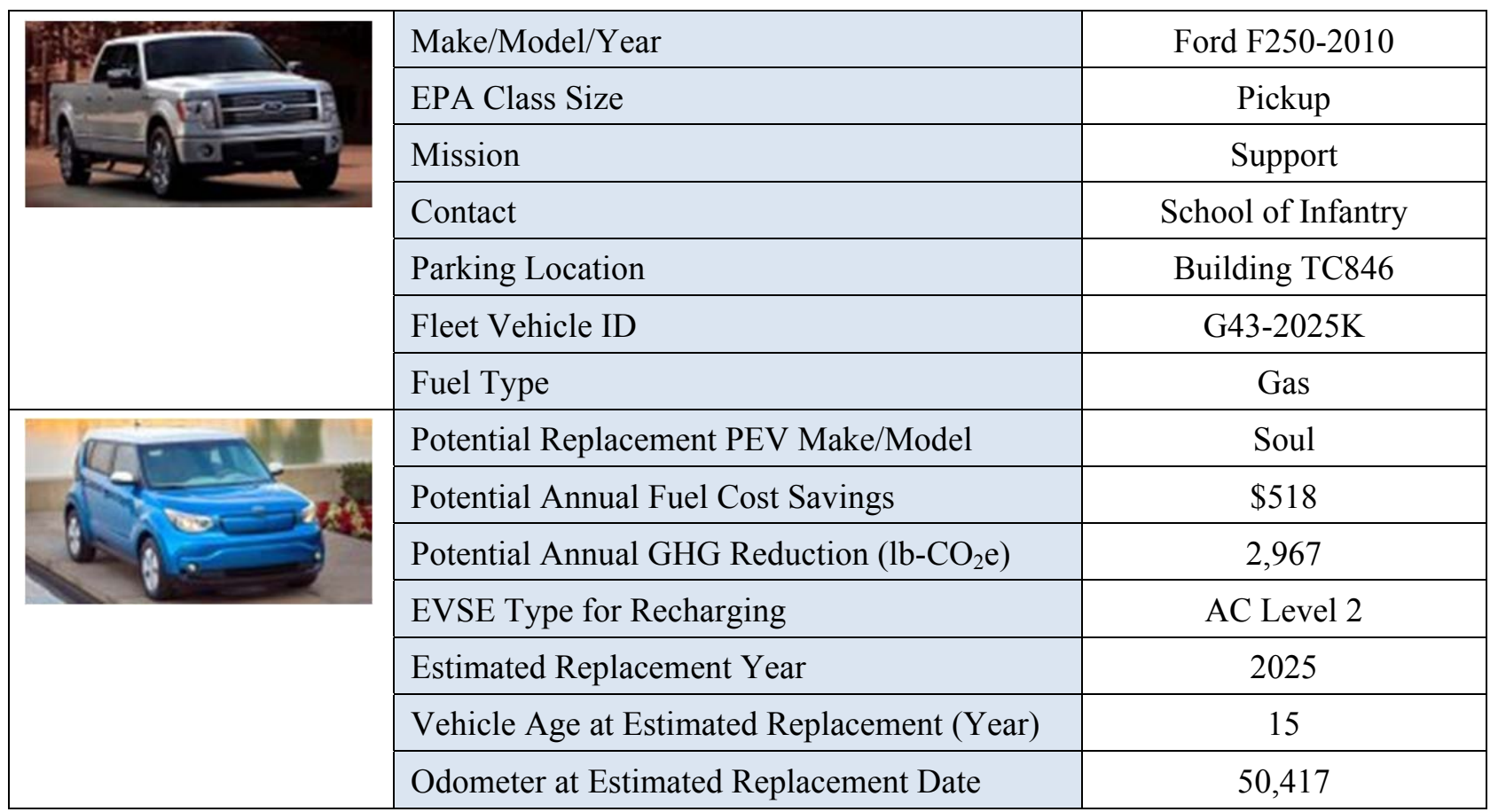




\section{Vehicle G43-4073F}

\begin{tabular}{|c|c|c|}
\hline & Make/Model/Year & Chevrolet G2300 - 2008 \\
\hline & EPA Class Size & Van - Passenger \\
\hline & Mission & Support \\
\hline & Contact & MARSOC \\
\hline & Parking Location & RR272 \\
\hline & Fleet Vehicle ID & G43-4073F \\
\hline & Fuel Type & Gas \\
\hline \multirow{7}{*}{$\mathrm{N}_{\mathrm{B}} \mathrm{V}_{\mathrm{V}}$} & Potential Replacement PEV Make/Model & eNV200 \\
\hline & Potential Annual Fuel Cost Savings & $\$ 630$ \\
\hline & Potential Annual GHG Reduction $\left(\mathrm{lb}-\mathrm{CO}_{2} \mathrm{e}\right)$ & 3,296 \\
\hline & EVSE Type for Recharging & AC Level 2 \\
\hline & Estimated Replacement Year & 2016 \\
\hline & Vehicle Age at Estimated Replacement (Year) & 8 \\
\hline & Odometer at Estimated Replacement Date & 55,950 \\
\hline
\end{tabular}

\section{Vehicle G61-0594L}

\begin{tabular}{|c|c|c|}
\hline \multirow{7}{*}{ 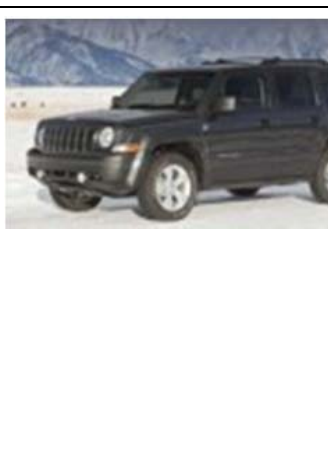 } & Make / Model / Year & Jeep Patriot - 2011 \\
\hline & EPA Class Size & SUV \\
\hline & Mission & Support \\
\hline & Contact & Special Operation Training \\
\hline & Parking Location & 518 \\
\hline & Fleet Vehicle ID & G61-0594L \\
\hline & Fuel Type & Gas \\
\hline \multirow{7}{*}{ 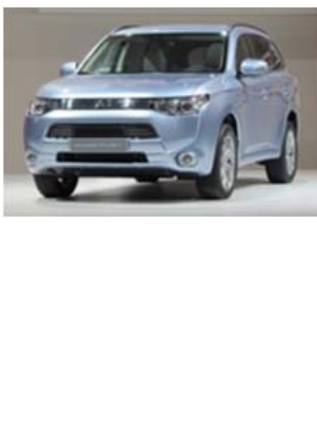 } & Potential Replacement PEV Make/Model & Outlander \\
\hline & Potential Annual Fuel Cost Savings & $\$ 239$ \\
\hline & Potential Annual GHG Reduction $\left(\mathrm{lb}-\mathrm{CO}_{2} \mathrm{e}\right)$ & 831 \\
\hline & EVSE Type for Recharging & AC Level 1 \\
\hline & Estimated Replacement Year & 2020 \\
\hline & Vehicle Age at Estimated Replacement (Year) & 9 \\
\hline & Odometer at Estimated Replacement Date & 79,392 \\
\hline
\end{tabular}




\section{Vehicle G61-2644P}

\begin{tabular}{|c|c|c|}
\hline \multirow{7}{*}{ 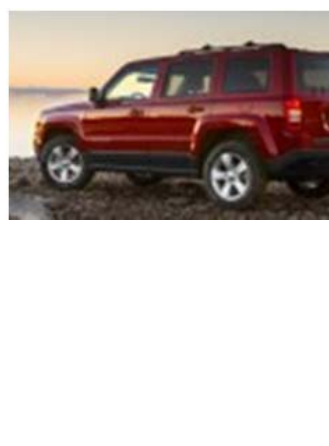 } & Make/Model/Year & Jeep Patriot -2015 \\
\hline & EPA Class Size & SUV \\
\hline & Mission & Support \\
\hline & Contact & Marine Aircraft Group 29 \\
\hline & Parking Location & Bldg AS4122 \\
\hline & Fleet Vehicle ID & G61-2644P \\
\hline & Fuel Type & Gas \\
\hline \multirow{7}{*}{ 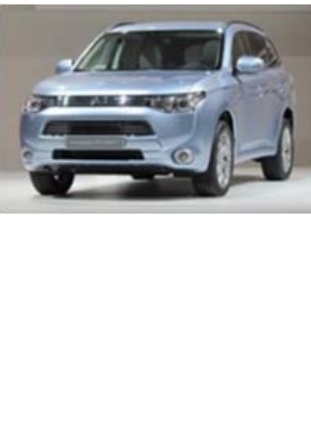 } & Potential Replacement PEV Make/Model & Outlander \\
\hline & Potential Annual Fuel Cost Savings & $\$ 524$ \\
\hline & Potential Annual GHG Reduction $\left(\mathrm{lb}-\mathrm{CO}_{2} \mathrm{e}\right)$ & 1,892 \\
\hline & EVSE Type for Recharging & ACL1 \\
\hline & Estimated Replacement Year & 2019 \\
\hline & Vehicle Age at Estimated Replacement (Year) & 4 \\
\hline & Odometer at Estimated Replacement Date & 96,010 \\
\hline
\end{tabular}

\section{Vehicle G62-0791H}

\begin{tabular}{|c|c|c|}
\hline & Make/Model/Year & Ford Expedition - 2009 \\
\hline & EPA Class Size & SUV - K9 \\
\hline & Mission & Support \\
\hline & Contact & Marine Headquarters Group \\
\hline & Parking Location & Building SAW353 \\
\hline & Fleet Vehicle ID & G62-0791H \\
\hline & Fuel Type & E85 \\
\hline & Potential Replacement PEV Make/Model & Outlander \\
\hline$=$ & Potential Annual Fuel Cost Savings & $\$ 846$ \\
\hline & Potential Annual GHG Reduction $\left(\mathrm{lb}-\mathrm{CO}_{2} \mathrm{e}\right)$ & 3,657 \\
\hline & EVSE Type for Recharging & AC Level 1 \\
\hline & Estimated Replacement Year & 2018 \\
\hline & Vehicle Age at Estimated Replacement (Year) & 9 \\
\hline & Odometer at Estimated Replacement Date & 73,433 \\
\hline
\end{tabular}




\section{Vehicle G63-0309R}

\begin{tabular}{|c|c|c|}
\hline \multirow{7}{*}{ 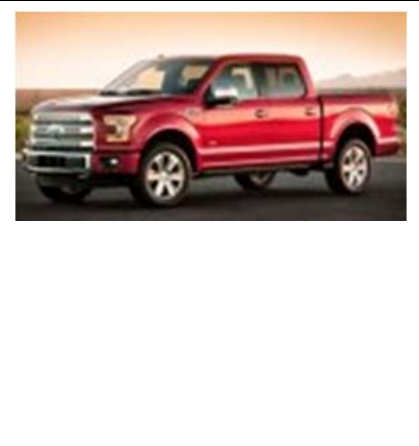 } & Make/Model/Year & Ford F350-2015 \\
\hline & EPA Class Size & Pickup \\
\hline & Mission & Support \\
\hline & Contact & Marine Wing SS 272 \\
\hline & Parking Location & Building AS4158 \\
\hline & Fleet Vehicle ID & G63-0309R \\
\hline & Fuel Type & E85 \\
\hline \multirow{7}{*}{ 16rand } & Potential Replacement PEV Make/Model & VTRUX PU \\
\hline & Potential Annual Fuel Cost Savings & $\$ 1,083$ \\
\hline & Potential Annual GHG Reduction $\left(\mathrm{lb}-\mathrm{CO}_{2} \mathrm{e}\right)$ & 3,527 \\
\hline & EVSE Type for Recharging & AC Level 1 \\
\hline & Estimated Replacement Year & 2025 \\
\hline & Vehicle Age at Estimated Replacement (Year) & 10 \\
\hline & Odometer at Estimated Replacement Date & 24,690 \\
\hline
\end{tabular}

Vehicle G63-0934G

\begin{tabular}{|l|l|c|}
\hline & Make/Model/Year & Pickup \\
\hline & EPA Class Size & Support \\
\hline & Mission & MARSOC \\
\hline Contact & RR450 \\
\hline & Parking Location & G63-0934G \\
\hline & Fleet Vehicle ID & Gas \\
\hline & Fuel Type & VTRUX PU \\
\hline \multirow{2}{*}{} & Potential Replacement PEV Make/Model & $\$ 181$ \\
\hline & Potential Annual Fuel Cost Savings & 858 \\
\hline & Potential Annual GHG Reduction (lb-CO $\left.\mathrm{CO}_{2} \mathrm{e}\right)$ & AC Level 1 \\
\hline & EVSE Type for Recharging & 2020 \\
\hline & Estimated Replacement Year & 12 \\
\hline & Vehicle Age at Estimated Replacement (Year) & 86,895 \\
\hline & Odometer at Estimated Replacement Date & \\
\hline
\end{tabular}




\section{Appendix B \\ Marine Corps Installations East Vehicle Data Sheets}

Note that the replacement years identified in the following data sheets are based on the GSA requirements noted in Table 2 and current fleet usage. The final replacement approach may suggest later years based on vehicle use.

Table B-1 identifies a potential replacement approach for the monitored sedan vehicles currently or previously on the GSA list.

Table B-1. MCIE PEV replacement (GSA-listed vehicle).

\begin{tabular}{cccccc} 
Fleet & \multicolumn{4}{c}{ GSA Listed Vehicle Replacement Approach } \\
Vehicle Id & Make/Model & Year & EPA Class & $\begin{array}{c}\text { GSA Replacement } \\
\text { Vehicle }\end{array}$ & $\begin{array}{c}\text { Replacement } \\
\text { Year }\end{array}$ \\
\hline 294285 & Chevrolet Malibu & 2009 & Sedan - Midsize & Leaf & 2023 \\
G10-3327L & Chevrolet Malibu & 2012 & Sedan - Midsize & Leaf & 2022 \\
G13-0325K & Ford Focus & 2012 & Sedan - Compact & Volt & 2022 \\
G13-7974P & Ford Focus & 2015 & Sedan - Compact & Volt & 2022 \\
\hline
\end{tabular}

Table B-2 identifies a potential replacement approach for the rest of the monitored vehicles using all currently or soon-to-be available PEVs. Note that a PEV replacement for the refrigeration truck 291007 is not suggested.

Table B-2. MCIE PEV replacement (all potential vehicles).

\begin{tabular}{cccccc}
\hline \multicolumn{5}{c}{ All Vehicle Replacement Approach } \\
Fleet & \multicolumn{5}{c}{$\begin{array}{c}\text { Potential } \\
\text { Replacement }\end{array}$} \\
Vehicle Id & Make/Model & Year & EPA Class & Vehicle & Year \\
\hline 290597 & Ford E350 & 1997 & Van - Cargo & VTRUX Van & 2022 \\
291007 & Ford F550 & 2004 & Specialty & NA & 2024 \\
294293 & Chevrolet HHR & 2009 & SUV & Soul & 2019 \\
294315 & Chevrolet 3500 & 2009 & Pickup & eNV200 & 2023 \\
294324 & Chevrolet HHR & 2009 & SUV & Outlander & 2018 \\
300672 & Ford F550 & 2011 & Specialty & EDI Bucket Truck & 2026 \\
302039 & Ford F250 XL & 2014 & Pickup & VTRUX PU & 2026 \\
302040 & Ford F250XL & 2014 & Pickup & VTRUX PU & 2022 \\
302334 & Ford F350 & 2015 & Pickup & VTRUX PU & 2031 \\
G41-0379H & Dodge Grd Caravan & 2009 & Minivan & Soul & 2022 \\
G41-0391H & Dodge Dakota & 2009 & Pickup & VTRUX PU & 2023 \\
G41-0754M & Dodge Grd Caravan & 2012 & Minivan & Outlander & 2027 \\
G41-0806P & Dodge Caravan & 2014 & Minivan & Outlander & 2020 \\
G41-1689L & Ford Ranger & 2011 & Pickup & VTRUX PU & 2021 \\
G41-3297K & Ford Ranger & 2011 & Pickup & eNV200 & 2026 \\
G41-3300K & Ford Ranger & 2011 & Pickup & VTRUX PU & 2018 \\
G41-3301K & Ford Ranger & 2011 & Pickup & eNV200 & 2023 \\
G42-0644M & Ford E150 & 2012 & Van - Pass & eNV200 & 2017 \\
G42-0667P & Ford F150 & 2014 & Pickup & VTRUX PU & 2024 \\
G42-0671P & Ford F150 & 2014 & Pickup & eNV200 & 2025 \\
G42-0911L & Chevrolet C1500 & 2012 & Pickup & eNV200 & 2024 \\
G42-0915M & Ford F150 & 2012 & Pickup & eNV200 & 2023 \\
\hline & & & & &
\end{tabular}




\begin{tabular}{|c|c|c|c|c|c|}
\hline \multicolumn{6}{|c|}{ All Vehicle Replacement Approach } \\
\hline $\begin{array}{c}\text { Fleet } \\
\text { Vehicle Id }\end{array}$ & Make/Model & Year & EPA Class & $\begin{array}{c}\text { Potential } \\
\text { Replacement } \\
\text { Vehicle }\end{array}$ & $\begin{array}{c}\text { Replacement } \\
\text { Year }\end{array}$ \\
\hline G42-2985H & Chevrolet C1500 & 2010 & Pickup & VTRUX PU & 2016 \\
\hline G43-0310H & Ford E350 & 2009 & Van - Pass & VTRUX Van & 2020 \\
\hline G43-0323H & Ford E50 & 2009 & Van - Cargo & VTRUX Van & 2016 \\
\hline G43-0324H & Ford E350 & 2009 & Van - Cargo & eNV200 & 2024 \\
\hline G43-1182M & Chevrolet CG3300 & 2012 & Van - Cargo & eNV200 & 2020 \\
\hline G43-4075P & Ford F250 & 2015 & Pickup & VTRUX PU & 2035 \\
\hline G61-0161H & Dodge Dakota & 2009 & Pickup & VTRUX PU & 2018 \\
\hline G61-0174H & Jeep Liberty & 2009 & SUV & Outlander & 2020 \\
\hline G61-0879P & Chevrolet Equinox & 2014 & SUV & Outlander & 2029 \\
\hline G61-1508D & Jeep Liberty & 2008 & SUV & Outlander & 2016 \\
\hline G61-1509D & Jeep Liberty & 2008 & SUV & Soul & 2016 \\
\hline G62-1583G & Chevrolet K1500 & 2008 & Pickup & VTRUX PU & 2016 \\
\hline G62-4085L & Dodge 1500 & 2012 & Pickup & VTRUX PU & 2020 \\
\hline G63-0163H & Chevrolet K2500 & 2009 & Pickup & eNV200 & 2017 \\
\hline G63-2885L & Chevrolet K2500 & 2012 & Pickup & eNV200 & 2029 \\
\hline G63-2888L & Chevrolet K2500 & 2012 & Pickup & Soul & 2029 \\
\hline
\end{tabular}

\section{Vehicle 290597}

\begin{tabular}{|c|c|c|}
\hline & Make/Model/Year & Ford E350 - 1997 \\
\hline & EPA Class Size & Van - Cargo \\
\hline & Mission & Pool \\
\hline & Contact & Motor Transport C-Pool \\
\hline & Parking Location & Building 1200 \\
\hline & Fleet Vehicle ID & 290597 \\
\hline & Fuel Type & Gas \\
\hline & Potential Replacement PEV Make/Model & VTRUX Van \\
\hline & Potential Annual Fuel Cost Savings & $\$ 99$ \\
\hline 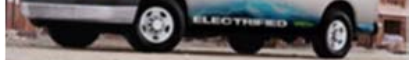 & Potential Annual GHG Reduction $\left(\mathrm{lb}-\mathrm{CO}_{2} \mathrm{e}\right)$ & 523 \\
\hline & EVSE Type for Recharging & AC Level 1 \\
\hline & Estimated Replacement Year & 2022 \\
\hline & Vehicle Age at Estimated Replacement (Year) & 25 \\
\hline & Odometer at Estimated Replacement Date & 34,648 \\
\hline
\end{tabular}




\section{Vehicle 291007}

\begin{tabular}{|c|c|c|}
\hline & Make/Model/Year & Ford F560 - 2004 \\
\hline & EPA Class Size & $\begin{array}{c}\text { Specialty - Refrigeration } \\
\text { Truck } \\
\end{array}$ \\
\hline & Mission & Specialty \\
\hline & Contact & MTO \\
\hline & Parking Location & No data \\
\hline & Fleet Vehicle ID & 291007 \\
\hline & Fuel Type & Diesel \\
\hline & Potential Replacement PEV Make/Model & NA \\
\hline & Potential Annual Fuel Cost Savings & - \\
\hline & Potential Annual GHG Reduction (lb- $\mathrm{CO}_{2} \mathrm{e}$ ) & - \\
\hline & EVSE Type for Recharging & - \\
\hline & Estimated Replacement Year & 2024 \\
\hline & Vehicle Age at Estimated Replacement (Year) & 20 \\
\hline & Odometer at Estimated Replacement Date & 34,042 \\
\hline
\end{tabular}

\section{Vehicle 294285}

\begin{tabular}{|c|c|c|}
\hline $8=$ & Make/Model/Year & Chevrolet Malibu - 2009 \\
\hline & EPA Class Size & Sedan - Midsize \\
\hline & Mission & Support \\
\hline & Contact & Postal \\
\hline & Parking Location & Building 1770 \\
\hline & Fleet Vehicle ID & 294285 \\
\hline & Fuel Type & Gas \\
\hline & Potential Replacement PEV Make/Model & Leaf \\
\hline & Potential Annual Fuel Cost Savings & $\$ 323$ \\
\hline 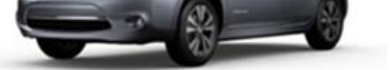 & Potential Annual GHG Reduction $\left(\mathrm{lb}-\mathrm{CO}_{2} \mathrm{e}\right)$ & 1,570 \\
\hline & EVSE Type for Recharging & AC Level 2 \\
\hline & Estimated Replacement Year & 2023 \\
\hline & Vehicle Age at Estimated Replacement (Year) & 14 \\
\hline & Odometer at Estimated Replacement Date & 74,550 \\
\hline
\end{tabular}


Vehicle 294293

\begin{tabular}{|l|l|c|}
\hline & Make/Model/Year & Chevrolet HHR - 2009 \\
\hline EPA Class Size & Enforcement \\
\hline Mission & Provost Marshal's Office \\
\hline Contact & Building AS302 \\
\hline Parking Location & 294293 \\
\hline Fleet Vehicle ID & E85 \\
\hline Fuel Type & Soul \\
\hline \multirow{2}{*}{} & Potential Replacement PEV Make/Model & $\$ 433$ \\
\hline Potential Annual Fuel Cost Savings & 1,676 \\
\hline & Potential Annual GHG Reduction (lb-CO $\left.{ }_{2} \mathrm{e}\right)$ & AC Level 2 \\
\hline & EVSE Type for Recharging & 2019 \\
\hline & Estimated Replacement Year & 10 \\
\hline & Vehicle Age at Estimated Replacement (Year) & 70,726 \\
\hline
\end{tabular}

\section{Vehicle 294315}

\begin{tabular}{|c|c|c|}
\hline & Make/Model/Year & Chevrolet $3500-2009$ \\
\hline & EPA Class Size & Pickup \\
\hline & Mission & Support \\
\hline & Contact & Fire Department \\
\hline & Parking Location & Building TC701 \\
\hline & Fleet Vehicle ID & 294315 \\
\hline & Fuel Type & Diesel \\
\hline & Potential Replacement PEV Make/Model & eNV200 \\
\hline & Potential Annual Fuel Cost Savings & $\$ 575$ \\
\hline & Potential Annual GHG Reduction $\left(\mathrm{lb}-\mathrm{CO}_{2} \mathrm{e}\right)$ & 3,701 \\
\hline & EVSE Type for Recharging & AC Level 2 \\
\hline & Estimated Replacement Year & 2023 \\
\hline & Vehicle Age at Estimated Replacement (Year) & 14 \\
\hline & Odometer at Estimated Replacement Date & 49,661 \\
\hline
\end{tabular}




\section{Vehicle 294324}

\begin{tabular}{|c|c|c|}
\hline 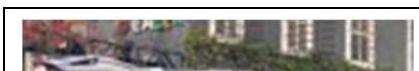 & Make/Model/Year & Chevrolet HHR - 2009 \\
\hline & EPA Class Size & SUV \\
\hline & Mission & Support \\
\hline & Contact & Public Works \\
\hline & Parking Location & Building 1005 \\
\hline & Fleet Vehicle ID & 294324 \\
\hline & Fuel Type & E85 \\
\hline & Potential Replacement PEV Make/Model & Soul \\
\hline & Potential Annual Fuel Cost Savings & $\$ 433$ \\
\hline & Potential Annual GHG Reduction $\left(\mathrm{lb}-\mathrm{CO}_{2} \mathrm{e}\right)$ & 1,676 \\
\hline & EVSE Type for Recharging & AC Level 1 \\
\hline & Estimated Replacement Year & 2018 \\
\hline & $\begin{array}{l}\text { Vehicle Age at Estimated Replacement } \\
\text { (Year) }\end{array}$ & 9 \\
\hline & Odometer at Estimated Replacement Date & 67,174 \\
\hline
\end{tabular}

\section{Vehicle 300672}

\begin{tabular}{|c|c|c|}
\hline \multirow{7}{*}{ 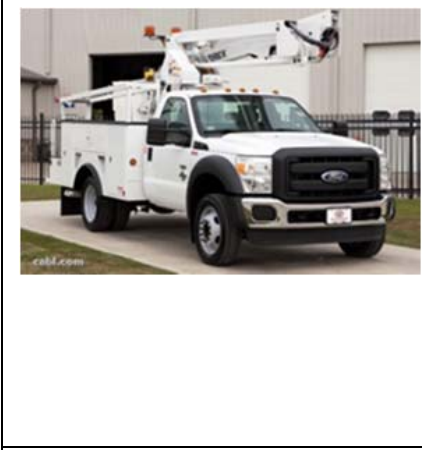 } & Make/Model/Year & Ford F550 - 2011 \\
\hline & EPA Class Size & Specialty - Bucket Truck \\
\hline & Mission & Specialty \\
\hline & Contact & Public Works \\
\hline & Parking Location & 1023 \\
\hline & Fleet Vehicle ID & 300672 \\
\hline & Fuel Type & Diesel \\
\hline & Potential Replacement PEV Make/Model & EDI Conversion \\
\hline & Potential Annual Fuel Cost Savings & $\$ 558$ \\
\hline & Potential Annual GHG Reduction $\left(\mathrm{lb}-\mathrm{CO}_{2} \mathrm{e}\right)$ & 2,955 \\
\hline & EVSE Type for Recharging & AC Level 1 \\
\hline & Estimated Replacement Year & 2026 \\
\hline & Vehicle Age at Estimated Replacement (Year) & 15 \\
\hline & Odometer at Estimated Replacement Date & 113,322 \\
\hline
\end{tabular}


Vehicle 302039

\begin{tabular}{|c|c|c|}
\hline$=$ & Make/Model/Year & Ford F250XL - 2014 \\
\hline & EPA Class Size & Pickup \\
\hline & Mission & Support \\
\hline & Contact & Public Works \\
\hline & Parking Location & Building 670 \\
\hline & Fleet Vehicle ID & 302039 \\
\hline & Fuel Type & Diesel \\
\hline & Potential Replacement PEV Make/Model & VTRUX PU \\
\hline & Potential Annual Fuel Cost Savings & $\$ 434$ \\
\hline I) & Potential Annual GHG Reduction $\left(\mathrm{lb}-\mathrm{CO}_{2} \mathrm{e}\right)$ & 2,647 \\
\hline & EVSE Type for Recharging & AC Level 1 \\
\hline & Estimated Replacement Year & 2026 \\
\hline & Vehicle Age at Estimated Replacement (Year) & 12 \\
\hline & Odometer at Estimated Replacement Date & 77,445 \\
\hline
\end{tabular}

Vehicle 302040

\begin{tabular}{|c|c|c|}
\hline & Make/Model/Year & Ford F250XL - 2014 \\
\hline & EPA Class Size & Pickup \\
\hline & Mission & Support \\
\hline & Contact & Public Works \\
\hline & Parking Location & Building FC436 \\
\hline & Fleet Vehicle ID & 302040 \\
\hline & Fuel Type & Diesel \\
\hline & Potential Replacement PEV Make/Model & VTRUX PU \\
\hline & Potential Annual Fuel Cost Savings & $\$ 809$ \\
\hline 1 & Potential Annual GHG Reduction $\left(\mathrm{lb}-\mathrm{CO}_{2} \mathrm{e}\right)$ & 4,933 \\
\hline & EVSE Type for Recharging & AC Level 1 \\
\hline & Estimated Replacement Year & 2022 \\
\hline & Vehicle Age at Estimated Replacement (Year) & 8 \\
\hline & Odometer at Estimated Replacement Date & 89,642 \\
\hline
\end{tabular}


Vehicle 302334

\begin{tabular}{|c|c|c|}
\hline \multirow{2}{*}{-18039} & Make/Model/Year & Ford F350 Stake -2015 \\
\hline & EPA Class Size & Pickup \\
\hline \multirow{5}{*}{ 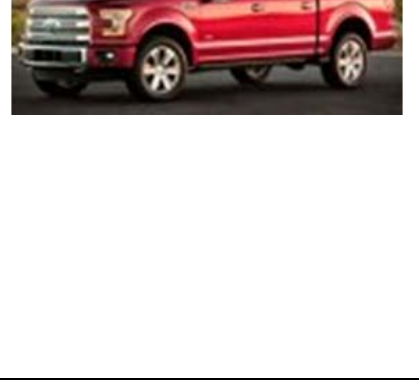 } & Mission & Support \\
\hline & Contact & $\begin{array}{c}\text { G3 - Operations and } \\
\text { Training }\end{array}$ \\
\hline & Parking Location & Building 56 \\
\hline & Fleet Vehicle ID & 302334 \\
\hline & Fuel Type & E85 \\
\hline \multirow{7}{*}{ ind } & Potential Replacement PEV Make/Model & VTRUX PU \\
\hline & Potential Annual Fuel Cost Savings & $\$ 124$ \\
\hline & Potential Annual GHG Reduction $\left(\mathrm{lb}-\mathrm{CO}_{2} \mathrm{e}\right)$ & 403 \\
\hline & EVSE Type for Recharging & AC Level 1 \\
\hline & Estimated Replacement Year & 2031 \\
\hline & Vehicle Age at Estimated Replacement (Year) & 16 \\
\hline & Odometer at Estimated Replacement Date & 19,206 \\
\hline
\end{tabular}

\section{Vehicle G10-3327L}

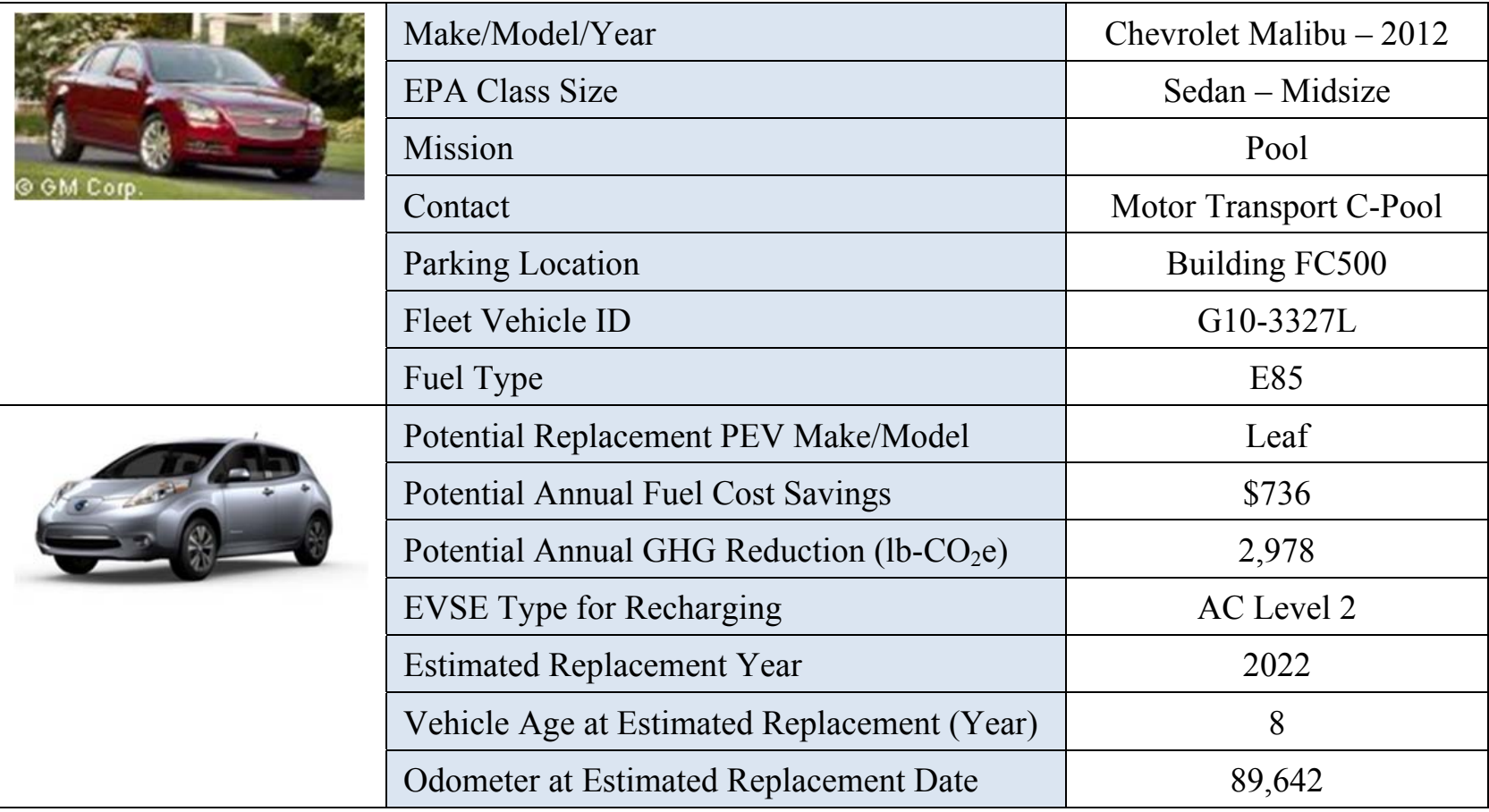




\section{Vehicle G13-0325K}

\begin{tabular}{|c|c|c|}
\hline & Make/Model/Year & Ford Focus - 2012 \\
\hline & EPA Class Size & Sedan - Compact \\
\hline$y_{i}-y^{2}$ & Mission & Support \\
\hline & Contact & Eastern Judicial Circuit \\
\hline & Parking Location & Building 67 \\
\hline & Fleet Vehicle ID & G13-0325K \\
\hline & Fuel Type & Gas \\
\hline & Potential Replacement PEV Make/Model & Volt \\
\hline & Potential Annual Fuel Cost Savings & $\$ 50$ \\
\hline 1. & Potential Annual GHG Reduction $\left(\mathrm{lb}-\mathrm{CO}_{2} \mathrm{e}\right)$ & 177 \\
\hline & EVSE Type for Recharging & AC Level 1 \\
\hline & Estimated Replacement Year & 2022 \\
\hline & Vehicle Age at Estimated Replacement (Year) & 10 \\
\hline & Odometer at Estimated Replacement Date & 13,639 \\
\hline
\end{tabular}

\section{Vehicle G13-7974P}

\begin{tabular}{|c|c|c|}
\hline \multirow{7}{*}{$\begin{array}{l}1, y=0 \\
5=-8\end{array}$} & Make/Model/Year & Ford Focus -2015 \\
\hline & EPA Class Size & Sedan - Compact \\
\hline & Mission & Support \\
\hline & Contact & G4 - Logistics \\
\hline & Parking Location & Building 1117 \\
\hline & Fleet Vehicle ID & G13-7974P \\
\hline & Fuel Type & E85 \\
\hline \multirow{7}{*}{$2=0$} & Potential Replacement PEV Make/Model & Volt \\
\hline & Potential Annual Fuel Cost Savings & $\$ 164$ \\
\hline & Potential Annual GHG Reduction $\left(\mathrm{lb}-\mathrm{CO}_{2} \mathrm{e}\right)$ & 617 \\
\hline & EVSE Type for Recharging & AC Level 1 \\
\hline & Estimated Replacement Year & 2022 \\
\hline & $\begin{array}{l}\text { Vehicle Age at Estimated Replacement } \\
\text { (Year) }\end{array}$ & 7 \\
\hline & Odometer at Estimated Replacement Date & 90,295 \\
\hline
\end{tabular}




\section{Vehicle G41-0379H}

\begin{tabular}{|c|c|c|}
\hline & Make/Model/Year & $\begin{array}{c}\text { Dodge Grand Caravan - } \\
2009 \\
\end{array}$ \\
\hline & EPA Class Size & Minivan \\
\hline 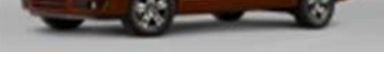 & Mission & Pool \\
\hline & Contact & Motor Transport - C-Pool \\
\hline & Parking Location & Building M305 \\
\hline & Fleet Vehicle ID & G41-0379H \\
\hline & Fuel Type & E85 \\
\hline & Potential Replacement PEV Make/Model & Soul \\
\hline & Potential Annual Fuel Cost Savings & $\$ 837$ \\
\hline & Potential Annual GHG Reduction $\left(\mathrm{lb}-\mathrm{CO}_{2} \mathrm{e}\right)$ & 3,866 \\
\hline & EVSE Type for Recharging & AC Level 2 \\
\hline & Estimated Replacement Year & 2022 \\
\hline & Vehicle Age at Estimated Replacement (Year) & 13 \\
\hline & Odometer at Estimated Replacement Date & 65,172 \\
\hline
\end{tabular}

\section{Vehicle G41-0391H}

\begin{tabular}{|c|c|c|}
\hline & Make/Model/Year & Dodge Dakota - 2009 \\
\hline $2=$ & EPA Class Size & Pickup \\
\hline 8 & Mission & Support \\
\hline & Contact & G4- Logistics \\
\hline & Parking Location & Building 1117 \\
\hline & Fleet Vehicle ID & G41-0391H \\
\hline & Fuel Type & $\mathrm{E} 85$ \\
\hline F & Potential Replacement PEV Make/Model & VTRUX PU \\
\hline So & Potential Annual Fuel Cost Savings & $\$ 508$ \\
\hline ine & Potential Annual GHG Reduction (lb- $\left.\mathrm{CO}_{2} \mathrm{e}\right)$ & 2,206 \\
\hline & EVSE Type for Recharging & AC Level 1 \\
\hline & Estimated Replacement Year & 2023 \\
\hline & Vehicle Age at Estimated Replacement (Year) & 14 \\
\hline & Odometer at Est. Replacement Date & 87,196 \\
\hline
\end{tabular}




\section{Vehicle G41-0754M}

\begin{tabular}{|c|c|c|}
\hline 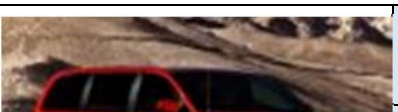 & Make/Model/Year & $\begin{array}{c}\text { Dodge Grand Caravan - } \\
2012 \\
\end{array}$ \\
\hline s. & EPA Class Size & Minivan \\
\hline 8 & Mission & Pool \\
\hline & Contact & Motor Transport - C-Pool \\
\hline & Parking Location & Building 1407 \\
\hline & Fleet Vehicle ID & G41-0754M \\
\hline & Fuel Type & E85 \\
\hline & Potential Replacement PEV Make/Model & Outlander \\
\hline & Potential Annual Fuel Cost Savings & $\$ 152$ \\
\hline 8 & Potential Annual GHG Reduction $\left(\mathrm{lb}-\mathrm{CO}_{2} \mathrm{e}\right)$ & 556 \\
\hline & EVSE Type for Recharging & AC Level 1 \\
\hline & Estimated Replacement Year & 2027 \\
\hline & Vehicle Age at Estimated Replacement (Year) & 15 \\
\hline & Odometer at Estimated Replacement Date & 73,114 \\
\hline
\end{tabular}

\section{Vehicle G41-0806P}

\begin{tabular}{|c|c|c|}
\hline \multirow{7}{*}{ 6. } & Make/Model/Year & Dodge Caravan - 2014 \\
\hline & EPA Class Size & Minivan \\
\hline & Mission & Support \\
\hline & Contact & Public Works \\
\hline & Parking Location & Building 1005 \\
\hline & Fleet Vehicle ID & G41-0806P \\
\hline & Fuel Type & E85 \\
\hline \multirow{7}{*}{ Pि } & Potential Replacement PEV Make/Model & Outlander \\
\hline & Potential Annual Fuel Cost Savings & $\$ 637$ \\
\hline & Potential Annual GHG Reduction $\left(\mathrm{lb}-\mathrm{CO}_{2} \mathrm{e}\right)$ & 2,236 \\
\hline & EVSE Type for Recharging & AC Level 1 \\
\hline & Estimated Replacement Year & 2020 \\
\hline & Vehicle Age at Estimated Replacement (Year) & 6 \\
\hline & Odometer at Estimated Replacement Date & 75,322 \\
\hline
\end{tabular}




\section{Vehicle G41-1689L}

\begin{tabular}{|l|l|c|}
\hline & Make/Model/Year & Ford Ranger - 2011 \\
\hline & EPA Class Size & Pickup \\
\hline Mission & Support \\
\hline Contact & Public Works \\
\hline & Parking Location & Building 1005 \\
\hline & Fleet Vehicle ID & G41-1689L \\
\hline & Fuel Type & Gas \\
\hline \multirow{3}{*}{} & Potential Replacement PEV Make/Model & VTRUX PU \\
\cline { 2 - 3 } & Potential Annual Fuel Cost Savings & \$290 \\
\cline { 2 - 3 } & Potential Annual GHG Reduction (lb-CO $\left.\mathrm{CO}_{2} \mathrm{e}\right)$ & 958 \\
\hline & EVSE Type for Recharging & AC Level 1 \\
\cline { 2 - 3 } & Estimated Replacement Year & 2021 \\
\hline & Vehicle Age at Estimated Replacement (Year) & 10 \\
\hline & Odometer at Estimated Replacement Date & 52,109 \\
\hline
\end{tabular}

Vehicle G41-3297K

\begin{tabular}{|c|c|c|}
\hline \multirow{7}{*}{$251 \frac{10}{2} !$} & Make/Model/Year & Ford Ranger - 2011 \\
\hline & EPA Class Size & Pickup \\
\hline & Mission & Support \\
\hline & Contact & Public Works \\
\hline & Parking Location & Building 1005 \\
\hline & Fleet Vehicle ID & G41-3297K \\
\hline & Fuel Type & Gas \\
\hline \multirow{7}{*}{ 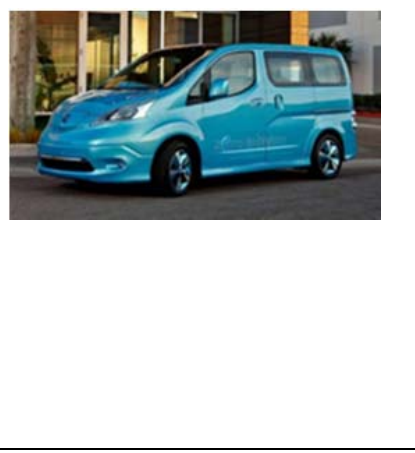 } & Potential Replacement PEV Make/Model & eNV200 \\
\hline & Potential Annual Fuel Cost Savings & $\$ 473$ \\
\hline & Potential Annual GHG Reduction $\left(\mathrm{lb}-\mathrm{CO}_{2} \mathrm{e}\right)$ & 1,944 \\
\hline & EVSE Type for Recharging & AC Level 2 \\
\hline & Estimated Replacement Year & 2026 \\
\hline & Vehicle Age at Estimated Replacement (Year) & 15 \\
\hline & Odometer at Estimated Replacement Date & 77,061 \\
\hline
\end{tabular}




\section{Vehicle G41-3300K}

\begin{tabular}{|l|l|c|}
\hline & Make/Model/Year & Ford Ranger -2011 \\
\hline & EPA Class Size & Pickup \\
\hline Mission & Enforcement \\
\hline Contact & Building 43 \\
\hline Parking Location & G41-3300K \\
\hline & Fleet Vehicle ID & Gas \\
\hline & Fuel Type & VTRUX PU \\
\hline \multirow{3}{*}{} & Potential Replacement PEV Make/Model & $\$ 459$ \\
\cline { 2 - 3 } & Potential Annual Fuel Cost Savings & 1,515 \\
\cline { 2 - 3 } & Potential Annual GHG Reduction (lb-CO $\left.\mathrm{CO}_{2} \mathrm{e}\right)$ & AC Level 1 \\
\hline & EVSE Type for Recharging & 2018 \\
\hline & Estimated Replacement Year & 7 \\
\hline & Vehicle Age at Estimated Replacement (Year) & 86,171 \\
\hline & Odometer at Estimated Replacement Date & \\
\hline
\end{tabular}

\section{Vehicle G41-3301K}

\begin{tabular}{|c|c|c|}
\hline \multirow{7}{*}{$25, \frac{1010}{2}$} & Make/Model/Year & Ford Ranger - 2011 \\
\hline & EPA Class Size & Pickup \\
\hline & Mission & Support \\
\hline & Contact & Public Works \\
\hline & Parking Location & Building 1005 \\
\hline & Fleet Vehicle ID & G41-3301K \\
\hline & Fuel Type & Gas \\
\hline \multirow{7}{*}{ 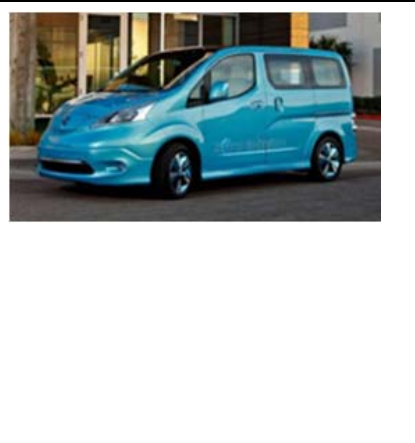 } & Potential Replacement PEV Make/Model & eNV200 \\
\hline & Potential Annual Fuel Cost Savings & $\$ 644$ \\
\hline & Potential Annual GHG Reduction $\left(\mathrm{lb}-\mathrm{CO}_{2} \mathrm{e}\right)$ & 2,646 \\
\hline & EVSE Type for Recharging & AC Level 2 \\
\hline & Estimated Replacement Year & 2023 \\
\hline & Vehicle Age at Estimated Replacement (Year) & 12 \\
\hline & Odometer at Estimated Replacement Date & 80,093 \\
\hline
\end{tabular}




\section{Vehicle G42-0644M}

\begin{tabular}{|c|c|c|}
\hline & Make/Model/Year & Ford E150 - 2012 \\
\hline & EPA Class Size & Van - Passenger \\
\hline$a=1$ & Mission & Pool \\
\hline & Contact & Motor Transport C-Pool \\
\hline & Parking Location & Bldg 58 \\
\hline & Fleet Vehicle ID & G42-0644M \\
\hline & Fuel Type & E85 \\
\hline & Potential Replacement PEV Make/Model & eNV200 \\
\hline & Potential Annual Fuel Cost Savings & $\$ 4,325$ \\
\hline 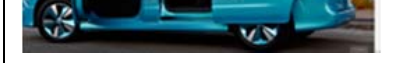 & Potential Annual GHG Reduction $\left(\mathrm{lb}-\mathrm{CO}_{2} \mathrm{e}\right)$ & 20,283 \\
\hline & EVSE Type for Recharging & ACL2 \\
\hline & Estimated Replacement Year & 2017 \\
\hline & Vehicle Age at Estimated Replacement (Year) & 5 \\
\hline & Odometer at Estimated Replacement Date & 87305 \\
\hline
\end{tabular}

Vehicle G42-0667P

\begin{tabular}{|c|c|c|}
\hline I1. & Make/Model/Year & Ford F150- 2014 \\
\hline & EPA Class Size & Pickup \\
\hline 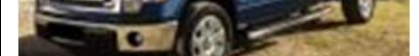 & Mission & Support \\
\hline & Contact & Public Works \\
\hline & Parking Location & Building 1005 \\
\hline & Fleet Vehicle ID & G42-0667P \\
\hline & Fuel Type & E85 \\
\hline-7 & Potential Replacement PEV Make/Model & VTRUX PU \\
\hline & Potential Annual Fuel Cost Savings & $\$ 561$ \\
\hline 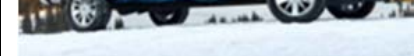 & Potential Annual GHG Reduction $\left(\mathrm{lb}-\mathrm{CO}_{2} \mathrm{e}\right)$ & 1,902 \\
\hline & EVSE Type for Recharging & AC Level 1 \\
\hline & Estimated Replacement Year & 2024 \\
\hline & Vehicle Age at Estimated Replacement (Year) & 10 \\
\hline & Odometer at Estimated Replacement Date & 92,976 \\
\hline
\end{tabular}




\section{Vehicle G42-0671P}

\begin{tabular}{|c|c|c|}
\hline 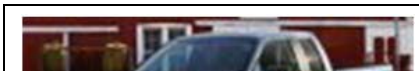 & Make/Model/Year & Ford F150 -2014 \\
\hline 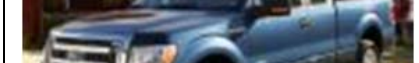 & EPA Class Size & Pickup \\
\hline & Mission & Support \\
\hline & Contact & Public Works \\
\hline & Parking Location & Building BA138 \\
\hline & Fleet Vehicle ID & G42-0671P \\
\hline & Fuel Type & E85 \\
\hline & Potential Replacement PEV Make/Model & eNV200 \\
\hline & Potential Annual Fuel Cost Savings & $\$ 1,019$ \\
\hline$\Rightarrow-y-$ & Potential Annual GHG Reduction $\left(\mathrm{lb}-\mathrm{CO}_{2} \mathrm{e}\right)$ & 3,999 \\
\hline & EVSE Type for Recharging & AC Level 2 \\
\hline & Estimated Replacement Year & 2025 \\
\hline & Vehicle Age at Estimated Replacement (Year) & 11 \\
\hline & Odometer at Estimated Replacement Date & 84,468 \\
\hline
\end{tabular}

\section{Vehicle G42-0911L}

\begin{tabular}{|c|c|c|}
\hline \multirow{7}{*}{ अ GM LoIP. } & Make/Model/Year & Chevrolet C1500 - 2012 \\
\hline & EPA Class Size & Pickup \\
\hline & Mission & Pool \\
\hline & Contact & Motor Transport C-Pool \\
\hline & Parking Location & Building 327 \\
\hline & Fleet Vehicle ID & G42-0911L \\
\hline & Fuel Type & E85 \\
\hline \multirow{7}{*}{ 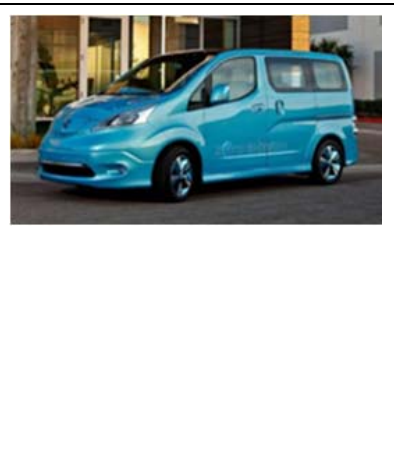 } & Potential Replacement PEV Make/Model & eNV200 \\
\hline & Potential Annual Fuel Cost Savings & $\$ 1,154$ \\
\hline & Potential Annual GHG Reduction $\left(\mathrm{lb}-\mathrm{CO}_{2} \mathrm{e}\right)$ & 4,771 \\
\hline & EVSE Type for Recharging & AC Level 2 \\
\hline & Estimated Replacement Year & 2024 \\
\hline & Vehicle Age at Estimated Replacement (Year) & 12 \\
\hline & Odometer at Estimated Replacement Date & 92,700 \\
\hline
\end{tabular}




\section{Vehicle G42-0915M}

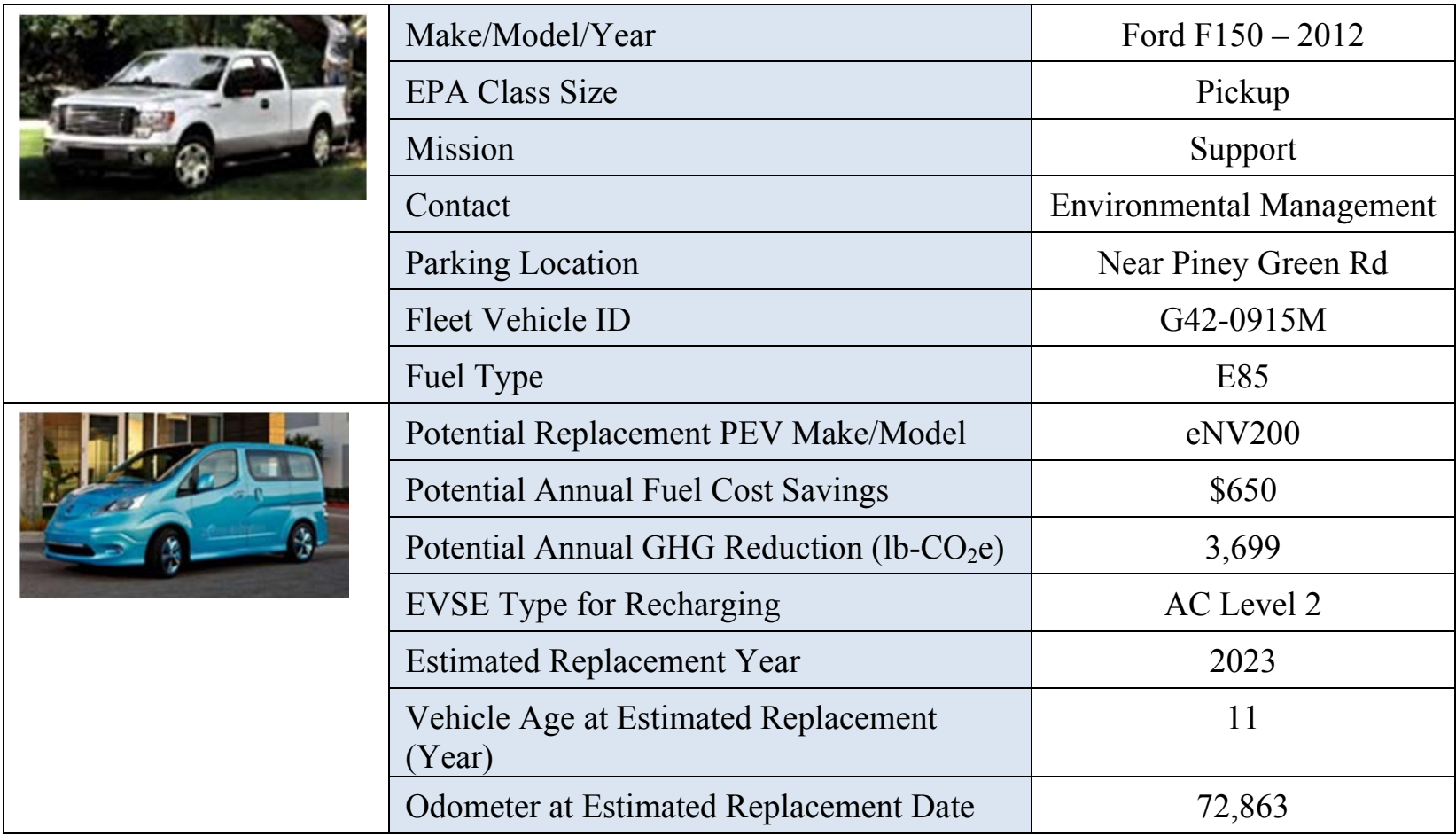

\section{Vehicle G42-2985H}

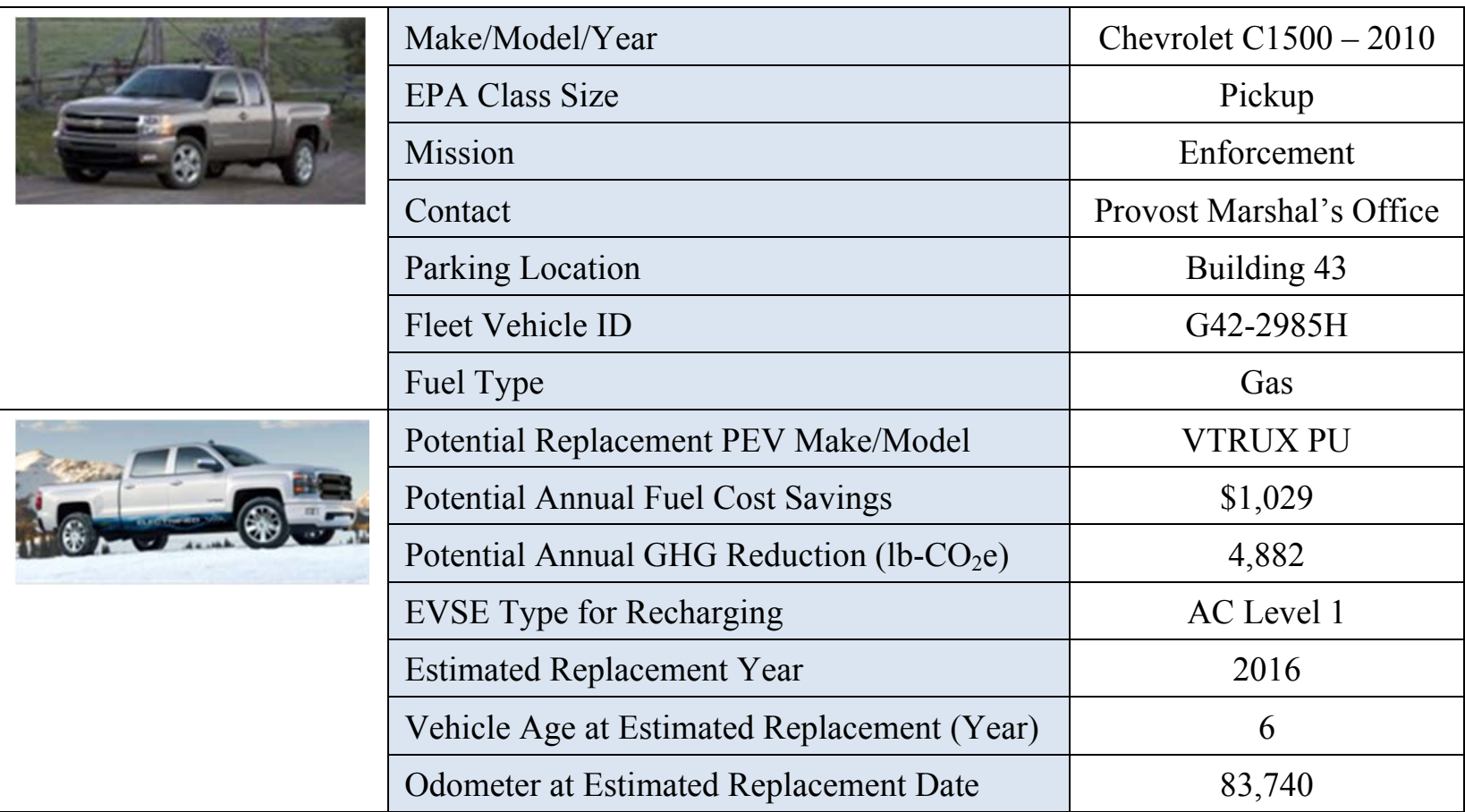




\section{Vehicle G43-0310H}

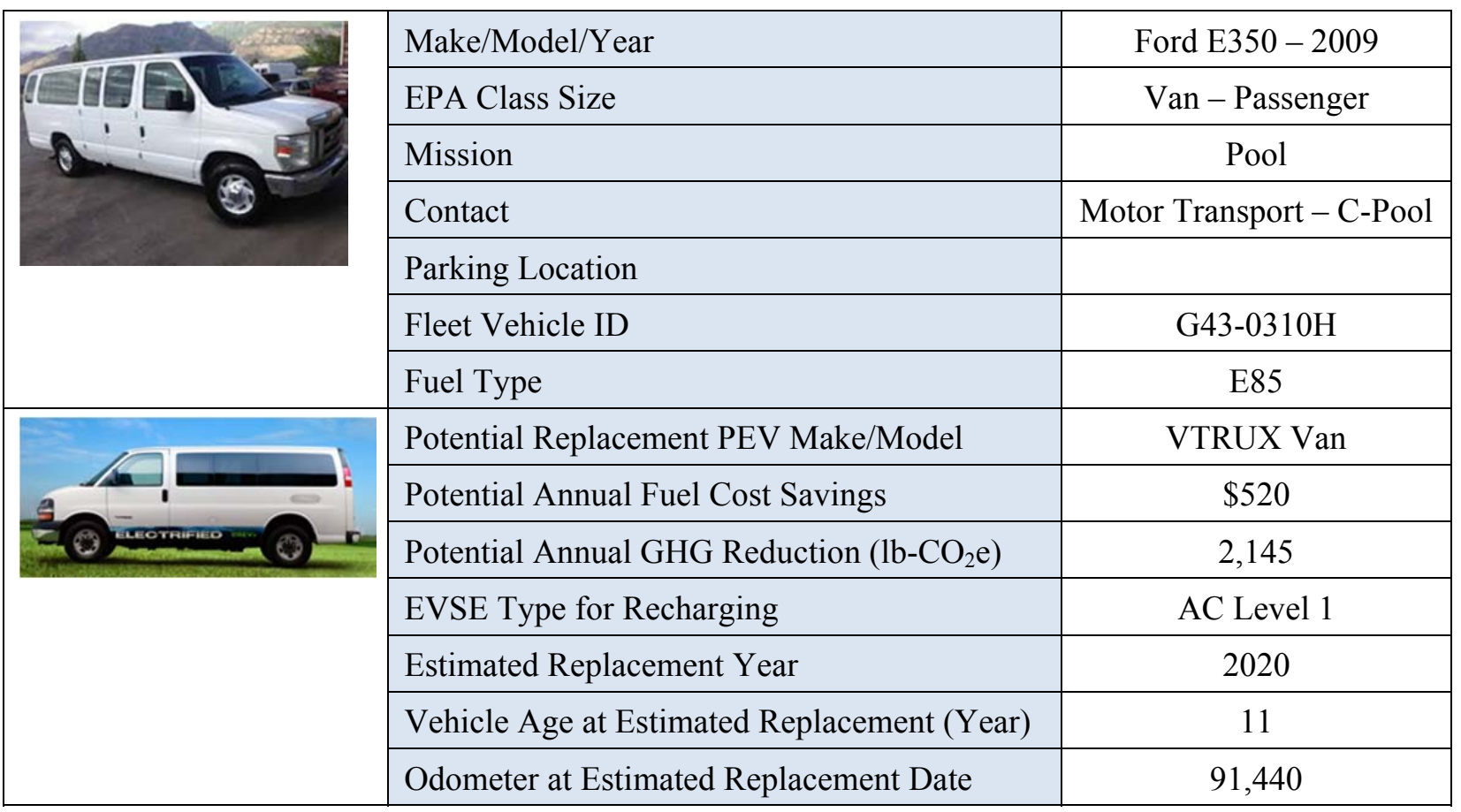

\section{Vehicle G43-0323H}

\begin{tabular}{|c|c|c|}
\hline & Make/Model/Year & Ford E350 - 2009 \\
\hline & EPA Class Size & Van - Cargo \\
\hline & Mission & Support \\
\hline & Contact & Public Works \\
\hline & Parking Location & Building 670 \\
\hline & Fleet Vehicle ID & G43-0323H \\
\hline & Fuel Type & Gas \\
\hline & Potential Replacement PEV Make/Model & VTRUX Van \\
\hline & Potential Annual Fuel Cost Savings & $\$ 697$ \\
\hline ). & Potential Annual GHG Reduction $\left(\mathrm{lb}-\mathrm{CO}_{2} \mathrm{e}\right)$ & 3,555 \\
\hline & EVSE Type for Recharging & AC Level 1 \\
\hline & Estimated Replacement Year & 2016 \\
\hline & Vehicle Age at Estimated Replacement (Year) & 7 \\
\hline & Odometer at Estimated Replacement Date & 79740 \\
\hline
\end{tabular}




\section{Vehicle G43-0324H}

\begin{tabular}{|c|c|c|}
\hline & Make/Model/Year & Ford E350 - 2009 \\
\hline & EPA Class Size & Van - Cargo \\
\hline & Mission & Support \\
\hline & Contact & Public Works \\
\hline & Parking Location & Building FC360 \\
\hline & Fleet Vehicle ID & G43-0324H \\
\hline & Fuel Type & Gas \\
\hline & Potential Replacement PEV Make/Model & eNV200 \\
\hline 4 & Potential Annual Fuel Cost Savings & $\$ 922$ \\
\hline 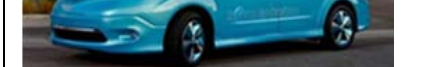 & Potential Annual GHG Reduction $\left(\mathrm{lb}-\mathrm{CO}_{2} \mathrm{e}\right)$ & 5,083 \\
\hline & EVSE Type for Recharging & AC Level 2 \\
\hline & Estimated Replacement Year & 2024 \\
\hline & Vehicle Age at Estimated Replacement (Year) & 15 \\
\hline & Odometer at Estimated Replacement Date & 85,756 \\
\hline
\end{tabular}

\section{Vehicle G43-1182M}

\begin{tabular}{|c|c|c|}
\hline & Make/Model/Year & Chevrolet CG3300 - 2012 \\
\hline & EPA Class Size & Van - Cargo \\
\hline & Mission & Support \\
\hline & Contact & Postal \\
\hline & Parking Location & Building 1770 \\
\hline & Fleet Vehicle ID & G43-1182M \\
\hline & Fuel Type & E85 \\
\hline \multirow{7}{*}{ 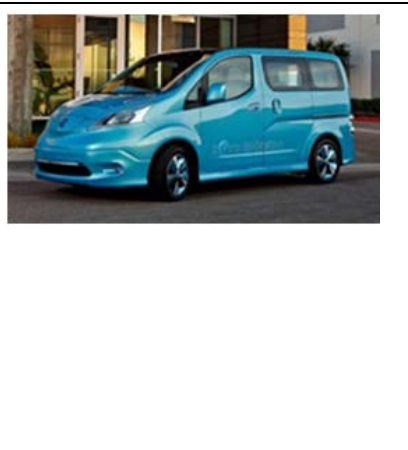 } & Potential Replacement PEV Make/Model & eNV200 \\
\hline & Potential Annual Fuel Cost Savings & $\$ 2,687$ \\
\hline & Potential Annual GHG Reduction $\left(\mathrm{lb}-\mathrm{CO}_{2} \mathrm{e}\right)$ & 13,082 \\
\hline & EVSE Type for Recharging & AC Level 2 \\
\hline & Estimated Replacement Year & 2020 \\
\hline & Vehicle Age at Estimated Replacement (Year) & 8 \\
\hline & Odometer at Estimated Replacement Date & 89,771 \\
\hline
\end{tabular}




\section{Vehicle G43-4075P}

\begin{tabular}{|c|c|c|}
\hline \multirow{2}{*}{ 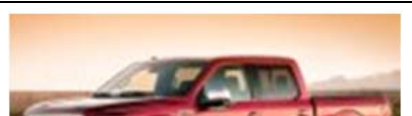 } & Make/Model/Year & Ford F250 - 2015 \\
\hline & EPA Class Size & Pickup \\
\hline \multirow{5}{*}{ 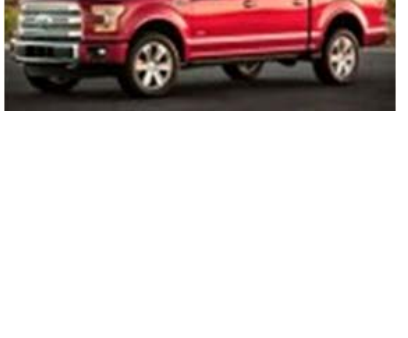 } & Mission & Pool \\
\hline & Contact & Motor Transport-C-Pool \\
\hline & Parking Location & Building 316 \\
\hline & Fleet Vehicle ID & G43-4075P \\
\hline & Fuel Type & E85 \\
\hline \multirow{7}{*}{ 6. } & Potential Replacement PEV Make/Model & VTRUX PU \\
\hline & Potential Annual Fuel Cost Savings & $\$ 962$ \\
\hline & Potential Annual GHG Reduction $\left(\mathrm{lb}-\mathrm{CO}_{2} \mathrm{e}\right)$ & 3,262 \\
\hline & EVSE Type for Recharging & AC Level 1 \\
\hline & Estimated Replacement Year & 2035 \\
\hline & Vehicle Age at Estimated Replacement (Year) & 20 \\
\hline & Odometer at Estimated Replacement Date & 72,464 \\
\hline
\end{tabular}

\section{Vehicle G61-0161H}

\begin{tabular}{|c|c|c|}
\hline & Make/Model/Year & Dodge Dakota - 2009 \\
\hline & EPA Class Size & Pickup \\
\hline B & Mission & Support \\
\hline & Contact & Environmental Management \\
\hline & Parking Location & Building TP464 \\
\hline & Fleet Vehicle ID & G61-0161H \\
\hline & Fuel Type & E85 \\
\hline & Potential Replacement PEV Make/Model & VTRUX PU \\
\hline $2^{2}$ & Potential Annual Fuel Cost Savings & $\$ 1,326$ \\
\hline 1) 181 & Potential Annual GHG Reduction $\left(\mathrm{lb}-\mathrm{CO}_{2} \mathrm{e}\right)$ & 5,762 \\
\hline & EVSE Type for Recharging & AC Level 1 \\
\hline & Estimated Replacement Year & 2018 \\
\hline & Vehicle Age at Estimated Replacement (Year) & 9 \\
\hline & Odometer at Estimated Replacement Date & 91,830 \\
\hline
\end{tabular}




\section{Vehicle G61-0174H}

\begin{tabular}{|c|c|c|}
\hline \multirow{7}{*}{$\sqrt{6-5 m}$} & Make/Model/Year & Jeep Liberty - 2009 \\
\hline & EPA Class Size & SUV \\
\hline & Mission & Support \\
\hline & Contact & $\begin{array}{c}\text { Environmental } \\
\text { Management }\end{array}$ \\
\hline & Parking Location & Building 27 \\
\hline & Fleet Vehicle ID & G61-0174H \\
\hline & Fuel Type & Gas \\
\hline \multirow{7}{*}{ 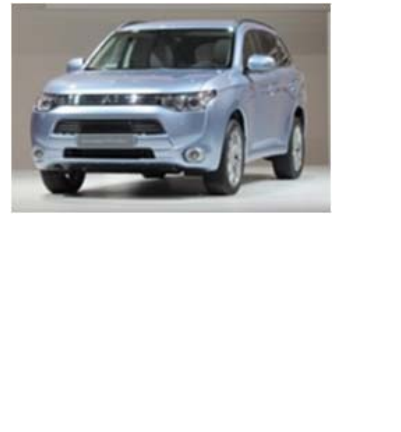 } & Potential Replacement PEV Make/Model & Outlander \\
\hline & Potential Annual Fuel Cost Savings & $\$ 613$ \\
\hline & Potential Annual GHG Reduction (lb- $\left.\mathrm{CO}_{2} \mathrm{e}\right)$ & 2,949 \\
\hline & EVSE Type for Recharging & AC Level 1 \\
\hline & Estimated Replacement Year & 2020 \\
\hline & Vehicle Age at Estimated Replacement (Year) & 11 \\
\hline & Odometer at Estimated Replacement Date & 81,564 \\
\hline
\end{tabular}

\section{Vehicle G61-0879P}

\begin{tabular}{|c|c|c|}
\hline \multirow[t]{7}{*}{ (-) General Motors } & Make/Model/Year & Chevrolet Equinox - 2014 \\
\hline & EPA Class Size & SUV \\
\hline & Mission & Enforcement \\
\hline & Contact & Provost Marshal's Office \\
\hline & Parking Location & Building 979 \\
\hline & Fleet Vehicle ID & G61-0879P \\
\hline & Fuel Type & E85 \\
\hline \multirow{7}{*}{ 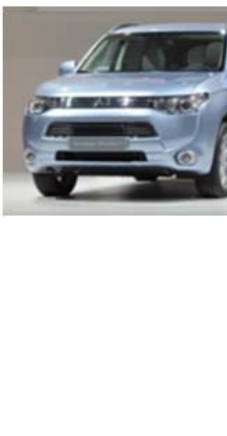 } & Potential Replacement PEV Make/Model & Outlander \\
\hline & Potential Annual Fuel Cost Savings & $\$ 217$ \\
\hline & Potential Annual GHG Reduction $\left(\mathrm{lb}-\mathrm{CO}_{2} \mathrm{e}\right)$ & 689 \\
\hline & EVSE Type for Recharging & AC Level 1 \\
\hline & Estimated Replacement Year & 2029 \\
\hline & Vehicle Age at Estimated Replacement (Year) & 15 \\
\hline & Odometer at Estimated Replacement Date & 63,682 \\
\hline
\end{tabular}




\section{Vehicle G61-1508D}

\begin{tabular}{|c|c|c|}
\hline \multirow{2}{*}{ 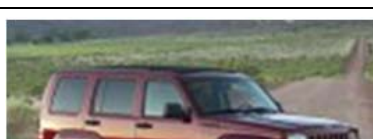 } & Make/Model/Year & Jeep Liberty -2008 \\
\hline & EPA Class Size & SUV \\
\hline \multirow{5}{*}{$8-x \rightarrow=$} & Mission & Pool \\
\hline & Contact & Motor Transport - C-Pool \\
\hline & Parking Location & Building 58 \\
\hline & Fleet Vehicle ID & G61-1508D \\
\hline & Fuel Type & Gas \\
\hline \multirow{7}{*}{ 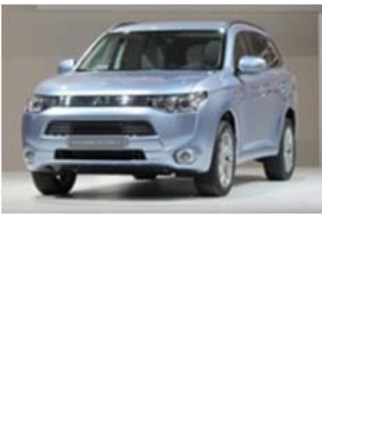 } & Potential Replacement PEV Make/Model & Outlander \\
\hline & Potential Annual Fuel Cost Savings & $\$ 78$ \\
\hline & Potential Annual GHG Reduction $\left(\mathrm{lb}-\mathrm{CO}_{2} \mathrm{e}\right)$ & 363 \\
\hline & EVSE Type for Recharging & AC Level 1 \\
\hline & Estimated Replacement Year & 2016 \\
\hline & Vehicle Age at Estimated Replacement (Year) & 8 \\
\hline & Odometer at Estimated Replacement Date & 32,203 \\
\hline
\end{tabular}

Vehicle G61-1509D

\begin{tabular}{|c|c|c|}
\hline & Make/Model/Year & Jeep Liberty - 2008 \\
\hline & EPA Class Size & SUV \\
\hline$\sqrt{\beta}$ & Mission & Pool \\
\hline & Contact & Motor Transport - C-Pool \\
\hline & Parking Location & Building 28211 \\
\hline & Fleet Vehicle ID & G61-1509D \\
\hline & Fuel Type & Gas \\
\hline & Potential Replacement PEV Make/Model & Soul \\
\hline & Potential Annual Fuel Cost Savings & $\$ 401$ \\
\hline & Potential Annual GHG Reduction $\left(\mathrm{lb}-\mathrm{CO}_{2} \mathrm{e}\right)$ & 2,202 \\
\hline & EVSE Type for Recharging & AC Level 2 \\
\hline & Estimated Replacement Year & 2016 \\
\hline & Vehicle Age at Estimated Replacement (Year) & 8 \\
\hline & Odometer at Estimated Replacement Date & 29,843 \\
\hline
\end{tabular}




\section{Vehicle G62-1583G}

\begin{tabular}{|l|l|c|}
\hline Make/Model/Year & Chevrolet K1500-2008 \\
\hline EPA Class Size & Pickup \\
\hline Mission & Support \\
\hline Contact & Bps and Training \\
\hline & Parking Location 54 \\
\hline & Fleet Vehicle ID & G62-1583G \\
\hline & Fuel Type & Gas \\
\hline \multirow{3}{*}{} & Potential Replacement PEV Make/Model & VTRUX PU \\
\cline { 2 - 3 } & Potential Annual Fuel Cost Savings & \$676 \\
\cline { 2 - 3 } & Potential Annual GHG Reduction (lb-CO $\left.{ }_{2} \mathrm{e}\right)$ & 3,206 \\
\hline & EVSE Type for Recharging & ACL1 \\
\cline { 2 - 3 } & Estimated Replacement Year & 2016 \\
\hline & Vehicle Age at Estimated Replacement (Year) & 8 \\
\hline & Odometer at Estimated Replacement Date & 7197 \\
\hline
\end{tabular}

\section{Vehicle G62-4085L}

\begin{tabular}{|l|l|c|}
\hline & Make/Model/Year & Dodge $1500-2012$ \\
\hline & EPA Class Size & Pickup \\
\hline & Mission & Fipport \\
\hline Contact & Building 58 \\
\hline & Parking Location & G62-4085L \\
\hline & Fleet Vehicle ID & E85 \\
\hline & Fuel Type & VTRUX PU \\
\hline \multirow{3}{*}{} & Potential Replacement PEV Make/Model & \$1,042 \\
\cline { 2 - 3 } & Potential Annual Fuel Cost Savings & 4,297 \\
\cline { 2 - 3 } & Potential Annual GHG Reduction (lb-CO $\left.\mathrm{CO}_{2} \mathrm{e}\right)$ & AC Level 1 \\
\hline & EVSE Type for Recharging & 2020 \\
\hline & Estimated Replacement Year & 8 \\
\hline & Vehicle Age at Estimated Replacement (Year) & 70,426 \\
\hline
\end{tabular}




\section{Vehicle G63-0163H}

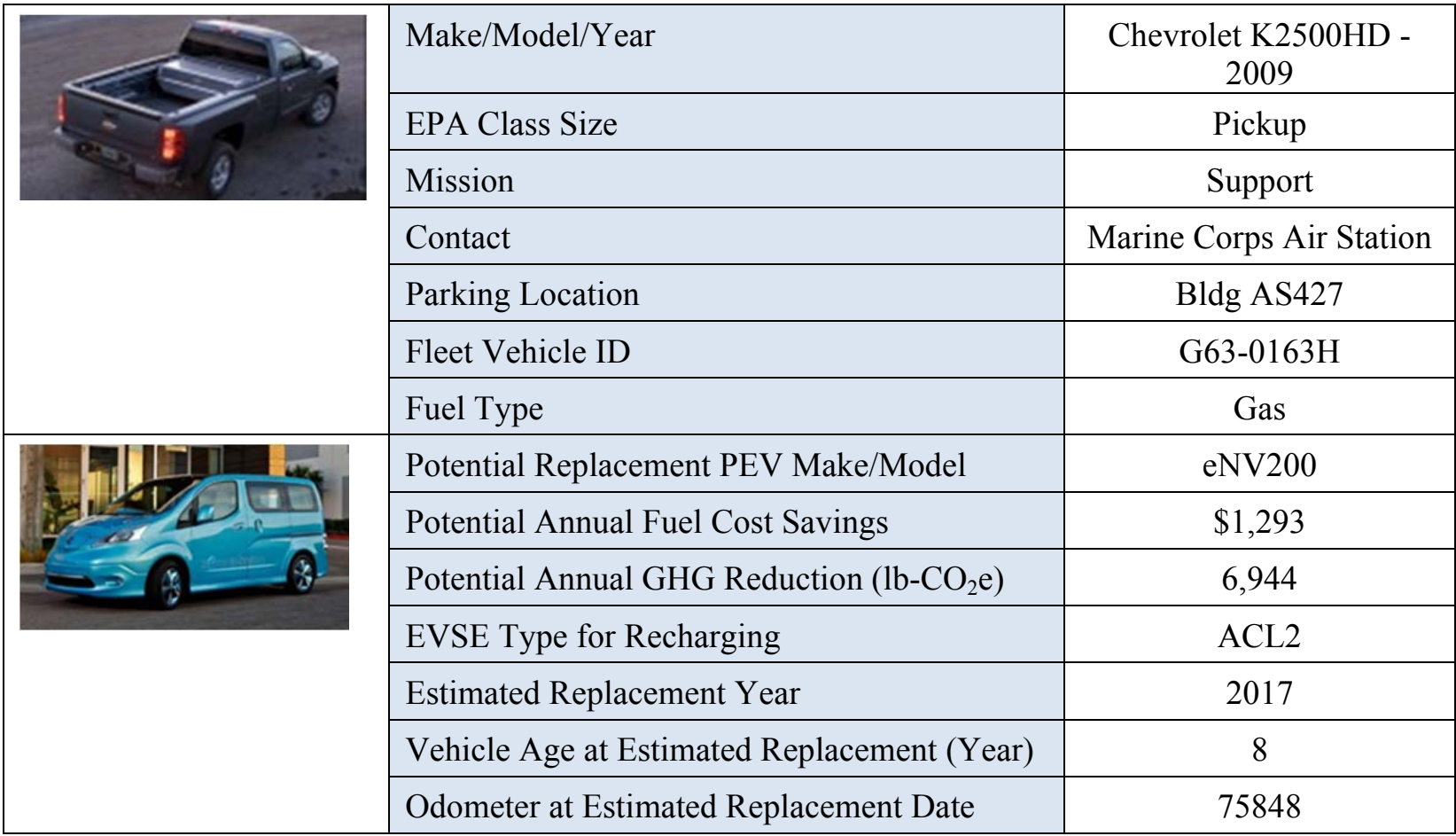

\section{Vehicle G63-2885L}

\begin{tabular}{|c|c|c|}
\hline \multirow{7}{*}{ 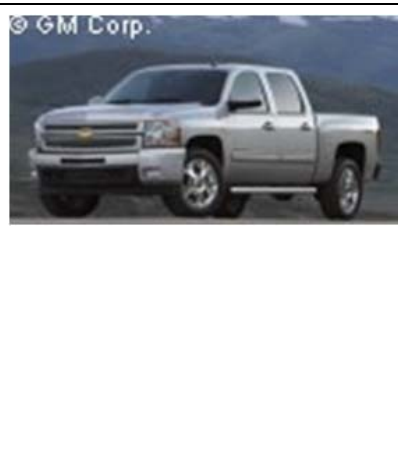 } & Make/Model/Year & Chevrolet K2500HD - 2012 \\
\hline & EPA Class Size & Pickup \\
\hline & Mission & Support \\
\hline & Contact & Fire Department \\
\hline & Parking Location & Building 2600 \\
\hline & Fleet Vehicle ID & G63-2885L \\
\hline & Fuel Type & E85 \\
\hline \multirow{7}{*}{$\Rightarrow \frac{8}{8}$} & Potential Replacement PEV Make/Model & eNV200 \\
\hline & Potential Annual Fuel Cost Savings & $\$ 595$ \\
\hline & Potential Annual GHG Reduction $\left(\mathrm{lb}-\mathrm{CO}_{2} \mathrm{e}\right)$ & 2,459 \\
\hline & EVSE Type for Recharging & AC Level 2 \\
\hline & Estimated Replacement Year & 2029 \\
\hline & Vehicle Age at Estimated Replacement (Year) & 17 \\
\hline & Odometer at Estimated Replacement Date & 68,042 \\
\hline
\end{tabular}


Vehicle G63-2888L

\begin{tabular}{|c|c|c|}
\hline \multirow{7}{*}{$\begin{array}{l}201 \\
=-9=3 \\
=-3\end{array}$} & Make/Model/Year & Chevrolet K2500HD - 2012 \\
\hline & EPA Class Size & Pickup \\
\hline & Mission & Enforcement \\
\hline & Contact & Provost Marshal's Office \\
\hline & Parking Location & Building SAW360B \\
\hline & Fleet Vehicle ID & G63-2888L \\
\hline & Fuel Type & E85 \\
\hline & Potential Replacement PEV Make/Model & Soul \\
\hline & Potential Annual Fuel Cost Savings & $\$ 668$ \\
\hline & Potential Annual GHG Reduction $\left(\mathrm{lb}-\mathrm{CO}_{2} \mathrm{e}\right)$ & 3,085 \\
\hline & EVSE Type for Recharging & AC Level 2 \\
\hline & Estimated Replacement Year & 2029 \\
\hline & $\begin{array}{l}\text { Vehicle Age at Estimated Replacement } \\
\text { (Year) }\end{array}$ & 17 \\
\hline & Odometer at Estimated Replacement Date & 76,268 \\
\hline
\end{tabular}




\section{Appendix C \\ Commands Fleet Vehicle Replacement Approach}

There are four replacement approaches identified for the Commands fleet vehicles:

- Monitored vehicles

- $\quad$ GSA-listed PEVs only for sedans

- All other potential PEV types

- Unmonitored vehicles part of the full fleet

- $\quad$ GSA-listed PEVs only for sedans

- All potential PEV types for non-sedan vehicles.

The extensive analysis conducted for monitored vehicles (Task 3) results in high confidence that the suggested vehicle can meet mission requirements. The suggested vehicles for the full fleet rely on extrapolation of those monitored vehicles and guidance identified in Section 3.

\section{C.1 Monitored Sedan Vehicle General Services Administration Replacement Approach}

No sedans assigned to the Commands group were monitored during this study.

\section{C.2 All Monitored Non-Sedan Vehicle Replacement Approach}

Table C-1 provides a replacement approach using currently or soon-to-be available PEVs. Although not currently listed by GSA, these or similar vehicles may be listed by the year identified or MCBCL may choose to justify the replacement. The replacement of these vehicles by PEVs is assumed in the analysis of Section 4.

Table C-1. Command fleet all monitored non-sedan vehicle replacement approach.

\begin{tabular}{ccccccc}
\hline \multicolumn{7}{c}{ Non-Sedan Replacement Approach } \\
Fleet Vehicle & \multicolumn{7}{c}{ Potential } \\
Id & Make & Model & Year & EPA Class & $\begin{array}{c}\text { Replacement } \\
\text { Vehicle }\end{array}$ & $\begin{array}{c}\text { Replacement } \\
\text { Year }\end{array}$ \\
\hline 291073 & Ford & E250 & 2007 & Van - Pass & eNV200 & 2022 \\
301321 & Ford & F350 & 2012 & Pickup & eNV200 & 2027 \\
G41-0762M & Dodge & Grd Caravan & 2012 & Minivan & Outlander & 2017 \\
G41-1846K & Dodge & Grd Caravan & 2011 & Minivan & Outlander & 2017 \\
G41-2399K & Dodge & Dakota & 2010 & Pickup & eNV200 & 2021 \\
G42-0216F & Ford & E150 & 2008 & Van - Pass & eNV200 & 2016 \\
G42-0883M & Ford & E150 & 2012 & Van - Pass & VTRUX Van & 2018 \\
G42-0898M & Ford & E150 & 2012 & Van - Pass & VTRUX Van & 2018 \\
G43-0326H & Chevrolet & $2500 H D$ & 2009 & Pickup & eNV200 & 2022 \\
G43-1453G & Chevrolet & G2300 & 2008 & Van - Pass & Soul & 2016 \\
G43-1855P & Ford & F350 & 2015 & Pickup & VTRUX PU & 2029 \\
G43-2025K & Ford & F250 & 2010 & Pickup & Soul & 2025 \\
G43-4073F & Chevrolet & G2300 & 2008 & Van - Pass & eNV200 & 2016 \\
G61-0594L & Jeep & Patriot & 2011 & SUV & Outlander & 2020 \\
G61-2644P & Jeep & Patriot & 2015 & SUV & Outlander & 2019 \\
G62-0791H & Ford & Expedition & 2009 & SUV & Outlander & 2018 \\
G63-0309R & Ford & F350 & 2015 & Pickup & VTRUX PU & 2025 \\
G63-0934G & Chevrolet & K3500 & 2008 & Pickup & VTRUX PU & 2020 \\
\hline
\end{tabular}




\section{C.3 Unmonitored Sedan Fleet Replacement Approach}

GSA currently lists only sedans for PEVs. It is assumed that additional sedans will be added to the list in the next few years. Table $\mathrm{C}-2$ provides the list of sedans in the Commands fleet other than those monitored and included in Section C.1. The projected year of replacement is identified based on the GSA requirements and expected usage. The mileage is projected from the odometer reading in 2014 and annual mileage provided by MCBCL. While other vehicles can certainly be replaced with PEVs, the vehicles identified in green are counted for replacement by PEVs in the analysis of Section 4.

Table C-2. Commands fleet unmonitored sedan fleet replacement options.

\begin{tabular}{lcccccc}
\multicolumn{1}{c}{$\begin{array}{c}\text { Gleet } \\
\text { Vehicle Id }\end{array}$} & Make & Model & Year & EPA Class & $\begin{array}{c}\text { Potential } \\
\text { Replacement } \\
\text { Vehicle }\end{array}$ & $\begin{array}{c}\text { Replacement } \\
\text { Year }\end{array}$ \\
\hline G103024L & Chevrolet & Malibu & 2011 & Sedan - Midsize & Fusion & 2022 \\
G103025L & Chevrolet & Malibu & 2011 & Sedan - Midsize & Leaf & 2022 \\
G103026L & Chevrolet & Malibu & 2011 & Sedan - Midsize & Leaf & 2022 \\
G103323L & Chevrolet & Malibu & 2012 & Sedan - Midsize & Fusion & 2018 \\
G103325L & Chevrolet & Malibu & 2012 & Sedan - Midsize & Fusion & 2022 \\
G103330L & Chevrolet & Malibu & 2012 & Sedan - Midsize & Fusion & 2022 \\
G103333L & Chevrolet & Malibu & 2012 & Sedan - Midsize & Fusion & 2022 \\
G111174P & Chevrolet & Impala & 2014 & Sedan - Large & Volt & 2021 \\
G111358P & Chevrolet & Impala & 2014 & Sedan - Large & Leaf & 2026 \\
G111360P & Chevrolet & Impala & 2014 & Sedan - Large & Leaf & 2025 \\
G111361P & Chevrolet & Impala & 2014 & Sedan - Large & Fusion & 2020 \\
G111362P & Chevrolet & Impala & 2014 & Sedan - Large & Leaf & 2025 \\
G130846P & Ford & Focus & 2014 & Sedan - Compact & Focus & 2022 \\
\hline
\end{tabular}

Note the GSA schedule does not currently list the Leaf although it did in previous years. It is expected that it will be listed again by 2016 .

\section{C.4 Unmonitored Non-Sedan Vehicle Replacement Approach}

Table C-3 provides the list of non-sedans in the Commands fleet other than those monitored and included in Section C. 2 above that are assumed to be replaced by PEVs through the year 2026. The projected year of replacement is identified based on GSA requirements and expected usage. The mileage is projected from the odometer reading in 2014 and annual mileage provided by MCBCL. This list includes 61 of the 218 vehicles projected for replacement by 2026; more vehicles can be replaced if desired.

Table C-3. Command fleet unmonitored non-sedan replacement options.

\begin{tabular}{|c|c|c|c|c|c|c|}
\hline \multicolumn{7}{|c|}{ Non-Sedan Replacement Approach } \\
\hline $\begin{array}{c}\text { Fleet Vehicle } \\
\text { Id }\end{array}$ & Make & Model & Year & EPA Class & $\begin{array}{c}\text { Potential } \\
\text { Replacement } \\
\text { Vehicle }\end{array}$ & $\begin{array}{c}\text { Replacement } \\
\text { Year }\end{array}$ \\
\hline G410383H & Dodge & Grd Caravan & 2009 & Minivan & Soul & 2017 \\
\hline G410382H & Dodge & Grd Caravan & 2009 & Minivan & Outlander & 2018 \\
\hline G420831L & Dodge & 1500 & 2011 & Pickup & VTRUX PU & 2018 \\
\hline G431455G & Chevrolet & $2500 \mathrm{HD}$ & 2008 & Pickup & eNV200 & 2018 \\
\hline 294341 & Chevrolet & HHR & 2009 & SUV & Soul & 2019 \\
\hline G416304H & Dodge & Grd Caravan & 2010 & Minivan & Outlander & 2019 \\
\hline G420176H & Ford & E150 & 2009 & Van - Pass & VTRUX Van & 2019 \\
\hline
\end{tabular}




\begin{tabular}{|c|c|c|c|c|c|c|}
\hline \multicolumn{7}{|c|}{ Non-Sedan Replacement Approach } \\
\hline $\begin{array}{c}\text { Fleet Vehicle } \\
\text { Id }\end{array}$ & Make & Model & Year & EPA Class & $\begin{array}{c}\text { Potential } \\
\text { Replacement } \\
\text { Vehicle }\end{array}$ & $\begin{array}{c}\text { Replacement } \\
\text { Year }\end{array}$ \\
\hline G420181H & Ford & E150 & 2009 & Van - Pass & eNV200 & 2019 \\
\hline G420235F & Ford & F150 & 2008 & Pickup & eNV200 & 2019 \\
\hline G420833L & Dodge & 1500 & 2011 & Pickup & VTRUX PU & 2019 \\
\hline G420902M & Ford & $\mathrm{E} 150$ & 2012 & Van - Pass & VTRUX Van & 2019 \\
\hline G421290M & Dodge & 1500 & 2012 & Pickup & VTRUX PU & 2019 \\
\hline G431456G & Chevrolet & $2500 \mathrm{HD}$ & 2008 & Pickup & eNV200 & 2019 \\
\hline G431459G & Ford & $\mathrm{F} 250$ & 2008 & Pickup & eNV200 & 2019 \\
\hline G621587G & Chevrolet & K1500 & 2008 & Pickup & eNV200 & 2019 \\
\hline G410394H & Dodge & Dakota & 2009 & Pickup & eNV200 & 2020 \\
\hline G410397H & Dodge & Dakota & 2009 & Pickup & eNV200 & 2020 \\
\hline G410403H & Dodge & Dakota & 2009 & Pickup & eNV200 & 2020 \\
\hline G411849K & Dodge & Grd Caravan & 2011 & Minivan & Soul & 2020 \\
\hline G420215F & Ford & E150 & 2008 & Van - Pass & eNV200 & 2020 \\
\hline G420292H & Ford & E150 & 2010 & Van - Pass & eNV200 & 2020 \\
\hline G421939K & Chevrolet & G1300 & 2011 & Van - Pass & eNV200 & 2020 \\
\hline G422972H & Ford & E150 & 2010 & Van - Pass & eNV200 & 2020 \\
\hline G431450G & Chevrolet & G2300 & 2008 & Van - Pass & eNV200 & 2020 \\
\hline G620374M & Dodge & 1500 & 2012 & Pickup & VTRUX PU & 2020 \\
\hline G631524M & Chevrolet & K2500HD & 2013 & Pickup & VTRUX PU & 2020 \\
\hline G410399H & Dodge & Dakota & 2009 & Pickup & eNV200 & 2021 \\
\hline G410766M & Dodge & Grd Caravan & 2012 & Minivan & Soul & 2021 \\
\hline G410810P & Dodge & Grd Caravan & 2014 & Minivan & Outlander & 2021 \\
\hline G420659P & Chevrolet & G1300 & 2014 & Van - Pass & VTRUX Van & 2021 \\
\hline G420832L & Dodge & 1500 & 2011 & Pickup & eNV200 & 2021 \\
\hline G420882M & Ford & E150 & 2012 & Van - Pass & VTRUX Van & 2021 \\
\hline G420884M & Ford & E150 & 2012 & Van - Pass & eNV200 & 2021 \\
\hline G420895M & Ford & E150 & 2012 & Van - Pass & VTRUX Van & 2021 \\
\hline G421289M & Dodge & 1500 & 2012 & Pickup & VTRUX PU & 2021 \\
\hline G431337L & Ford & F350 & 2011 & Pickup & VTRUX PU & 2021 \\
\hline G611507D & Jeep & Liberty & 2008 & SUV & Outlander & 2021 \\
\hline G622008F & Chevrolet & K1500 & 2008 & Pickup & eNV200 & 2021 \\
\hline G710143K & Ford & $\mathrm{F} 450$ & 2011 & Pickup & eNV200 & 2021 \\
\hline 291238 & Ford & E250 & 2007 & Van - Pass & VTRUX Van & 2022 \\
\hline 294288 & Chevrolet & HHR & 2009 & SUV & Outlander & 2022 \\
\hline G430312H & Ford & E350 & 2009 & Van - Pass & eNV200 & 2022 \\
\hline G624088L & Dodge & 1500 & 2012 & Pickup & eNV200 & 2022 \\
\hline G632733F & Ford & F350 & 2008 & Pickup & eNV200 & 2022 \\
\hline G710141K & Ford & F550 & 2011 & Van - Cargo & VTRUX Van & 2022 \\
\hline 294287 & Chevrolet & HHR & 2009 & SUV & Soul & 2023 \\
\hline G420242F & Ford & E150 & 2008 & Van - Pass & eNV200 & 2023 \\
\hline G420647M & Ford & E150 & 2012 & Van - Pass & eNV200 & 2023 \\
\hline G422980H & Ford & E150 & 2010 & Van - Pass & eNV200 & 2023 \\
\hline $\mathrm{G} 431457 \mathrm{G}$ & Ford & F250 & 2008 & Pickup & Soul & 2023 \\
\hline
\end{tabular}




\begin{tabular}{ccccccc}
\hline \multicolumn{7}{c}{ Non-Sedan Replacement Approach } \\
$\begin{array}{c}\text { Fleet Vehicle } \\
\text { Id }\end{array}$ & Make & Model & Year & EPA Class & $\begin{array}{c}\text { Potential } \\
\text { Replacement } \\
\text { Vehicle }\end{array}$ & $\begin{array}{c}\text { Replacement } \\
\text { Year }\end{array}$ \\
\hline G624093L & Dodge & 1500 & 2012 & Pickup & eNV200 & 2023 \\
G710587N & Ford & F450 & 2008 & Pickup & eNV200 & 2023 \\
G410809P & Dodge & Caravan & 2014 & Minivan & Outlander & 2024 \\
G420177H & Ford & E150 & 2009 & Van - Pass & eNV200 & 2024 \\
G710112F & Ford & F450 & 2008 & Pickup & eNV200 & 2024 \\
G710186L & Ford & F450 & 2012 & Pickup & eNV200 & 2024 \\
G610167H & Jeep & Liberty & 2009 & SUV & Soul & 2025 \\
G420241F & Ford & E150 & 2008 & Van - Pass & eNV200 & 2026 \\
G430478M & Ford & F250 & 2012 & Pickup & eNV200 & 2026 \\
G431340L & Ford & F350 & 2011 & Pickup & eNV200 & 2026 \\
G432024K & Dodge & 3500 & 2011 & Pickup & eNV200 & 2026 \\
\hline
\end{tabular}




\section{Appendix D Marine Corps Installations East Fleet Vehicle Analysis}

There are four replacement approaches identified for the MCIE fleet:

- Monitored vehicles

- GSA-listed PEVs only for sedans

- All potential PEV types

- Unmonitored vehicles part of the full fleet

- $\quad$ GSA-listed PEVs only for sedans

- All potential PEV types for non-sedan vehicles

The extensive analysis conducted for monitored vehicles (Task 3) results in high confidence that the suggested vehicle can meet mission requirements. The suggested vehicles for the full fleet rely on extrapolation of those monitored vehicles and guidance identified in Section 3.

\section{D.1 Monitored Vehicle General Services Administration Replacement Approach}

The monitored sedans are shown in Table D-1, along with potential replacement PEVs and year of potential replacement. The replacement of these vehicles by PEV is assumed in the analysis of Section 5.

Table D-1. MCIE fleet GSA sedan monitored vehicle replacement approach.

GSA Replacement Approach

\begin{tabular}{|c|c|c|c|c|c|c|}
\hline $\begin{array}{c}\text { Fleet Vehicle } \\
\text { Id }\end{array}$ & Make & Model & Year & EPA Class & $\begin{array}{c}\text { Potential } \\
\text { Replacement } \\
\text { Vehicle }\end{array}$ & $\begin{array}{c}\text { Replacement } \\
\text { Year }\end{array}$ \\
\hline 294285 & Chevrolet & Malibu & 2009 & Sedan - Midsize & Leaf & 2023 \\
\hline G10-3327L & Chevrolet & Malibu & 2012 & Sedan - Midsize & Leaf & 2022 \\
\hline G13-0325K & Ford & Focus & 2012 & Sedan - Compact & Volt & 2022 \\
\hline G13-7974P & Ford & Focus & 2015 & Sedan - Compact & Volt & 2022 \\
\hline
\end{tabular}

Note that the GSA schedule does not currently list the Leaf, although it did in previous years. It is expected that the Leaf will be listed again by 2016 .

\section{D.2 Monitored Non-Sedan Vehicle All Replacement Approach}

Table D-2 provides a replacement approach for the non-sedan type monitored vehicles using currently or soon-to-be available PEVs. Although not currently listed by GSA, these or similar vehicles may be listed by the year identified or MCBCL may choose to justify the replacement.

Table D- 2. MCIE fleet non-sedan monitored vehicle replacement approach.

\begin{tabular}{ccccccc}
\hline \multirow{2}{*}{$\begin{array}{c}\text { Fleet Vehicle } \\
\text { Id }\end{array}$} & Make & Model & Year & EPA Class & $\begin{array}{c}\text { Potential } \\
\text { Replacement } \\
\text { Vehicle }\end{array}$ & $\begin{array}{c}\text { Replacement } \\
\text { Year }\end{array}$ \\
\hline 290597 & Ford & E350 & 1997 & Van - Cargo & VTRUX Van & 2022 \\
291007 & Ford & F650 & 2004 & SP-Refrig. & NA & 2024 \\
294293 & Chevrolet & HHR & 2009 & SUV & Soul & 2019 \\
294315 & Chevrolet & 3500 & 2009 & Pickup & eNV200 & 2023 \\
294324 & Chevrolet & HHR & 2009 & SUV & Outlander & 2018 \\
300672 & Ford & F550 & 2011 & SP/Bucket Tr & EDI Conv. & 2026 \\
302039 & Ford & F250XL & 2014 & Pickup & VTRUX PU & 2026 \\
\hline
\end{tabular}




\begin{tabular}{|c|c|c|c|c|c|c|}
\hline \multicolumn{7}{|c|}{ Non-Sedan Replacement Approach } \\
\hline $\begin{array}{c}\text { Fleet Vehicle } \\
\text { Id }\end{array}$ & Make & Model & Year & EPA Class & $\begin{array}{c}\text { Potential } \\
\text { Replacement } \\
\text { Vehicle }\end{array}$ & $\begin{array}{c}\text { Replacement } \\
\text { Year }\end{array}$ \\
\hline 302040 & Ford & F250XL & 2014 & Pickup & VTRUX PU & 2022 \\
\hline 302334 & Ford & F350 Stake & 2015 & Pickup & VTRUX PU & 2031 \\
\hline G410379H & Dodge & Grd Caravan & 2009 & Minivan & Soul & 2022 \\
\hline G410391H & Dodge & Dakota & 2009 & Pickup & VTRUX PU & 2023 \\
\hline G410754M & Dodge & Grd Caravan & 2012 & Minivan & Outlander & 2027 \\
\hline G410806P & Dodge & Grd Caravan & 2014 & Minivan & Outlander & 2020 \\
\hline G411689L & Ford & Ranger & 2011 & Pickup & VTRUX PU & 2021 \\
\hline G413297K & Ford & Ranger & 2011 & Pickup & eNV200 & 2026 \\
\hline G413300K & Ford & Ranger & 2011 & Pickup & VTRUX PU & 2018 \\
\hline G413301K & Ford & Ranger & 2011 & Pickup & eNV200 & 2023 \\
\hline G420644M & Ford & E150 & 2012 & Van - Pass & eNV200 & 2017 \\
\hline G420667P & Ford & $\mathrm{F} 150$ & 2014 & Pickup & VTRUX PU & 2024 \\
\hline G420671P & Ford & F150 & 2014 & Pickup & eNV200 & 2025 \\
\hline G420911L & Chevrolet & $\mathrm{C} 1500$ & 2012 & Pickup & eNV200 & 2024 \\
\hline G420915M & Ford & F150 & 2012 & Pickup & eNV200 & 2023 \\
\hline G422985H & Chevrolet & $\mathrm{C} 1500$ & 2010 & Pickup & VTRUX PU & 2016 \\
\hline G430310H & Ford & E350 & 2009 & Van - Pass & VTRUX Van & 2020 \\
\hline G430323H & Ford & E350 & 2009 & Van - Cargo & VTRUX Van & 2016 \\
\hline G430324H & Ford & E350 & 2009 & Van - Cargo & eNV200 & 2024 \\
\hline G431182M & Chevrolet & CG3300 & 2012 & Van - Cargo & eNV200 & 2020 \\
\hline G434075P & Ford & $\mathrm{F} 250$ & 2015 & Pickup & VTRUX PU & 2035 \\
\hline G610161H & Dodge & Dakota & 2009 & Pickup & VTRUX PU & 2018 \\
\hline G610174H & Jeep & Liberty & 2009 & SUV & Outlander & 2020 \\
\hline G610879P & Chevrolet & Equinox & 2014 & SUV & Outlander & 2029 \\
\hline G611508D & Jeep & Liberty & 2008 & SUV & Outlander & 2016 \\
\hline G611509D & Jeep & Liberty & 2008 & SUV & Soul & 2016 \\
\hline G621583G & Chevrolet & K1500 & 2008 & Pickup & VTRUX PU & 2016 \\
\hline G624085L & Dodge & 1500 & 2012 & Pickup & VTRUX PU & 2020 \\
\hline G630163H & Chevrolet & $\mathrm{K} 2500 \mathrm{HD}$ & 2009 & Pickup & eNV200 & 2017 \\
\hline G632885L & Chevrolet & $\mathrm{K} 2500 \mathrm{HD}$ & 2012 & Pickup & eNV200 & 2029 \\
\hline G632888L & Chevrolet & $\mathrm{K} 2500 \mathrm{HD}$ & 2012 & Pickup & Soul & 2029 \\
\hline
\end{tabular}

\section{D.3 Unmonitored Sedan Fleet Replacement Approach}

GSA currently lists only sedans for PEVs. It is assumed that additional sedans will be added to the list in the next few years. Table D-3 provides the list of sedans in the MCIE fleet other than those monitored and included in Section D.1. The projected year of replacement is identified based on the GSA requirements and expected usage. The mileage is projected from the odometer reading in 2015 and annual mileage provided by MCBCL. While other vehicles can certainly be replaced with PEVs, the vehicles identified in green are counted for replacement by PEVs in the analysis of Section 4.

Table D-3. MCIE unmonitored sedan fleet replacement approach. 


\begin{tabular}{|c|c|c|c|c|c|c|}
\hline \multicolumn{7}{|c|}{ Non-Sedan Replacement Approach } \\
\hline $\begin{array}{c}\text { Fleet Vehicle } \\
\text { Id }\end{array}$ & Make & Model & Year & EPA Class & $\begin{array}{c}\text { Potential } \\
\text { Replacement } \\
\text { Vehicle }\end{array}$ & $\begin{array}{c}\text { Replacement } \\
\text { Year }\end{array}$ \\
\hline 294278 & Chevrolet & Malibu & 2009 & Sedan - Midsize & Leaf & 2021 \\
\hline 294279 & Ford & Fusion & 2010 & Sedan - Midsize & Leaf & 2020 \\
\hline 294280 & Chevrolet & Malibu & 2009 & Sedan - Midsize & Fusion & 2017 \\
\hline 294282 & Chevrolet & Malibu & 2009 & Sedan - Midsize & Leaf & 2020 \\
\hline 294283 & Ford & Fusion & 2010 & Sedan - Midsize & Leaf & 2025 \\
\hline 294285 & Chevrolet & Malibu & 2009 & Sedan - Midsize & Leaf & 2023 \\
\hline 294286 & Chevrolet & Malibu & 2009 & Sedan - Midsize & Leaf & 2023 \\
\hline 294291 & Chevrolet & Malibu & 2010 & Sedan - Midsize & Leaf & 2020 \\
\hline G103321L & Chevrolet & Malibu & 2012 & Sedan - Midsize & Leaf & 2022 \\
\hline G103322L & Chevrolet & Malibu & 2012 & Sedan - Midsize & Leaf & 2022 \\
\hline G103324L & Chevrolet & Malibu & 2012 & Sedan - Midsize & Volt & 2022 \\
\hline G103326L & Chevrolet & Malibu & 2012 & Sedan - Midsize & Volt & 2017 \\
\hline G103327L & Chevrolet & Malibu & 2012 & Sedan - Midsize & Leaf & 2022 \\
\hline G103328L & Chevrolet & Malibu & 2012 & Sedan - Midsize & Fusion & 2022 \\
\hline G103329L & Chevrolet & Malibu & 2012 & Sedan - Midsize & Leaf & 2022 \\
\hline G104001M & Dodge & Avenger & 2013 & Sedan - Compact & Focus & 2023 \\
\hline G104002M & Dodge & Avenger & 2013 & Sedan - Compact & Volt & 2023 \\
\hline G104412K & Chevrolet & Malibu & 2011 & Sedan - Midsize & Leaf & 2021 \\
\hline G110419P & Chevrolet & Impala & 2014 & Sedan - Large & Leaf & 2020 \\
\hline G110420P & Chevrolet & Impala & 2014 & Sedan - Large & Fusion & 2019 \\
\hline G110421P & Chevrolet & Impala & 2014 & Sedan - Large & Fusion & 2018 \\
\hline G110422P & Chevrolet & Impala & 2014 & Sedan - Large & Fusion & 2018 \\
\hline G1 10423P & Chevrolet & Impala & 2014 & Sedan - Large & Volt & 2018 \\
\hline G1 10424P & Chevrolet & Impala & 2014 & Sedan - Large & Fusion & 2019 \\
\hline G110425P & Chevrolet & Impala & 2014 & Sedan - Large & Volt & 2019 \\
\hline G110426P & Chevrolet & Impala & 2014 & Sedan - Large & Volt & 2019 \\
\hline G1 10427P & Chevrolet & Impala & 2014 & Sedan - Large & Fusion & 2018 \\
\hline G110428P & Chevrolet & Impala & 2014 & Sedan - Large & Volt & 2020 \\
\hline G110429P & Chevrolet & Impala & 2014 & Sedan - Large & Fusion & 2021 \\
\hline G110430P & Chevrolet & Impala & 2014 & Sedan - Large & Leaf & 2023 \\
\hline G110677L & Chevrolet & Impala & 2012 & Sedan - Large & Fusion & 2016 \\
\hline G110678L & Chevrolet & Impala & 2012 & Sedan - Large & Fusion & 2016 \\
\hline G110679L & Chevrolet & Impala & 2012 & Sedan - Large & Volt & 2016 \\
\hline G110680L & Chevrolet & Impala & 2012 & Sedan - Large & Fusion & 2016 \\
\hline G110682L & Chevrolet & Impala & 2012 & Sedan - Large & Fusion & 2016 \\
\hline G110683L & Chevrolet & Impala & 2012 & Sedan - Large & Fusion & 2016 \\
\hline G110684L & Chevrolet & Impala & 2012 & Sedan - Large & Fusion & 2016 \\
\hline G110685L & Chevrolet & Impala & 2012 & Sedan - Large & Fusion & 2016 \\
\hline G110686L & Chevrolet & Impala & 2012 & Sedan - Large & Fusion & 2015 \\
\hline G110687L & Chevrolet & Impala & 2012 & Sedan - Large & Fusion & 2016 \\
\hline G110688L & Chevrolet & Impala & 2012 & Sedan - Large & Fusion & 2016 \\
\hline G110689L & Chevrolet & Impala & 2012 & Sedan - Large & Fusion & 2016 \\
\hline G111357P & Chevrolet & Impala & 2014 & Sedan - Large & Leaf & 2025 \\
\hline
\end{tabular}




\begin{tabular}{ccccccc}
\hline Fleet Vehicle & \multicolumn{5}{c}{ Non-Sedan Replacement Approach } & Potential \\
Id & Make & Model & Year & EPA Class & $\begin{array}{c}\text { Replacement } \\
\text { Vehicle }\end{array}$ & $\begin{array}{c}\text { Replacement } \\
\text { Year }\end{array}$ \\
\hline G111359P & Chevrolet & Impala & 2014 & Sedan - Large & Leaf & 2026 \\
G112749L & Chevrolet & Impala & 2013 & Sedan - Large & Volt & 2016 \\
G112750L & Chevrolet & Impala & 2013 & Sedan - Large & Fusion & 2016 \\
G112751L & Chevrolet & Impala & 2013 & Sedan - Large & Fusion & 2016 \\
G112752L & Chevrolet & Impala & 2013 & Sedan - Large & Fusion & 2016 \\
G112753L & Chevrolet & Impala & 2013 & Sedan - Large & Fusion & 2016 \\
G112754L & Chevrolet & Impala & 2013 & Sedan - Large & Fusion & 2016 \\
G112755L & Chevrolet & Impala & 2013 & Sedan - Large & Fusion & 2016 \\
G112756L & Chevrolet & Impala & 2013 & Sedan - Large & Volt & 2016 \\
G112757L & Chevrolet & Impala & 2013 & Sedan - Large & Fusion & 2015 \\
G112758L & Chevrolet & Impala & 2013 & Sedan - Large & Fusion & 2015 \\
G112759L & Chevrolet & Impala & 2013 & Sedan - Large & Fusion & 2016 \\
G112760L & Chevrolet & Impala & 2013 & Sedan - Large & Fusion & 2018 \\
G130325K & Ford & Focus & 2012 & Sedan - Compact & Volt & 2022 \\
G137973P & Ford & Focus & 2014 & Sedan - Compact & Focus & 2026 \\
G137974P & Ford & Focus & 2015 & Sedan - Compact & Volt & 2022 \\
\hline
\end{tabular}

\section{D.4 Unmonitored Non-sedan Vehicle Replacement Approach}

Table D-4 provides the list of non-sedans in the MCIE fleet other than those monitored and included in Section D.2. The projected year of replacement is identified based on the GSA requirements and expected usage. The mileage is projected from the odometer reading in 2014 and annual mileage provided by MCBCL. There are 137 vehicles projected for replacement with PEVs by 2026 included in the analysis of Section 4. This is too numerous to list individually here. This list includes the 62 projected for replacement with PEVs by 2022; more can be replaced if desired.

Table D-4. MCIE fleet unmonitored non-sedan replacement options.

\begin{tabular}{ccccccc}
\hline Fleet Vehicle & & \multicolumn{7}{c}{ Non-Sedan Replacement Approach } & Potential \\
Id & Make & Model & Year & EPA Class & Vehicle & $\begin{array}{c}\text { Replacement } \\
\text { Year }\end{array}$ \\
\hline 294345 & Chevrolet & HHR & 2009 & SUV & Outlander & 2017 \\
G420949L & Chevrolet & C1500 & 2012 & Pickup & VTRUX PU & 2017 \\
G434559D & Ford & E350 & 2007 & Van - Cargo & VTRUX Van & 2017 \\
G611498D & Jeep & Liberty & 2008 & SUV & Outlander & 2017 \\
G624087L & Dodge & 1500 & 2012 & Pickup & VTRUX PU & 2017 \\
290746 & Ford & F450 & 2000 & Pickup & VTRUX PU & 2018 \\
290923 & Ford & F550 & 2003 & Pickup & eNV200 & 2018 \\
290924 & Ford & F550 & 2003 & Pickup & eNV200 & 2018 \\
G430248F & Ford & E350 & 2007 & Van - Cargo & VTRUX Van & 2018 \\
G434068F & Chevrolet & CG3300 & 2008 & Van - Cargo & VTRUX Van & 2018 \\
G610684M & Chevrolet & Colorado & 2008 & Pickup & eNV200 & 2018 \\
G622012F & Chevrolet & K1500 & 2008 & Pickup & eNV200 & 2018 \\
294325 & Chevrolet & HHR & 2009 & SUV & Soul & 2019 \\
G420948L & Chevrolet & C1500 & 2012 & Pickup & Soul & 2019 \\
\hline
\end{tabular}




\begin{tabular}{|c|c|c|c|c|c|c|}
\hline \multicolumn{7}{|c|}{ Non-Sedan Replacement Approach } \\
\hline $\begin{array}{c}\text { Fleet Vehicle } \\
\text { Id }\end{array}$ & Make & Model & Year & EPA Class & $\begin{array}{c}\text { Potential } \\
\text { Replacement } \\
\text { Vehicle }\end{array}$ & $\begin{array}{c}\text { Replacement } \\
\text { Year }\end{array}$ \\
\hline G431189M & Ford & F350 & 2012 & Pickup & VTRUX PU & 2019 \\
\hline G432010K & Ford & E350 & 2010 & Van - Pass & eNV200 & 2019 \\
\hline G434553D & Ford & E350 & 2007 & Van - Cargo & VTRUX Van & 2019 \\
\hline G610166H & Jeep & Liberty & 2009 & SUV & Outlander & 2019 \\
\hline G611246K & Chevrolet & Colorado & 2011 & Pickup & VTRUX PU & 2019 \\
\hline G630183H & Chevrolet & $\mathrm{K} 2500 \mathrm{HD}$ & 2009 & Pickup & eNV200 & 2019 \\
\hline 294318 & Chevrolet & HHR & 2009 & SUV & Outlander & 2020 \\
\hline 294320 & Chevrolet & HHR & 2009 & SUV & Soul & 2020 \\
\hline G434541D & Ford & E350 & 2007 & Van - Cargo & VTRUX Van & 2020 \\
\hline G434548D & Ford & E350 & 2007 & Van - Cargo & VTRUX Van & 2020 \\
\hline G621730H & Chevrolet & K1500 & 2010 & Pickup & VTRUX PU & 2020 \\
\hline G624090L & Dodge & 1500 & 2012 & Pickup & VTRUX PU & 2020 \\
\hline G630556M & Ford & F350 & 2012 & Pickup & VTRUX PU & 2020 \\
\hline 291230 & Ford & E350 & 2005 & Van - Cargo & eNV200 & 2021 \\
\hline 294292 & Chevrolet & HHR & 2009 & SUV & Soul & 2021 \\
\hline 294299 & Chevrolet & HHR & 2009 & SUV & Soul & 2021 \\
\hline 294317 & Chevrolet & HHR & 2009 & SUV & Soul & 2021 \\
\hline 294319 & Chevrolet & HHR & 2009 & SUV & Soul & 2021 \\
\hline 294335 & Chevrolet & HHR & 2009 & SUV & Outlander & 2021 \\
\hline G410400H & Dodge & Dakota & 2009 & Pickup & VTRUX PU & 2021 \\
\hline G420220F & Ford & F150 & 2008 & Pickup & eNV200 & 2021 \\
\hline G420231F & Ford & $\mathrm{F} 150$ & 2008 & Pickup & eNV200 & 2021 \\
\hline G420248F & Chevrolet & G1300 & 2008 & Van - Cargo & eNV200 & 2021 \\
\hline G420989K & Chevrolet & G1300 & 2011 & Van - Pass & eNV200 & 2021 \\
\hline G430247F & Ford & E350 & 2007 & Van - Cargo & VTRUX Van & 2021 \\
\hline G431188M & Ford & F350 & 2012 & Pickup & VTRUX PU & 2021 \\
\hline G434543D & Ford & E350 & 2007 & Van - Cargo & VTRUX Van & 2021 \\
\hline G630092P & Ford & $\mathrm{F} 250$ & 2015 & Pickup & VTRUX PU & 2021 \\
\hline G630175H & Chevrolet & $\mathrm{K} 2500 \mathrm{HD}$ & 2009 & Pickup & eNV200 & 2021 \\
\hline 294290 & Chevrolet & HHR & 2009 & SUV & Soul & 2022 \\
\hline 294316 & Chevrolet & HHR & 2009 & SUV & Soul & 2022 \\
\hline 300652 & Ford & F550 & 2009 & $\mathrm{SP}$ & EDI & 2022 \\
\hline G410387H & Dodge & Grd Caravan & 2009 & Minivan & Soul & 2022 \\
\hline G412401K & Dodge & Dakota & 2010 & Pickup & eNV200 & 2022 \\
\hline G420221F & Ford & $\mathrm{F} 150$ & 2008 & Pickup & VTRUX PU & 2022 \\
\hline G420886M & Ford & E150 & 2012 & Van - Pass & VTRUX Van & 2022 \\
\hline G420899M & Ford & E150 & 2012 & Van - Pass & eNV200 & 2022 \\
\hline G430316H & Chevrolet & $2500 \mathrm{HD}$ & 2009 & Pickup & eNV200 & 2022 \\
\hline G431175M & Chevrolet & G2300 & 2012 & Van - Pass & VTRUX Van & 2022 \\
\hline G432620K & Chevrolet & G2300 & 2011 & Van - Pass & VTRUX Van & 2022 \\
\hline G434547D & Ford & E350 & 2007 & Van - Cargo & VTRUX Van & 2022 \\
\hline G434550D & Ford & E350 & 2007 & Van - Cargo & eNV200 & 2022 \\
\hline G610171H & Jeep & Liberty & 2009 & SUV & Outlander & 2022 \\
\hline
\end{tabular}




\begin{tabular}{ccccccc}
\hline \multirow{2}{*}{$\begin{array}{c}\text { Nleet Vehicle } \\
\text { Id }\end{array}$} & Make & Model & Year & EPA Class & $\begin{array}{c}\text { Potential } \\
\text { Replacement } \\
\text { Vehicle }\end{array}$ & $\begin{array}{c}\text { Replacement } \\
\text { Year }\end{array}$ \\
\hline G630091P & Ford & F250 & 2015 & Pickup & eNV200 & 2022 \\
G630196N & Chevrolet & K3500 & 2013 & Pickup & VTRUX PU & 2022 \\
G631013N & Chevrolet & K2500HD & 2014 & Pickup & VTRUX PU & 2022 \\
G631053M & Ford & F350 & 2012 & Pickup & eNV200 & 2022 \\
G631365P & Ford & F250 & 2015 & Pickup & VTRUX PU & 2022 \\
\hline
\end{tabular}

